\title{
SPINA BIFIDA AND PARENTAL OCCUPATION
}

Nederlands Instituut voor Arbeidsomstandigheden

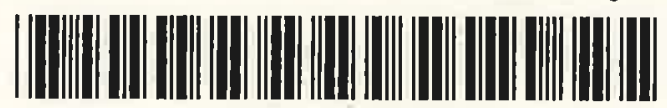
*NIA1187457*

\section{Birgitte Blatter}




\section{SPINA BIFIDA AND PARENTAL OCCUPATION}

Birgitte Blatter

NIA TNO, BDOC

Postbus 78668

1070 AR AMSTERD

Tel. $020-8498468$ isn $=37565$

RECIR. 42496

plaats $56-225$ 


\section{SPINA BIFIDA AND PARENTAL OCCUPATION}

Spina bifida en het beroep van de ouders

Een wetenschappelijke proeve op het gebied van de Medische Wetenschappen

\section{Proefschrift}

ter verkrijging van de graad van doctor aan de Katholieke Universiteit Nijmegen, volgens besluit van het College van Decanen

in het openbaar te verdedigen op dinsdag 15 april 1997

des namiddags om 3.30 uur precies

door

Birgitte Marieke Blatter

geboren op 8 juli 1968 te Eindhoven 
Promotores:

Prof.dr.ir. GA Zielhuis

Prof.dr. FJM Gabreels

Prof.dr. ALM Verbeek

Copromotor: $\quad$ Dr.ir. N Roeleveld

Manuscriptcommissie: Prof.dr. RCA Sengers

Prof.dr. J Noordhoek

Dr. JWJ van der Gulden

The studies presented in this thesis were financially supported by the Prinses Beatrix Fonds. Travel grants were received from 'The Netherlands Organization for Scientific Research' (NWO). Publication of this thesis was made possible by a grant from TNO Nutrition and Food Research Institute, Zeist.

Druk: Mediagroep KU Nijmegen

(C) BM Blatter, Nijmegen, 1997 


\section{CONTENTS}

Chapter 1 General introduction

Chapter 2 Review of Neural tube defects: Risk factors in parental occupation and the environment

Environ Health Persp 1994;102:140-145.

Chapter 3 Methodologic issues

3.1 Assessment of occupational exposure in a population based case-control study: comparing postal questionnaires with personal interviews

Occup Environ Med 1997;54:54-59.

3.2 Hospital or population referents in a study on congenital malformations?

Submitted for publication.

Chapter 4 Spina bifida and parental occupation

Epidemiology 1996;7:188-193.

Chapter 5 Heterogeneity of spina bifida.

Teratology (accepted for publication).

Chapter 6 Registry-based studies in Europe

6.1 Spina bifida and parental occupation in a Swedish registerbased study

Scand J Work Env Hea 1996;22:433-437.

6.2 Spina bifida and parental occupation: results from three malformation monitoring programs in Europe.

Submitted for publication. 
Chapter 7 Spina bifida and parental occupational exposure

7.1 Maternal occupational exposure during pregnancy and the risk of spina bifida

Occup Environ Med 1996;53:80-86.

7.2 Paternal occupational exposure around conception and spina bifida in offspring.

Am / Ind Med (accepted for publication)

Chapter 8 General discussion

Summary

Samenvatting

Dankwoord 


\section{AUTHORS}

drs. M Bakker, Municipal Health Service of Groningen (at the time student Biomedical Health Sciences, University of Nijmegen)

dr. E. Bermejo, ECEMC, Faculty of Medicine, University of Madrid, Spain

prof.dr. AE Czeizel, National Institute of Hygiene, Budapest, Hungary

prof.dr. FJM Gabreëls, Interdisciplinary Centre of Child Neurology, University Hopsital Nijmegen

drs. R Hermens, Department of General Practice and Social Medicine, University of Nijmegen (at the time student Biomedical Health Sciences, University of Nijmegen)

drs. AB Lafeber, Department of General Practice, University of Utrecht (at the time student Biomedical Health Sciences, University of Nijmegen)

prof.dr. ML Martínez-Frías, ECEMC, Faculty of Medicine, University of Madrid, Spain

drs. RA Mullaart, Interdisciplinary Centre of Child Neurology, University Hopsital Nijmegen

prof.dr. PWJ Peters, Department of Obstetrics and Gynaecology, University of Utrecht

dr.ir. N Roeleveld, Department of Medical Informatics, Epidemiology and Statistics, University of Nijmegen

dr. C Siffel, National Institute of Hygiene, Budapest, Hungary

drs. M van der Star, Department of General Practice and Social Medicine, University of Nijmegen (at the time student Biomedical Health Sciences, University of Nijmegen)

prof.dr. ALM Verbeek, Department of Medical Informatics, Epidemiology and Statistics, University of Nijmegen

drs. E Welp, at the time student Biomedical Health Sciences, University of Nijmegen

prof.dr.ir. GA Zielhuis, Department of Medical Informatics, Epidemiology and Statistics, University of Nijmegen 


\section{CHAPTER 1}

\section{GENERAL INTRODUCTION}

\section{Background and motivation}

Spina bifida forms part of a group of major congenital anomalies named neural tube defects (NTD), which are caused by a disturbance in the fusion of the neural folds occurring in the first month of pregnancy. Spina bifida is a complex anomaly that may cause severe handicaps involving multiple body systems. Its severity depends on the level and extent of the lesion. The anomaly is among the most prevalent of congenital malformations and poses difficult medical, social, and ethical problems to physicians, families and society. ${ }^{1}$ Estimates of the total birth prevalence of spina bifida range from about 2 per 10.000 in Finland to 17 per 10.000 in Northern Ireland; ${ }^{2}$ prevalence estimates in The Netherlands are about 7 per $10.000 .^{3}$ Secular variations in the prevalence rates have been reported in almost all well-studied areas. In recent years there is evidence of a decline in prevalence, a limited proportion of which can be accounted for by antenatal screening and induced abortion. ${ }^{4}$

In the past few decades, the aetiology of neural tube defects has been studied extensively in order to find starting points for primary prevention. However, the understanding of the embryology, genetics, and epidemiology of spina bifida has made relatively limited progress. While animal studies on teratogenic factors of spina bifida have yielded some insight in the different modes of action and the cellular mechanisms involved, ${ }^{5,6}$ the search for teratogens in humans is more difficult due to the observational character of the studies. Epidemiologic studies have revealed associations of spina bifida with familial occurrence of neural tube defects, use of antiepileptics and ovulation stimulating agents, diabetes, and infections, as well as with socioeconomic, geographic, racial, nutritional, environmental, and occupational factors. ${ }^{4}$ It is thus likely that spina bifida has a multifactorial aetiology. As spina bifida exhibits a strong variation by socioeconomic status in several countries, ${ }^{4}$ a search for environmental factors that are possibly associated with socioeconomic status is indicated. In recent years, research on maternal vitamin status and periconceptional vitamin supplementation has yielded evidence of a preventive effect of folic acid supplementation. ${ }^{7,8}$ Subsequent studies have focused on the homocysteine and methionine metabolism of the mother. ${ }^{9,10}$

Because classifications of socioeconomic status are primarily based on occupation, the presence of potential teratogens in the work environment may be an explanation for the differential prevalence rates by socioeconomic class, in addition to 
lifestyle factors. Maternal occupational exposure around conception and up to the 28th day of embryonic development could have a direct effect on the morphogenesis of the neural tube. Paternal chemical occupational exposure could theoretically result in genetic damage to germ cells ${ }^{11,12}$ and introduce teratogenic substances in the seminal fluid at conception or later during embryonic development. ${ }^{13}$

Studies specific to neural tube defects and parental occupation have been scarce. Most studies include congenital anomalies in general or central nervous system defects as a group, including neural tube defects. In these studies, some associations were found for women working in industry, construction, transport and communication, ${ }^{14,15}$ dental surgeries, ${ }^{16}$ nursing, ${ }^{17}$ and for women exposed to organic solvents. ${ }^{18}$ Studies on fathers yielded increased risks for painters, ${ }^{19}$ agricultural workers, ${ }^{20}$ workers in the food, beverage, wood, and textile industries, ${ }^{21}$ and fathers exposed to low-level radiation. ${ }^{22}$

Some studies that focussed on neural tube defects, including larger numbers of cases, have revealed increased risks for women working as hairdressers ${ }^{23}$ and agricultural workers ${ }^{23,24}$ and for men working as painters, ${ }^{25,26}$ printers, decorators, transport and communication workers, ${ }^{25}$ plastic production workers, ${ }^{27}$ bricklayers, ${ }^{23}$ agricultural workers, ${ }^{23,28}$ forestry and logging workers, service station attendants, ${ }^{26}$ and vehicle manufacturers. ${ }^{29}$ It is stressed, however, that except for male painters and male and female agricultural workers, few findings have been repeated in two or more studies.

Important limitations of the studies mentioned above are that occupational titles were often derived from birth certificates and used as a surrogate for occupational exposure. As Sever ${ }^{30}$ and Olshan ${ }^{26}$ point out, there is a need for large-scale casereferent studies on neural tube defects that include improved assessment of parental exposure and allow for potentially confounding factors. Until recently, no studies had been published that investigated the effect of occupational exposure of the parents on the risk of spina bifida in offspring. Such a study is presented in this thesis. It is designed as a case-referent study to verify or refute previously found associations between spina bifida and parental occupation and explore new hypotheses concerning occupational exposures. A similar study is being performed by Shaw and co-workers at the California Birth Defects Monitoring Program, but only preliminary results have been presented on occupational exposure so far. ${ }^{31}$

\section{Aims of the study}

The aims that were formulated at the start of the study are:

- to identify parental occupations with an increased risk of spina bifida in offspring - to study whether parental occupational exposure to chemicals or radiation during or shortly before pregnancy is a risk factor for the occurrence of spina bifida. 
In order to answer these questions, an epidemiologic case-referent study was designed. In this study, the cases were children with spina bifida who were born between 1980 and 1992 and diagnosed in 9 hospitals in The Netherlands. The referents were for the most part derived from the general population and partially from the hospitals where the cases came from. Data were collected in two phases. A postal questionnaire was used to gather information on parental occupation and potential confounders; subsequently, personal interviews were performed to collect exposure information. Following the study in The Netherlands, three case-referent studies were performed in Sweden, Spain, and Hungary, using data that were available in birth defect registries. If the results of these studies, in which parental occupations were categorised in a comparable way as in The Netherlands, support the Dutch findings, leads for future research may emerge.

\section{Scope of the thesis}

An extensive review of the literature on risk factors for neural tube defects, with emphasis on occupational and environmental factors, forms the basis for the hypotheses of this thesis. This review is presented in Chapter 2. To evaluate the design of the epidemiologic study, some methodologic issues had to be studied. These relate to the validity and feasibility of occupational exposure assessment by postal questionnaires relative to personal interviews, and to the choice of referents from hospitals or from the general population with a view to recall bias, selection bias, and feasibility aspects. Both issues are dealt with in Chapter 3.

The subsequent chapters deal with the core questions of this thesis, that is the relation between parental occupation or occupational exposure and the risk of spina bifida in offspring, using different methodologies. In Chapter 4, the results of a casereferent study are presented, in which questionnaires were used to assess the occupation of the parents around the time of conception. Because spina bifida exhibits a heterogeneous morphology which might be associated with a heterogeneous aetiology, we investigated in Chapter 5 if risk factors were specifically associated with different types of spina bifida. In Chapter 6, three case-referent studies are described which were conducted with registry-based data from Sweden, Spain, and Hungary, in order to verify or refute our earlier findings in The Netherlands. Chapter 7 deals with the question of whether parental occupational exposure to chemicals or radiation is associated with a higher risk of spina bifida in offspring. Finally, in Chapter 8, the results of the present study are compared with the literature and evaluated with a view to practical implications and leads for future research.

\section{References}

1 McClone DG, Naidich TP. Myelomeningocele. In: Hoffman HJ, Epstein F. eds. Disorders of the developing nervous system: diagnosis and treatment. Boston: Blackwell Scientific Publications, 1986;87-109. 
2 International Clearinghouse for Birth Defects Monitoring Systems. Congenital Malformations Worldwide. A report from the International Clearinghouse for Birth Defects Monitoring Systems. Amsterdam: Elsevier, 1991.

3 Zandwijken GRJ, Walle HEK de, Breed AC, Langendoen ESL, Mühlenberg N, Oosthoek Y, Op 't Veld MCHF, Pliester-Engel E, Rengelink-van der Lee JH, Smitshoek C, Straver MM, Cornel MC. Eurocat Report, Tables 1981-1993.

4 Elwood JM, Little J, Elwood JH. Epidemiology and control of neural tube defects. Monographs in epidemiology and biostatistics. Vol 20. Oxford: Oxford University Press, 1992.

5 Morrissey RE, Mottet NK. Neural tube defects and brain anomalies: a review of selected teratogens and their possible modes of action. Neurotoxicol 1980;2:125-162.

6 Copp AJ, Brook FA, Estibeiro JP, Shum ASW, Cockroft DL. The embryonic development of mammalian neural tube defects. Progr in Neurobiol 1990;35:363-403.

7 MRC Vitamin Study Research Group. Prevention of neural tube defects: results of the Medical Research Council Vitamin Study. Lancet 1991;338:131-137.

8 Czeizel AE, Dudás I. Prevention of the first occurrence of neural-tube defects by periconceptional vitamin supplementation. N Engl J Med 1992;327:1832-1835.

9 Steegers-Theunissen RPM, Boers GHJ, Trijbels FJM, Finkelstein JD, Blom HJ, Thomas CMG, Borm GF, Wouters MGAJ, Eskes TKAB. Maternal hyperhomocysteinemia: a risk factor for neural tube defects? Metabolism 1994;43:1475-1480.

10 Aerts LAGJM van, Poirot CM, Herberts CA, Blom HJ, DeAbreu RA, Trijbels JMF, Eskes TKAB, Copius Peereboom-Stegeman JHJ, Noordhoek J. Development of methionine synthase, cystathionine- $\beta$-synthase and S-adenosylhomocysteine hydrolase during gestation in the rat. J Reprod Fertil 1995;103:227-232.

11 Olshan AF, Faustman EM. Male-mediated developmental toxicity. Reprod Toxicol 1993;7:191-202.

12 Colie CF. Male mediated teratogenesis. Reprod Toxicol 1993;7:3-9.

13 Hales BF, Smith S, Robaire B. Cyclophosphamide in the seminal fluid of treated males: Transmission to females by mating and effect on pregnancy outcome. Toxicol Appl Pharm 1986;84:423-430.

14 Hemminki K, Mutanen P, Luoma K, Saloniemi I. Congenital malformations by the parental occupation in Finland. Int Arch Occup Environ Health 1980;46:93-98.

15 Hemminki K, Mutanen P, Saloniemi I, Luoma K. Congenital malformations and maternal occupation in Finland: multivariate analysis. J Epidemiol Community Health 1981;35:5-10.

16 Sikorski R, Juszkiewicz T, Paszkowski T, Sprengier-juszkiewicz T. Women in dental surgeries: reproductive hazards in occupational exposure to metallic mercury. Int Arch Occup Environ Health 1987; 59:551-557.

17 Matte TD, Mulinare J, Erickson JD. Case-control study of congenital defects and parental employment in health care. Am J Ind Med 1993;24:11-23.

18 Holmberg PC, Nurminen $M$. Congenital defects of the central nervous system and occupational factors during pregnancy. A case-referent study. Am J Ind Med 1980;1: 167-176. 
19 Olsen J. Risk of exposure to teratogens amongst laboratory staff and painters. Dan Med Bull 1983;30:24-28.

20 Balarajan R, McDowall M. Congenital malformations and agricultural workers (Letter). Lancet 1983;l:1112-1113.

21 McDonald AD, McDonald JC, Armstrong B, Cherry NM, Nolin AD, Robert D. Fathers' occupation and pregnancy outcome. $\mathrm{Br} J$ ind Med 1989;46:329-333.

22 Sever LE, Gilbert ES, Hessol NA, Mclntyre JM. A case-control study of congenital malformations and occupational exposure to low-level ionizing radiation. Am J Epidemiol 1988; 127:226-242.

23 Hammond FG, Canache MF. Some epidemiological aspects of neural tube defects in Barquisimeto, Venezuela (Abstract). Am J Hum Genet 1991;49 (suppl.):470.

24 Ericson A, Källén B, Löfkvist E. Environmental factors in the etiology of neural tube defects: a negative study. Environ Res 1988;45:38-47.

25 Fedrick J. Anencephalus in the Oxford Record Linkage Study Area. Dev Med Child Neurol 1976;18:643-656.

26 Olshan AF, Teschke K, Baird PA. Paternal occupation and congenital anomalies in offspring. Am J Ind Med 1991;20:447-475.

27 Brender CJ, Suarez L. Paternal occupation and anencephaly. Am J Epidemiol 1990;131:517-521.

28 Polednak AP, Janerich DT. Uses of available record systems in epidemiologic studies of reproductive toxicology. Am J ind Med 1983;4:329-348.

29 Schnitzer PG, Olshan AF, Erickson JD. Paternal occupation and risk of birth defects in offspring. Epidemiol 1995;6:577-583.

30 Sever LE. Male-mediated developmental toxicity (Editorial). Epidemiol 1995;6:573-574.

31 Shaw GM, Velie EM, Katz EA, Morland KB, Harris JA. Maternal occupational exposures as risk factors for neural tube defects (Abstract). Am J Epidemiol 1996;142:S1. 


\title{
REVIEW OF NEURAL TUBE DEFECTS: RISK FACTORS IN PARENTAL OCCUPATION AND THE ENVIRONMENT
}

BM Blatter, M van der Star, N Roeleveld

Environ Health Perspect 1994;102:140-145

\begin{abstract}
We conducted a study of published work to evaluate the evidence for the hypothesis that environmental exposure and parental occupation are risk factors for neural tube defects. As other risk factors such as maternal illnesses, medication, and dietary factors have been reviewed before, the review only summarizes this information. In studies concerning environmental pollution, only a few weak associations were found. It appears that specific studies on the topic of parental occupation and neural tube defects are scarce. Therefore, studies on broader malformation categories, such as central nervous system defects, were also taken into account. Both maternal and paternal occupation seem to be associated with the occurrence of neural tube defects. However, results are not always consistent with each other, and relevant recommendations concerning prevention thus cannot be given before more studies with larger populations are conducted to confirm or refute the findings reviewed.
\end{abstract}

\section{Introduction}

Neural tube defects are one of the commonest congenital malformations of the central nervous system, with an average prevalence at birth of 1 per 1000 . They are caused by a failure in the process of neural tube closure. Under normal circumstances, the nervous system forms a closed tube after 4 weeks of gestation. Sometimes, for principally unknown reasons, the neural walls do not fuse. This may result in a minor or a major defect: spina bifida occulta or spina bifida aperta, respectively. When the lesion occurs in the cranial region the anomaly is called anencephaly. ${ }^{1,2}$

In contrast to some other congenital malformations, neural tube defects are strongly believed to be caused by multiple factors. It was established that the frequency of spina bifida and anencephaly varies with a number of demographic 
factors - time, place of residence, sex, ethnic group, family history, social class, and maternal age and parity - which can be partly genetic and partly exogenous. ${ }^{3}$ The association of neural tube defects with socioeconomic status (higher prevalence of neural tube defects in lower socioeconomic classes) is assumed to be caused by maternal vitamin deficiency and dietary habits. Accordingly, many articles have been published about this relationship. ${ }^{4}$

Another possible hypothesis for the difference in the prevalence of neural tube defects between high and low socioeconomic status is the influence of parental occupational exposure. As the classification of socioeconomic status is mainly based on the occupation of the father, occupation thus seems to be the most important component of socioeconomic status. Other exogenous factors include the occurrence of infections, alcohol consumption, smoking and environmental pollution. ${ }^{5}$

Reviews about risk factors in general and diet in particular have already been written. ${ }^{3-6}$ Therefore, this review does not aim to provide a complete summary but only gives a brief overview of the main risk factors for neural tube defects described in recent literature. In addition, it summarizes the available epidemiological evidence for the occupational exposure hypothesis. We consider environmental and occupational exposure extensively in order to highlight specific occupations and environmental and occupational factors that may play a part in the etiology of neural tube defects.

\section{Materials and Methods}

To evaluate all relevant articles concerning neural tube defects, spina bifida, anencephaly, and factors associated with their occurrence (especially environmental and occupational factors), we conducted an online computer search on Medline of the years 1988 - 1991 and on the department's literature system on reproduction and occupation with the key words: 'neural tube defects' or 'congenital defects' in general, 'environmental and occupational exposure,' 'industry' and 'occupation'. Additional papers were traced through the references listed in the articles and reviews found in the search. We selected articles concerning etiologic factors in general, whereas the articles on environmental and occupational exposure were all included. Because the results from experimental animal studies cannot easily be extrapolated to man, only human epidemiological studies were selected. Furthermore, only recent articles (the majority published after 1980) have been included in this review. Finally, the quality of the papers has not been a criterion for selection because of the small number of publications on this subject, although this factor is addressed when appropriate. 


\section{Risk Factors for Neural Tube Defects}

A number of demographic factors are associated with the occurrence of neural tube defects, like time, place of residence, sex, ethnic group, family history, and social class. In relation to the social class, some exogenous factors seem to be related to the occurrence of neural tube defects (e.g., maternal illness and medication, diet, smoking, and alcohol consumption). These (possible) risk factors are discussed briefly below, followed by a more thourough consideration of occupational and environmental factors.

Sex, race, and place

Sex differences clearly exist in the prevalence of neural tube defects. More girls than boys are born with spina bifida (sex ratio $1 / 0.8$ ); the sex ratio for anencephaly varies more widely (between $1 / 0.45$ and $1 / 1)^{3}$ The prevalence rates of neural tube defects also differ noticeably between geographical areas and ethnic and racial groups. Although these differences are widely accepted, Borman and $\mathrm{Cryer}^{7}$ claim that geographical patterns may be attributable to variations in the design, definitions, precision, and validity of the studies used to describe these patterns. Still, it has been found that whites have higher rates than blacks; Jews have an extremely low prevalence. ${ }^{8}$ Data from the International Clearinghouse for Birth Defects Monitoring Systems ${ }^{9}$ show that both the rates for anencephaly and spina bifida are exceptionally high in Mexico (average rates between 1985 and 1988 of 19/10,000 and 18/10,000, respectively) and in Northern Ireland (10/10,000 and 17/10,000, respectively). On the contrary, rates from Finland are as low as $1 / 10,000$ for spina bifida, while most countries report rates between 3 and 6 per 10,000 births. As for anencephaly, the variability is somewhat greater. ${ }^{9}$ What is noteworthy is the suggestion by Seller ${ }^{10}$ that the incidence of neural tube defects associated with chromosome abnormalities may be uniform and that it is the incidence of the multifactorial type (with normal chromosomes) that varies geographically. This points toward an effect of exogenous risk factors.

\section{Time and season}

As investigated in studies of long-term trends, the prevalence of neural tube defects varies with time and season, although the trends are different among different countries. Trends in the form of an epidemic (increase of two-thirds and decrease to original level) have been observed several times. Nowadays, a worldwide decrease in prevalence figures is seen, in high as well as in low prevalence areas ${ }^{3,10-13}$ One explanation for this decrease in prevalence is an increase in $a$-fetoprotein and ultrasound screening in pregnancy and consequent induced abortions. Adjusted prevalence figures from Stone ${ }^{12}$ and from Bound et al. ${ }^{13}$ (combining live births with terminations) showed, however, that antenatal screening only partly accounts for the 
decline in prevalence.

Seasonal fluctuations in the occurrence of neural tube defects vary with time and place. In Britain, for example, peaks were seen in spring conceptions for spina bifida and anencephaly in some areas, whereas an absence of both defects among spring conceptions was observed in South Wales. An excess of spina bifida among spring conceptions was also seen in Hungary during the $1960 \mathrm{~s}^{3}$ More recent data from Britain show a statistically significant peak of July conceptions, which is a constant pattern in all parts of Great Britain. ${ }^{14}$ No seasonal variation was proven for any malformation type in tropical or nontropical South America or in Italy. ${ }^{15}$

Maternal age, parity, and obstetrical history

The risk of having a child with spina bifida is found to be higher when maternal age exceeds 35; some studies also report a higher risk for mothers aged under 20 years of age. ${ }^{3}$ Feldman et al. ${ }^{16}$ and Strassburg et al., ${ }^{8}$ for instance, reported a statistically significant increase in the risk of neural tube defects and anencephaly with increasing maternal age. Parity has also been found to be significantly related to the risk of neural tube defects. As in age, both monotonic and U-shaped relationships (high prevalence in primiparae, low prevalence in second births and again increasing prevalence with increasing parity) have been found, the former occurring mainly in low-risk, the latter in high-risk areas. Whether maternal age or parity or both factors are responsible for the association is not entirely clear. Leck ${ }^{3}$ and Roberts and Lowe ${ }^{17}$ refer to a Japanese study in which the prevalence of neural tube defects in artificially interrupted pregnancies is ten times higher than the prevalence at birth, suggesting that $90 \%$ of the neural tube defects are lost in early pregnancy and the true incidence is much higher than the reported birth prevalences. In line with this hypothesis, investigators from Finland reported that mothers with children affected by spina bifida significantly more often had a history of stillbirths [odds ratio (OR) $=4.5$, $p<0.051$ and spontaneous abortions $(O R=1.8, p<0.05)$ than control mothers. The number of other live-born infants with anomalies was also higher among mothers of children with spina bifida. ${ }^{18}$ The previous pregnancy outcome of the mother also seems to be a risk factor for the occurrence of neural tube defects.

Siblings and consanguinity of parents

Relatives of people with a neural tube defect face higher risks of having a child with a neural tube defect than the general population. ${ }^{18}$ This risk will depend on the number of predisposing genes they have in common with the patient: ${ }^{19} 50 \%$ for firstdegree relatives, $25 \%$ for second-degree relatives, and $12 \%$ for third-degree relatives. The recurrence risk of a neural tube defect is $5 \%$. Consanguinity of parents has also been found to more than double the risk in high prevalence areas. ${ }^{6}$ 


\section{Socioeconomic status}

Several studies have investigated the relationship between the occurrence of neural tube defects and socioeconomic status. ${ }^{20-22}$ Relationships found have the same direction among different countries and for different ethnic groups: a progressive increase in the prevalence rate of neural tube defects from higher to lower socioeconomic class, as determined by the father's occupation. The biological significance of socioeconomic status is unknown. Factors such as housing conditions, frequency of infections, age at marriage, alcohol consumption, and smoking may be partly responsible for the association with neural tube defects. In addition, dietary factors such as the intake of vitamins and folic acid have been causally related to neural tube defects. ${ }^{23-25}$ Less has been written about the occupation of the father and mother, on which the classification of socioeconomic class is principally based. In addition to other exogenous factors, exposure to physical and chemical agents at work and environmental pollution may be logical explanations for the different prevalence rates of neural tube defects among socioeconomic classes.

\section{Maternal illnesses and medication}

Several years ago, associations of neural tube defects with influenza infection, analgesics, and the use of antidepressants were suggested, ${ }^{3}$ which may indicate merely that women with a low resistance in early pregnancy are probably more liable to have affected offspring, regardless of any infection acquired or treatment received. Recently, only a few studies concerning this factor have been conducted. Saxen et al. ${ }^{26}$ found no association between influenza epidemics in general and the occurrence of anencephaly, based on combined (but not linked) data on influenza epidemics in Finland and national prevalence figures of anencephaly.

After Milunsky et al. $^{27}$ discovered an increased incidence of neural tube defects among predominantly white insulin-dependent diabetic women $(20 / 10,000)$, Zacharias and Jenkins ${ }^{28}$ observed a significant increase in the incidence of neural tube defects in black insulin-dependent diabetic women, though the numbers were small. The risk in the diabetic women was 21 times that in the nondiabetic population.

Maternal epilepsy as well as the use of the anti-epileptic drug valproic acid increases the risk of spina bifida. Findings of Robert and Guibaud ${ }^{29}$ of a possible relationship between valproic acid and spina bifida prompted them to conduct a case-control study. Results from this study showed an OR that was statistically significant $(\mathrm{OR}=20.6,95 \% \mathrm{Cl}$ : 8.2-47.9) for spina bifida and use of valproic acid during the first trimester of pregnancy, compared with other structural malformations. This high risk persisted after controlling for maternal epilepsy $(\mathrm{OR}=17.1,95 \% \mathrm{Cl}: 2.1-769)$ through a restriction to epileptic mothers. ${ }^{30}$ Lindhout and Meinardi ${ }^{31}$ concluded from 
their data that a causal relationship existed as well. The absolute risk for spina bifida after use of valproic acid during pregnancy is believed to be $1-2 \%$, comparable to the recurrence risk for neural tube defects. ${ }^{30}$ In addition, an association between the use of the anticonvulsant carbamazepine and spina bifida, controlled for valproic acid, has been described, ${ }^{32}$ although only small numbers were found in this cohort study. A pooled analysis of 22 cohort studies led to the conclusion that a $1 \%$ risk of spina bifida exists after carbamazepine use.

In view of the excessive use of oral contraceptives, studies have been performed to investigate the effect of their use on subsequent offspring. Kasan and Andrews $^{33}$ found significantly more infants with neural tube defects among users of oral contraception in the 3 months before their last menstrual period or in early pregnancy compared with nonusers. In a smaller study, increased, but not statistically significant, $O R s$ for oral contraceptive and intrauterine device use a month before pregnancy were found.

It has also been reported that women who use drugs to induce ovulation before conception are more likely to have children with neural tube defects., ${ }^{5,35-37}$ Whether this association is caused by the drug clomiphene or by the underlying infertility is not clear. In some studies the association has not been found at all. ${ }^{38,39}$

\section{Dietary intake}

Differences in neural tube defect prevalences, varying with time and place of residence, have been explained by different intake of vitamins, minerals, and other contents of food and drink. A high prevalence of anencephaly in the Middle East has been correlated with zinc deficiency and in England and Wales to use of water with a low mineral content. ${ }^{3}$ Studies considering the influence of vitamins in particular were started after it was found that the occurrence of neural tube defects was related to socioeconomic status and that vitamin levels differ between high and low socioeconomic status. ${ }^{40}$ The majority of research has focused on folic acid and other vitamin deficiencies. Although one (case-referent) study reported no association between periconceptional multivitamin supplementation and neural tube defects, ${ }^{41}$ most studies found a protective effect associated with multivitamin use or high levels of dietary folate intake. ${ }^{4}$ In a clinical trial by Smithells et al. ${ }^{24}$ a dramatic decrease in recurrence risk after periconceptional multivitamin use was observed. The recurrence risk for supplemented women was $0.7 \%$, compared with a recurrence risk of $4.7 \%$ for control mothers. Methodological shortcomings in both observational studies and clinical trials have been discussed extensively. ${ }^{4}$ Recently, a randomized, double-blind prevention trial from the Medical Research Council Vitamin Study finally provided evidence of a protective effect of folic acid: a $72 \%$ reduction of the recurrence risk of neural tube defects was found. ${ }^{25}$ Results from the Hungarian randomized controlled 
trial of multivitamin supplementation among women who had not had a prior neural tube defect-affected pregnancy were reported in $1992 .{ }^{42}$ This first trial among the general population was stopped recently because of evidence of a protective effect: of 2104 women who received vitamin supplements, none had a child with a neural tube defect, compared to 6 of 2052 women who received the placebo (trace elements) supplement.

Folic acid also seems to play a role regarding other factors associated with the risk of neural tube defects, such as undergoing gastric bypass, ${ }^{43}$ use of oral contraceptives, ${ }^{33,44}$ suffering from the metabolic disorder homocysteinaemia, ${ }^{45}$ and the use of valproic acid and aminopterin, both of which are folic acid antagonists. ${ }^{3,4}$

It has been stressed by Seller ${ }^{46}$ that a deficiency of nutrients need not only result simply from a deficiency in the mother, but might also be caused by a disorder in metabolic processes. In regard to folic acid, Smithells had earlier suggested that pregnancy itself might be of more significance than changes in folate consumption. ${ }^{40}$ In the studies cited above, only deficiencies have been discussed as causal factors for neural tube defects. On the other hand, excessive intake of specific nutrients may also have adverse effects. An example of a teratogenic nutrient is vitamin $A .{ }^{46}$

\section{Smoking and alcohol consumption}

Few studies have been carried out with respect to smoking and alcohol consumption as risk factors for the development of neural tube defects. Heary et al. ${ }^{47}$ found a statistically significant positive association of smoking of the father with neural tube defects in a study with small sample size, which disappeared when matched analyses were performed. Recently Zhang et al. ${ }^{48}$ conducted a case-referent study of paternal smoking and birth defects in a population in which paternal alcohol use and maternal smoking (both possible confounders) are rare. They found a modest relationship between paternal smoking and overall birth defects $(\mathrm{OR}=1.2,95 \% \mathrm{Cl}$ : 1.0-1.5); more markedly elevated risks were identified for anencephaly $(O R=2.1)$, spina bifida $(O R=1.9)$, and two other anomalies. In a Swedish study, the OR for smoking of the mother was $2.0(95 \% \mathrm{Cl}: 0.9-4.6)$, based on information from 84 case mothers and 156 control mothers. ${ }^{34}$ With respect to alcohol consumption, casestudies from Castro-Gago et al. $^{49}$ and Friedman ${ }^{50}$ report alcohol abuse in the first month of pregnancy in several mothers of infants with neural tube defects.

\section{Environmental pollution}

It is difficult to investigate the effect of environmental pollution, and results are hard to interpret. Incidence rates have to be related to factors of pollution in a particular area, while other demographic variables have to be considered as well. Still, some studies concerning environmental pollution and neural tube defects have been 
conducted.

In the United States, two studies have been carried out with respect to airport noise and birth defects. In the first one, a higher-than-expected number of abnormal births, including spina bifida and anencephaly, was found in the noisiest census tracts. ${ }^{51}$ The authors do not automatically attribute the increased prevalence of abnormal births to jet landing noise. They suggest alternative factors such as jet aircraft pollutants, among which metallic particles are probably the most serious, and stress through the disturbance of sleep patterns. ${ }^{51}$ The other study ${ }^{52}$ did not entirely confirm the earlier findings. No association with any category of defects was found, except for spina bifida with hydrocephalus. Because of the small number of cases, a case-referent study of all neural tube defects was done afterwards. Although the data did not rule out a slight association, no statistically significant association was found between the high-noise area and neural tube defects.

Recently, several studies have been carried out with respect to neural tube defects as a consequence of the Chernobyl accident in May 1986. In the Bursa region in Turkey, a dramatically increased frequency of neural tube defects was reported during the first 6 months of 1987 (20/1000 compared to 6/1000 between 1983 and 1986). During the period July 1987 - June 1988, the total number of neural tube defects decreased gradually, supporting the hypothesis of an adverse effect of radiation. ${ }^{53} \mathrm{~A}$ significant increase in the incidence of neural tube defects after 1986 was also observed in the Black Sea region in Turkey (4.4/1000 compared to $2.1 / 1000$ between 1981 and $1986, p<0.0001) . .^{54}$ Although detection bias (increased detection through more attention to anomalies in that region) might have accounted for part of these increases, they might also be due to the nuclear contamination of the region after the Chernobyl accident. In Norway, no associations were found for conditions earlier reported to be associated with radiation, such as anencephaly and spina bifida. ${ }^{55}$

Sever et al. ${ }^{56}$ examined the prevalence of congenital malformations among two counties around the Hanford site near Richland, Washington, a nuclear power plant for the production of plutonium and electric energy. The investigators found no rates of any defects that were elevated compared with rates from the Birth Defect Monitoring Program, except for neural tube defects. A statistically significant elevated rate of 1.7 per 1000 births versus 1.0 per 1000 was observed. However, neither occupational exposure nor exposure of the general public was found to have caused the observed increase. The estimated exposure represented less than a $0.05 \%$ increase over the natural background of $1 \mathrm{mSv}$, whereas the dose required to double the incidence is more than $1000 \mathrm{mSv}$. Because agriculture was an important activity in the area, the authors hypothesized that the increased rates might be related to the use of agricultural chemicals. 
In this context research has been done in Australia, in which incidence rates of spina bifida and anencephaly in New South Wales and annual usage rates of the herbicide 2,4,5,-T for the whole of Australia were examined. ${ }^{57}$ Data covering 10 years yielded a linear correlation between a previous year's usage and the annual combined birth rate of anencephaly and spina bifida. A significant seasonal variation in birth rates of neural tube defects was also found: highest for summer conceptions, and a survey in New South Wales revealed maximum spraying during the summer months. These data cannot be taken as direct evidence of a causal association, but they are an indication that seasonal events may be important in the origin of neural tube defects. A more recent study conducted by White et al..$^{58}$ on birth defects in general revealed no association between pesticides used in forestry and reproductive problems. Yet, for agricultural chemicals, evidence of an association with spina bifida without hydrocephalus was found. Despite limitations in exposure assessment, the authors suggest a possible association between factors in the agricultural environment and neural tube defects.

Exposure to herbicides and pesticides may also occur through the consumption of green leafy vegetables and the use of polluted drinking water. Studies on nitrate concentrations in drinking water and the risk of neural tube defects and central nervous system defects in general have been conducted. An Australian study revealed an associaton between nitrate concentrations and the risk of neural tube defects. ${ }^{59}$ A more recent study ${ }^{60}$ was not able to confirm these data; only weak associations were found between nitrate exposure in water and central nervous system defects. Likewise, Swedish investigators did not find associations between the occurrence of neural tube defects and average water nitrate content. ${ }^{34}$

\section{Occupational risk factors}

So far, little has been known about the effects of parental occupational exposure on the development of neural tube defects in general or spina bifida and anencephaly in particular. Yet many studies have focused on congenital anomalies in general. Although neural tube defects often form part of that group, sample size is consequently small, and conclusions cannot be drawn with respect to neural tube defects alone. These studies are only be considered when a cluster of central nervous system defects (of which the greatest part are neural tube defects ${ }^{2}$ ) or a cluster of neural tube defects is sufficiently large to yield possible associations.

In a study on congenital malformations and parental occupation in Finland, women working in industrial occupations and construction had more children with central nervous system malformations than referent mothers $(O R=1.6, p<0.05)$. No statistically significant ORs were found with respect to paternal occupation. Noteworthy is the fact that differences in the risk of malformations were more 
pronounced for the occupational groups than for the social classes, suggesting that occupation itself or related factors determine the risk to a greater extent than social class. ${ }^{61}$ in a subsequent article, Hemminki et al. ${ }^{62}$ report results from the same sample of cases and referents, adjusted for a number of confounding factors such as social class, tobacco smoking, and medication. Controlling for these factors increased the risk of central nervous system malformations for mothers employed in industry, construction, transport, and communication $(O R=2.0, p<0.001)$, again suggesting that social class was not responsible for the effect. ${ }^{62} \mathrm{~A}$ Danish study, investigating the relationship between organic solvent exposure and malformations of the central nervous system, revealed an increased risk that was statistically significant for fathers working as painters (prevalence ratio of $4.9,95 \% \mathrm{Cl}: 1.4-17.1$ ). This association was unexpected because the hypothesis concerned exposure of women. However, only two women were employed in occupations with possible exposure to organic solvents, so an association between maternal exposure and central nervous system defects could not be investigated. ${ }^{63}$

Some studies indicate an increased risk for neural tube defects when congenital malformations are divided into malformation categories. Among these is the study of Holmberg and Nurminen, ${ }^{64}$ who found that significantly more mothers of a child with a central nervous system defect had been exposed to organic solvents during the first trimester of pregnancy compared with control mothers. Among the 14 cases of central nervous system defects in which the mother had been exposed were 8 children with anencephaly or spina bifida. Sikorski et al. ${ }^{65}$ conducted a study among women in dental surgeries. Metallic mercury exposure was determined through levels in scalp and pubic hair and found to differ statistically significantly from a control group. More spontaneous abortions, stillbirths, and congenital defects occurred in dentists and dental assistants compared with the control group ( $24 \%$ and $11 \%$, respectively), whereas five out of six malformations were spina bifida. A study in England on congenital malformations among offspring of agricultural workers showed that gardeners and groundsmen, who are likely to handle 2,4,5,-T, experienced increased ratios for spina bifida, anencephaly, and facial clefts [observed/expected ratios (O/E) were 123, 117, and 142, respectively], while agricultural workers had increased ratios for spina bifida and facial clefts $(\mathrm{O} / \mathrm{E}$ ratio of 128 and 127, respectively). ${ }^{66} \mathrm{McD}$ onald et al. ${ }^{67}$ found an association between developmental defects and fathers working in the food, beverage, and wood and textile processing industries. Among these, the observed number of neural tube defects was higher than expected (O/E ratio: $5 / 1.8$ ), but sample size was small.

With respect to exposure to low-level ionizing radiation of employees of a nuclear power plant, the relation between parental occupational exposure and the risk of congenital malformations in their offspring was investigated. ${ }^{68}$ When all 
malformations were analyzed as a group, no evidence of any association was found. Analyses of fathers' cumulative exposure showed positive but nonsignificant trends; a statistically significant association was only seen for neural tube defects (mean exposure $24.2 \mathrm{mSv}$ compared to an expected mean value of $13.4 \mathrm{mSv}, \mathrm{p}=0.04$ ), even on the basis of a small number of cases.

Recently, a registry-based case-control study of congenital defects and parental employment in health care was conducted. ${ }^{69}$ Offspring of mothers employed in a nursing occupation were found to be at statistically significantly increased risk of having, among others, anencephaly or spina bifida [relative risk $(R R)=2.0,95 \% \mathrm{Cl}$ : 1.0-4.3]. The authors admit, however, that the finding of several statistically significant relative risks was expected because they estimated RRs for a large number of associations.

Only a few studies have been carried out with the specific aim of investigating the relation between neural tube defects, spina bifida, or anencephaly and parental occupational exposure. One of these studies is the Anencephalus Oxford Record Linkage Study conducted by Fedrick, ${ }^{70}$ in which occupations of the fathers of children with anencephaly, as described on the birth certificates, were compared with the occupations of all fathers in the area. Although numbers were small, statistically significant associations were found for printers $(R R=6.7, p<0.001)$, painters and decorators $(R R=2.5, p<0.005)$, and transport and communication workers $(R R=1.7, p<0.01)$, who were mainly drivers of road vehicles. Maternal occupations were not considered. Hearey et al. ${ }^{47}$ investigated a cluster of anencephaly and spina bifida with regard to a range of factors, including occupation and chemical exposure. The authors concluded that no exposure was associated with neural tube defects. However, this study included only 9 cases and 27 controls. A larger scale study did not reveal any significant association with maternal occupation either, although the case mothers had slightly more occupations where chemical exposure is likely..$^{34}$ In a study investigating area differences in the prevalence of anencephaly, a slightly but significantly higher risk among mothers who reported employment during pregnancy was found $(R R=1.3, p<0.01) .{ }^{22}$ Recently Brender and Suarez ${ }^{71}$ examined the association between parental occupation and anencephalic births. Among 585 cases and 1286 controls, they especially studied whether pesticide and solvent exposure were of importance. With respect to the mothers, the number of exposed cases and controls was too low to find any exposure effect. However, women working as laborers had the highest risk for anencephalic offspring when professional, managerial, and technical women were used as a reference group. As for the fathers, exposure to solvents was associated with a significantly elevated risk for anencephalic offspring $(\mathrm{OR}=2.5,95 \% \mathrm{Cl}$ : 1.6-4.1). Painters had a more than threefold risk, and plastic production workers had a twofold risk. Finally, 
research in Venezuela $\mathrm{a}^{72}$ revealed remarkable differences in certain occupations between parents of children with neural tube defects and control parents. For instance, $13 \%$ of case mothers were hairdressers, compared with $1.3 \%$ of the control mothers; $8 \%$ of the case mothers were farmers and none of the controls were farmers. As for fathers, $31.6 \%$ of the cases were also farmers, compared with $13.2 \%$ among controls $(p=0.01)$ and $19.7 \%$ of fathers of cases were bricklayers, compared with $5.3 \%$ among controls $(p=0.01)$.

\section{Discussion and conclusion}

During the past years, many studies have been conducted and much has been hypothesized concerning risk factors of neural tube defects. ${ }^{5,6}$ Especially the relation with dietary intake and vitamin supplementation, prompted after low socioeconomic status seemed associated with high risks, has been thoroughly examined. ${ }^{4}$ However, studies about environmental and occupational exposure to chemicals, also obviously related to socioeconomic status, are scarce. From the few environmental studies in this review it is clear that only a few weak associations have been found for nuclear contamination in Turkey, ${ }^{53,54}$ use of agricultural chemicals, ${ }^{57}$ and nitrate concentrations in drinking water. ${ }^{59}$

The specific relation between the risk of neural tube defects and occupation of the parents has not often been investigated, and seldomly properly. In the majority of studies, registries or job titles were used instead of information about exposures given by the parents or actual measurements. Thus, because of the limited studies on neural tube defects, studies on central nervous system malformations in general were taken into account in this review. Furthermore, most of the studies involve small numbers. As case-referent studies are concerned, this means that only a few cases are found per category of occupation; as for cohort studies investigating one occupational group, this means that only a few cases occur in a specific malformation category. Also, some studies only concern occupations of the mothers, whereas others investigate only paternal occupation, the latter being biologically less plausible.

Because of the limitations and methodological differences described above, it is difficult to draw conclusions. Yet, although negative results have been found, there are some occupations that appear to have a higher risk of having offspring with neural tube defects. With regard to mothers, sample size is sometimes too small to detect any association. Still it has been found that mothers employed in industry, construction, transport, and communication have a higher risk of having offspring with central nervous system defects. ${ }^{61,62}$ Mothers working as dentists, ${ }^{65}$ hairdressers, farmers, ${ }^{71}$ or laborers ${ }^{70}$ and mothers exposed to solvents ${ }^{64}$ probably face higher risks of delivering a child with a neural tube defect. With respect to the fathers, it has 
been found that painters, ${ }^{69,70}$ printers, decorators, drivers, ${ }^{69}$ plastic production workers, ${ }^{70}$ farmers, ${ }^{66,71}$ those working in the food, beverage, wood and textile processing industrie ${ }^{67}$ and those exposed to low-level ionizing radiation ${ }^{68}$ probably have a higher risk of having children with neural tube defects.

It is not very surprising that, despite differences in methodology, the different researchers have not found unequivocal results. As Little and Elwood also conclude in their review, ${ }^{73}$ working conditions and legislative control on occupational exposures vary between countries and within time. Because the results are not always consistent with each other, straightforward conclusions about the etiology of neural tube defects thus cannot be drawn, and relevant recommendations concerning prevention cannot be given until more specific and especially larger studies are conducted that confirm or refute the findings. Further research should not only focus on occupational title but on specific exposures and exposure levels as well. Attention should be directed towards the workers mentioned above, as these groups seem to be at an increased risk to have more infants with neural tube defects.

\section{References}

1 Forfar JO, Arneil GC. Textbook of paediatrics, 3rd edition. Edinburgh: Churchil Livingstone, 1984;693-696.

2 Gabriel RS. Malformations of the central nervous system. In: Menkes JH, Ed. Textbook of child neurology. Philadelphia: Lea and Febiger, 1974;125-181.

3 Leck I. Causation of neural tube defects: clues from epidemiology. Br Med Bull 1974;30:158-163.

4 Slattery ML, Janerich DT. The epidemiology of neural tube defects: a review of dietary intake and related factors as etiologic agents. Am / Epidemiol 1991;133:526540.

5 Elwood JM, Elwood JH. Epidemiology of anencephalus and spina bifida. Oxford: Oxford University Press, 1980.

6 Leck I. Epidemiological clues to the causation of neural tube defects. In: Dobbing J. Ed. Prevention of spina bifida and other neural tube defects. New York: Academic Press, 1983.

7 Borman B, Cryer C. Fallacies of international and national comparisons of disease occurrence in the epidemiology of neural tube defects. Teratology 1990;42:405-412.

8 Strassburg MA, Greenland S, Portigal LD, Sever LE. A population based case-control study of anencephalus and spina bifida in a low risk area. Dev Med Child Neurol 1983;25:632-641.

9 International Clearinghouse for Birth Defects Monitoring Systems. Congenital malformations worldwide. Amsterdam: Elsevier, 1991.

10 Seller MJ. Unanswered questions on neural tube defects. Editorial. Brit Med J 1987;294(6563):1-2.

11 Källén B, Löfkvist E. Time trends of spina bifida in Sweden 1947-81. J Epid Comm 
Health 1984;38:103-107.

12 Stone $\mathrm{DH}$. The declining prevalence of anencephalus and spina bifida. Its nature, causes and implications. Dev Med Child Neurol 1987;29:541-549.

13 Bound JP, Francis BJ, Harvey PW. Neural tube defects, maternal cohorts, and age: a pointer to aetiology. Arch Dis Child 1991;66:1223-1226.

14 Maclean $\mathrm{MH}$, MacLeod A. Seasonal variation in the frequency of anencephalus and spina bifida births in the United Kingdom. J Epid Comm Health 1984;38:99-102.

15 Castilla EE, Orioli IM, Lugarinho R, Dutra GP, Lopez-Camelo JS, Campana HE, Spagnolo A, Mastroiacovo P. Monthly and seasonal variations in the frequency of congenital anomalies. Int J Epidemiol 1990;19:399-404.

16 Feldman JG, Stein SC, Klein RJ, Kohl S, Casey G. The prevalence of neural tube defects among ethnic groups in Brooklyn, New York. J Chron Dis 1982;35:53-60.

17 Roberts CJ, Lowe CR. Where have all the conceptions gone. Lancet 1975;I:498-499.

18 Granroth G, Haapakoski J, Hakama $M$. Defects of the central nervous system in Finland. II Birth order, outcome of previous pregnancies and family history. Teratology 1978;17:213-222.

19 Morriss G. Neural tube defects: towards prevention and understanding. Nature 1980;284:121-123.

20 Nevin NC, Johnston WP, Merrit JD. Influence of social class on the risk of recurrence of anencephalus and spina bifida. Dev Med Child Neurol 1981;23:155-159.

21 Campbell LR, Dayton DH, Sohal GS. Neural Tube Defects: a review of human and animal studies on the etiology of neural tube defects. Teratology 1986;34:171-187.

22 Elwood JM, Elwood JH. Investigation of area differences in the prevalence at birth of anencephalus in Belfast. Int J Epidemiol 1984;13:45-52.

23 Laurence $K M$, James $N$, Miller $M$, Campbell $H$. Increased risk of recurrence of pregnancies complicated by fetal neural tube defects in mothers receiving poor diets, and possible benefit of dietary councelling. Brit Med J 1980;281:1592-1594.

24 Smithells RW, Seller MJ, Harris R, Fielding DW, Schorah Cl, Nevin NC, Sheppard S, Read AP, Walker S, Wild J. Further experience of vitamin supplementation for prevention of neural tube defect recurrences. Lancet 1983;l:1027-1031.

25 Wald N, Sneddon J, Frost C, Stone R. Prevention of neural tube defects: Results of the Medical Research Council Vitamin Study. Lancet 1991;338:131-137.

26 Saxén L, Holmberg PC, Kurppa K, Kuosma E, Pyhälä R. Influenza epidemics and anencephaly. Am J Publ Health 1990;80:473-475.

27 Milunsky A, Alpert E, Kitzmiller JL, Younger MD, Neff RK. Prenatal diagnosis of neural tube defects. VIII. The importance of serum alpha-fetoprotein screening in diabetic pregnant women. Am J Obstet Gynecol 1982;142:1030-1032.

28 Zacharias JF, Jenkins $\mathrm{JH}$. The incidence of neural tube defects in the fetus and neonate of the insulin-dependent diabetic woman (Letter). Am J Obstet Gynecol 1984; 150:797.

29 Robert E, Guibaud P. Maternal valproic acid and congenital neural tube defects (Letter). Lancet 1982;1l:937. 
30 Lammer EJ, Sever LE, Oakley GP. Teratogen update: valproic acid. Teratology 1987;35:465-473.

31 Lindhout D, Meinardi H. Spina bifida and in-utero exposure to valproate (Letter). Lancet 1984;11:396.

32 Rosa FW. Spina bifida in infants of women treated with carbamazepine during pregnancy. N Eng J Med 1991;423:674-677.

33 Kasan PN, Andrews J. Oral contraception and congenital abnormalities. Br J Obstet Gynecol 1980;87:545-551.

34 Ericson A, Källén B, Köfkvist E. Environmental factors in the etiology of neural tube defects: a negative study. Environ Res 1988;45:38-47.

35 Cornel MC, Ten Kate LP, Graham Dukes MN. Ovulation induction and neural tube defects (Letter). Lancet 1989;I:1386.

36 Milunsky A, Derby LE, Jick $H$. Ovulation induction and neural tube defects (Letter). Teratology 1990;42:467.

37 Robert E, Pradat E, Laumon B. Ovulation induction and neural tube defects: a registry study. Reprod Toxicol 1991;5:83-84.

38 Mills JL, Simpson JL, Rhoads GG, Graubard BI, Hoffman H, Conley MR, Lassman M, Cunningham $\mathrm{G}$. Risk of neural tube defects in relation to maternal fertility drug use. Lancet 1990;336:103-104.

39 Rosa F. Ovulation induction and neural tube defects. Letter. Lancet 1990;336:1327.

40 Smithells RW, Sheppard S, Schorah CJ. Vitamin deficiencies and neural tube defects. Arch Dis Child 1976;51:944-950.

41 Mills JL, Roads GG, Simpson JL, Cunningham GC, Conley MR, Lassman MR, Walden MA, Depp OR, Hoffman HJ. The absence of a relation between the periconceptional use of vitamins and neural tube defects. N Engl J Med 1989;321:430-435.

42 Czeizel AE, Dudas I. Prevention of the first occurrence of neural tube defects by periconceptional vitamin supplementation. N Engl J Med 1992;327:1832-1835.

43 Haddow JE, Hill LE, Kloza EM, Thanhauser D. Neural tube defects after gastric bypass (Letter). Lancet 1986;:1:1330.

44 Meuwissen JHJM. Kan periconceptionele vitamine-suppletie aangeboren neurale buisdefecten voorkomen (Letter)? Ned T Geneesk 1981;125:2067-2068.

45 Steegers-Theunissen RPM, Boers GHJ, Trijbels FJM, Eskes TKAB. Neural-tube defects and derangement of homocysteine-metabolism (Letter). N Eng J Med 1991;324:199200.

46 Seller MJ. Nutritionally induced congenital defects. Proc Nutr Soc 1987;46:227-235.

47 Hearey CD, Harris JA, Usatin MS, Epstein DM, Ury HK, Neutra RR. Investigation of a cluster of anencephaly and spina bifida. Am J Epidemiol 1984;120:559-564.

48 Zhang J, Savitz DA, Schwingl PJ, Cai W. A case-control study of paternal smoking and birth defects. Int J Epidemiol 1992;21:273-278.

49 Castro-Gago M, Rodriguez-Cervilla J, Ugarte J, Novo I, Pombo M. Maternal alcohol ingestion and neural tube defects (Letter). J Pediatr 1984;104:796-797.

50 Friedman JM. Can maternal alcohol ingestion cause neural tube defects? J Pediatr 
1982;101:232-233.

51 Jones FN, Tauscher J. Residence under an airport landing pattern as a factor in teratism. Arch Environ Health 1978;33:10-12.

52 Edmonds LD, Layde PM, Erickson JD. Airport noise and teratogenesis. Arch Environ Health 1979;34:243-247.

53 Akar N, Ata Y, Aytekin AF. Neural tube defects and Chernobyl? Paed Perinat Epidemiol 1989;3:102-103.

54 Mocan $\mathrm{H}$, Bozkaya $\mathrm{H}$, Mocan $\mathrm{MZ}$, Furtun EM. Changing incidence of anencephaly in the eastern Black Sea Region of Turkey and Chernobyl. Paed Perinat Epidemiol 1990;4:264-268.

55 Lie RT, Irgens LM, Skjærven R, Reitan JB, Strand P, Strand T. Birth defects in Norway by levels of external and food-based exposure to radiation from Chernobyl. Am J Epidemiol 1992;136:377-388.

56 Sever LE, Hessol NA, Gilbert ES, McIntyre JM. The prevalence at birth of congenital malformations in communities near the Hanford Site. Am J Epidemiol 1988;127:243254.

57 Field B, Kerr C. Herbicide use and incidence of neural tube defects (Letter). Lancet 1979;:1:1341-1342.

58 White FMM, Cohen FG, Sherman G, McCurdy R. Chemicals, birth defects and stillbirths in New Brunswick: associations with agricultural activity. Can Med Assoc J 1988; 138:117-124.

59 Dorsch MM, Scragg RKR, MCMichael AJ, Baghurst PA, Dyer KF. Congenital malformations and maternal drinking water supply in rural south Australia: a casecontrol study. Am J Epidemiol 1984;119:473-486.

60 Arbuckle TE, Sherman GJ, Corey PN, Walters D, Lo B. Water nitrates and CNS birth defects: a population based case-control study. Arch Environ Health 1988;43:162167.

61 Hemminki K, Mutanen P, Luoma K, Saloniemi I. Congenital malformations by the parental occupation in Finland. Int Arch Occup Environ Health 1980;46:93-98.

62 Hemminki K, Mutanen P, Saloniemi I, Luoma K. Congenital malformations and maternal occupation in Finland: multivariate analysis. J Epid Comm Health 1981;35:5-10.

63 Olsen J. Risk of exposure to teratogens amongst laboratory staff and painters. Dan Med Bull 1983;30:24-28.

64 Holmberg PC, Nurminen M. Congenital defects of the central nervous system and occupational factors during pregnancy. A case-referent study. Am J Ind Med 1980;1:167-176.

65 Sikorski R, Juszkiewicz T, Paszkowski T, Szprengier-Juszkiewicz T. Women in dental surgeries: reproductive hazards in occupational exposure to metallic mercury. Int Arch Occup Environ Health 1987;59:551-557.

66 Balarajan $R$, McDowall $M$. Congenital malformations and agricultural workers (Letter). Lancet 1983;:11112-1113. 
67 McDonald AD, McDonald JC, Armstrong B, Cherry NM, Nolin AD, Robert D. Fathers' occupation and pregnancy outcome. Br J Ind Med 1989;46:329-333.

68 Sever LE, Gilbert ES, Hessol NA, Mclntyre JM. A case-control study of congenital malformations and occupational exposure to low-level ionizing radiation. Am J Epidemiol 1988;127:226-242.

69 Matte TD, Mulinare J, Erickson JD. Case-control study of congenital defects and parental employment in health care. Am J Ind Med 1993;24:11-23.

70 Fedrick J. Anencephalus in the Oxford Record Linkage Study Area. Dev Med Child Neurol 1976;18:643-656.

71 Brender CJ, Suarez L. Paternal occupation and anencephaly. Am J Epidemiol 1990;131:517-521.

72 Hammond FG, Canache MF. Some epidemiological aspects of neural tube defects in Barquisimeto, Venezuela (Abstract). Am J Hum Genet 1991;49 (suppl.):470.

73 Little J, Elwood JH. Socio-economic status and occupation. In: Elwood JM, Little J, Elwood JH, Eds. Monographs in Epidemiology and Biostatistics, vol 20: Epidemiology and control of neural tube defects. Oxford: Oxford University Press, 1992. 


\section{CHAPTER 3}

\section{METHODOLOGIC ISSUES}




\title{
ASSESSMENT OF OCCUPATIONAL EXPOSURE IN A POPULATION BASED CASE-CONTROL STUDY: COMPARING POSTAL QUESTIONNAIRES WITH PERSONAL INTERVIEWS
}

\author{
BM Blatter, N Roeleveld, GA Zielhuis, ALM Verbeek \\ Occup Environ Med 1997;54:54-59 \\ with the permission of BMJ Publishing Group
}

\begin{abstract}
Objectives In case-control studies, data collection on occupational exposures by means of personal interviews is usually costly and time consuming. As detailed semi-quantitative information on exposure from these interviews often has to be dichotomised in the analyses due to the small numbers of exposed subjects, the question is raised whether simple postal questionnaires yield the same results for occupational exposure in epidemiological studies as job specific personal interviews.

Methods Data on occupational exposures during pregnancy were compared from 121 women who both completed a checklist with 17 occupational exposure categories in a postal questionnaire and were personally interviewed with specific questions on exposure with details of job and task. $x$ Coefficients were calculated as measures of agreement corrected for chance, and sensitivity and positive predictive values as measures of validity and usefulness, with the exposure assessment based on information from the interview as the gold standard.

Results Values of $\alpha$ varied from 0.09 for domestic cleaning agents to 0.70 for pesticides, indicating only low to moderate agreement between the questionnaire and the interview. Sensitivity ranged from $38 \%$ to $100 \%$, with the highest values for agents used by healthcare workers. Positive predictive values were lower, between $9 \%$ and $63 \%$, which indicates that overreporting was more common than underreporting in the questionnaire.

Conclusions These results underline the high potential for misclassification of occupational exposure in studies based on questionaires. Therefore, postal questionnaires are not considered an alternative to job and task specific personal interviews in epidemiological studies.
\end{abstract}




\section{Introduction}

Population based case-control studies in occupational epidemiology usually involve retrospective exposure assessment of a large variety of occupations and chemical or physical agents and widely varying levels of exposure. Exposure assessment in these studies is often based on self reported information from postal questionnaires or interviews. Currently, much attention is given to the improvement of assessment of exposure to minimise misclassification and consequently to better identify weak associations. ${ }^{1}$ Traditionally, in occupational epidemiology data have been collected by asking subjects whether they were exposed to specific agents or asking open ended generic questions. Later, more specific methods of data collection were suggested. One such method is to obtain general information on the occupation of the respondent, which is then used by chemists and industrial hygienists to infer the presence and the level of specific agents. Also, job specific questionnaires, including questions on tasks and activities, equipment, and work environment, were designed to increase the accuracy of the exposure assessment. ${ }^{2-5}$ However, this method of exposure assessment is costly and labour-intensive.

Several studies have been published on the validity of job titles and occupational histories, ${ }^{6,7}$ showing satisfactory validity in most cases. Validity and reliability studies of occupational exposure usually concern current exposure data and are conducted in a single type of work site. ${ }^{8,9}$ Teschke et al. ${ }^{9}$ compared two different questionnaire formats used in saw filers with air sampling results and observations of work patterns. Although the questionnaire with detailed prompting of chemical agents had a higher sensitivity than the open ended and partly prompted questionnaire, overall, both sensitivity and specificity were low. Therefore, the authors suggested probing about exposures in terms of the tasks performed as a better method.

Validity studies on retrospective exposure data derived from population based case-control studies, are extremely difficult. As it is often impossible to perform measurements or retrieve company records, no gold standard is available in these studies. ${ }^{9}$ Ezkenazi and Pearson compared self administered questionnaires with detailed clinical interviews by an occupational health professional and examined whether the validity could be improved through review of the postal questionnaires by an industrial hygienist. ${ }^{10}$ They found that the questionnaire was substantially accurate, although $\boldsymbol{\kappa}$ coefficients were only presented for general exposure categories. They recommended the use of a self administered questionnaire, thoroughly reviewed by an industrial hygienist.

We recently performed a population based case-control study on spina bifida and maternal occupational exposure, in which data were collected by means of detailed job specific interviews. ${ }^{11}$ Also, information on occupational exposure of the 
same respondents was available from postal questionnaires used in an earlier phase of the study. ${ }^{12}$ Because the numbers of exposed women were small and the levels of exposure were low, several chemical or physical agents had to be clustered into broader exposure categories. Also, qualitative instead of quantitative or semiquantitative measurements had to be used. As a result, much of the detailed information that was collected in the interviews was lost. The question then arose whether the self administered postal questionnaire would have yielded the same results on occupational exposure as the job specific, time consuming personal interviews with additional exposure assessment by the investigators. The purpose of the present study was to investigate the degree of agreement between these two methods of assessment of occupational exposure and to examine the validity and usefulness of a postal questionnaire when the detailed interview is considered to be the gold standard.

\section{Population and methods}

The study population included 470 mothers of children with spina bifida aperta (cases) and 2350 mothers of children who had experienced a trauma capitis or meningitis or were sampled from the general population (controls). All children were born between 1 January 1980 and 31 December 1992. Data collection was carried out in two phases. Firstly, all mothers were approached for the study by post with a letter from their child's attending physician or from a municipal administrator. A letter from the investigators, a brochure with information, and a questionnaire were enclosed. The questionnaire included questions about occupational title and industry and a list with 17 chemical and physical exposure groups. For ease of completion, all questions referred to one date of interest as a proxy for the period around conception. This date was defined as the date of birth of the index child minus one year.

Detailed information on occupational exposures was collected from a subset of 121 mothers by means of personal interviews at home. The time lag between the interview and the questionnaire ranged from two months to one year and four months. As detailed interviews would be redundant for mothers who did not have a job or who worked in jobs without chemical or physical exposure, only mothers who worked in occupations with a potential for exposure to chemicals or radiation were actually interviewed. This group included healthcare workers, cleaners, hairdressers, workers in industry and transport, and agricultural workers.

A set of interviews was specifically designed for each of the following 10 occupations: nurses, laboratory assistants, dental assistants, pharmaceutical assistants, physiotherapists, hairdressers, cleaners, printers, agricultural occupations, and occupations in industry or transport. In each interview, traditional work history questions on job title, industry, company name, number of hours worked, and tasks 
performed were asked first. Subsequently, detailed standardised questions developed by the investigators on the basis of occupational hygiene information were used to inquire about every occupational task that had possibly been performed and about the associated use of chemicals and radiation, the frequency of the activity or the exposure, the use of protective devices, and exposure through the proximity of colleagues. For example, hairdressers were asked whether they applied hair sprays, what type of hair spray they used (with propellant gas or pump sprays), how often they applied hair dyes, and whether they had to prepare hair dyes themselves. Workers in the printing industry were asked whether they had to refill the ink supply and wash the ink rollers. At the end of each interview, the checklist used in the postal questionnaire was shown to find any agents that might have been missed. Detailed questions were asked again for the agents that were reported on the checklist. The period of interest ranged from two weeks before conception until six weeks after conception, calculated from the duration of pregnancy that was reported in the questionnaire.

The exposures from the interview were classified into 23 categories. For each exposure category, the information that was obtained was coded into two variables. The first variable concerned the exposure that the women themselves reported during the interview, which was coded dichotomously (variable A). The second variable, indiçating the level of exposure, was assessed by professional judgement of the investigators on a four point scale (high, moderate, low, and no exposure) and was based on the frequency of exposure, the type of protective equipment used, and exposure through colleagues. Eventually, the variable for level of exposure was dichotomised into no exposure versus any level of exposure (variable B) because of comparability with the postal questionnaire and small numbers.

In the analyses, only those exposure categories were included that were identically defined in the questionnaire and the interview (anaesthetics, antineoplastic drugs and antibiotics; disinfecting and sterilising agents; domestic cleaning agents; dyes and pigments; pesticides; dust; ionising radiation; and non-ionising radiation). Firstly, the exposure data from the postal questionnaire were compared with the self reported data obtained by the personal interview (variable A). Secondly, the data from the postal questionnaire were compared with the interview exposure data after assessment of exposure by the investigators (variable B). In both comparisons, the personal interview with detailed job specific and task specific questions was assumed to be the gold standard. The $\kappa$ coefficients $\left(\kappa_{\mathrm{A}}\right.$ and $\left.\kappa_{\mathrm{B}}\right)$ with $95 \%$ confidence intervals $(95 \% \mathrm{Cls})^{13}$ were calculated as measures of agreement corrected for chance, and sensitivity and positive predictive values as measures of validity and usefulness. Table 3.1.1 shows the formulas and a $2 \times 2$ table used for calculation of these measures. High sensitivity for a specific agent indicates that little underreporting of that agent in the questionnaire exists; a high positive predictive value is interpreted 
as little overreporting in the questionnaire. To test whether both forms of misclassification (overreporting and underreporting) occurred randomly or whether systematic overreporting or underreporting occurred, McNemar's tests were calculated. A low P value means a high probability of systematic overeporting or underreporting.

TABLE 3.1.1 Two by two table with formulas of proportion of agreement (agr), $k$, sensitivity, positive predictive value, and McNemar's test

\begin{tabular}{|c|c|c|c|c|}
\hline & & \multicolumn{3}{|c|}{ Exposed according to interview } \\
\hline & & Yes & No & \multirow{4}{*}{$\begin{array}{l}a+b \\
c+d \\
n\end{array}$} \\
\hline \multirow[t]{3}{*}{ Exposed according to questionnaire } & Yes & $\mathbf{a}$ & $\mathrm{b}$ & \\
\hline & No & c & d & \\
\hline & & $\overline{a+c}$ & $b+d$ & \\
\hline Proportion of agreement $=$ & \multicolumn{4}{|c|}{$(a+d) / n$} \\
\hline Proportion of chance agreement $=$ & \multicolumn{4}{|c|}{$(a+c) / n^{*}(a+b) / n+(b+d) / n^{*}(c+d) / n$} \\
\hline$\kappa$ Coefficient $=$ & \multicolumn{4}{|c|}{$\left(\operatorname{agr}_{\text {obs }}-\operatorname{agr}_{\text {chance }}\right) /\left(1-\operatorname{agr}_{\text {chance }}\right)$} \\
\hline Sensitivity $=$ & \multicolumn{4}{|c|}{$a /(a+c)$} \\
\hline Positive predictive value $=$ & \multicolumn{4}{|c|}{$a /(a+b)$} \\
\hline McNemar's test $\left(x^{2}, 1 \mathrm{df}\right)=$ & \multicolumn{4}{|c|}{$(|b-c|-1)^{2} /(b+c)$} \\
\hline
\end{tabular}

\section{Results}

All 121 women who were invited for the interview (55 cases and 66 controls) in this part of the study participated. Table 3.1.2 presents the frequencies of some characteristics of this study population. Of the women, $70 \%$ were between 30 and 40 years of age at the time of the interview; the same percentage of women had at least 10 years of education. More than half of the women worked in health care.

Table 3.1.3 shows the results of the comparisons made between the postal questionnaires and the self reported information on exposure from the job specific interviews, and Table 3.1.4 shows the results of the comparison between the postal questionnaire and the exposure assessed from the interviews by an investigator. In the first column of both tables the numbers of exposed people according to questionnaire and interview are given. Also, the differences between the results in Table 3.1.3 and Table 3.1.4 are visually presented in the figure. Figure $A$ depicts the results of the $\kappa$ coefficients. Most of the coefficients are $<0.4$, so agreement is considered to be poor. This implies that the respondents were not very accurate in reporting occupational exposure by means of a postal questionnaire. The figure also shows that large variability existed between the different categories. For instance, typical occupationally used agents, such as anaesthetics and drugs by healthcare workers $\left(\kappa_{\mathrm{A}}=0.63, \kappa_{\mathrm{B}}=0.56\right)$ and pesticides by agricultural workers $\left(\kappa_{\mathrm{A}}=0.70, \kappa_{\mathrm{B}}=0.48\right)$ gave better results than categories such as dust $\left(\kappa_{A}=0.20, \kappa_{B}=0.23\right)$ or cleaning agents 
$\left(\kappa_{\mathrm{A}}=0.16, \kappa_{\mathrm{B}}=0.09\right)$. Many women might have considered common household dust or the use of domestic cleaning agents at home as a workplace exposure while filling out the questionnaire. Because the $\boldsymbol{k}$ coefficient is influenced by the prevalence of exposure, ${ }^{14}$ which differed between the exposure categories in this study (Tables 3.1.3 and 3.1.4), comparisons between the $\kappa$ coefficients must be interpreted with care.

TABLE 3.1.2 Characteristics of study population

\begin{tabular}{lcc}
\hline & Women $(\mathrm{N}=121)$ & \\
\hline Case-referent status & $\mathrm{N}$ & \\
$\quad$ Cases & 55 & 45.5 \\
$\quad$ Referents & 66 & 54.5 \\
Age at interview & & \\
Between 20 and 30 yrs & 20 & 16.5 \\
Between 30 and 40 yrs & 85 & 70.2 \\
Above 40 yrs & 15 & 12.4 \\
Low & & \\
Middle & 35 & 29.4 \\
High & 64 & 53.7 \\
Health care workers & 20 & 16.8 \\
Cleaners & & \\
Hairdressers & 71 & 58.7 \\
Industry and transport workers & 16 & 13.2 \\
Agricultural workers & 8 & 6.6 \\
Occupation & 15 & 12.4 \\
\hline
\end{tabular}

*Low: comparable with up to grade 9; middle: comparable with grades 10-14; high: comparable with grade 15 and higher

The sensitivity (Figure B) ranged between $38 \%$ and 100\%. For drugs and anaesthetics, disinfecting agents, domestic cleaning agents, and ionising radiation, sensitivity was almost $100 \%$. This indicates that women who were exposed to these agents could be reasonably well detected by the questionnaire. However, for dust and non-ionising radiation sensitivity was low, which may reflect the fact that some people do not realise that they are exposed to these agents. It is clear that the sensitivity did not change much when the data assessed by the investigator instead of the self reported data were used as the gold standard. 


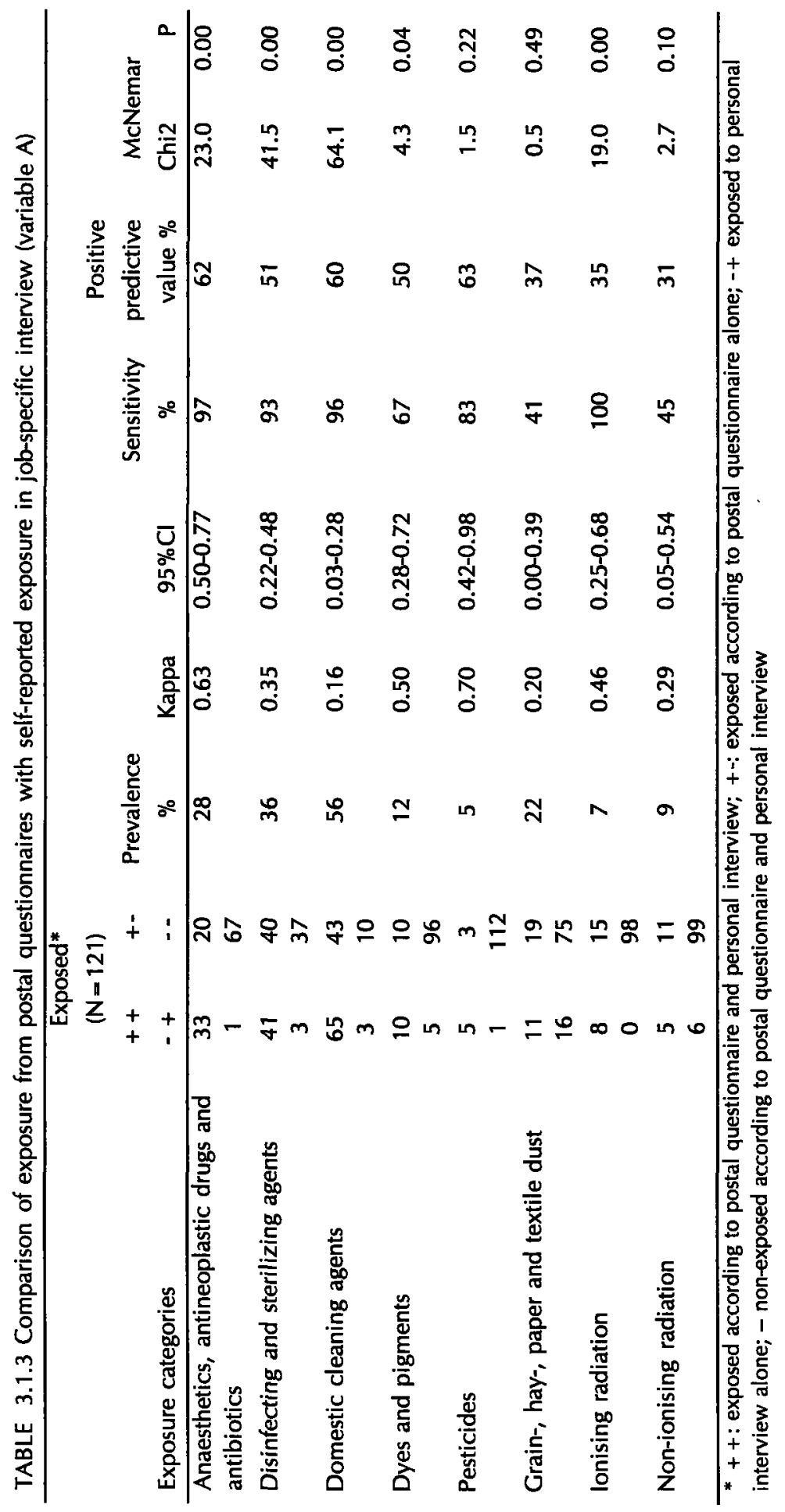




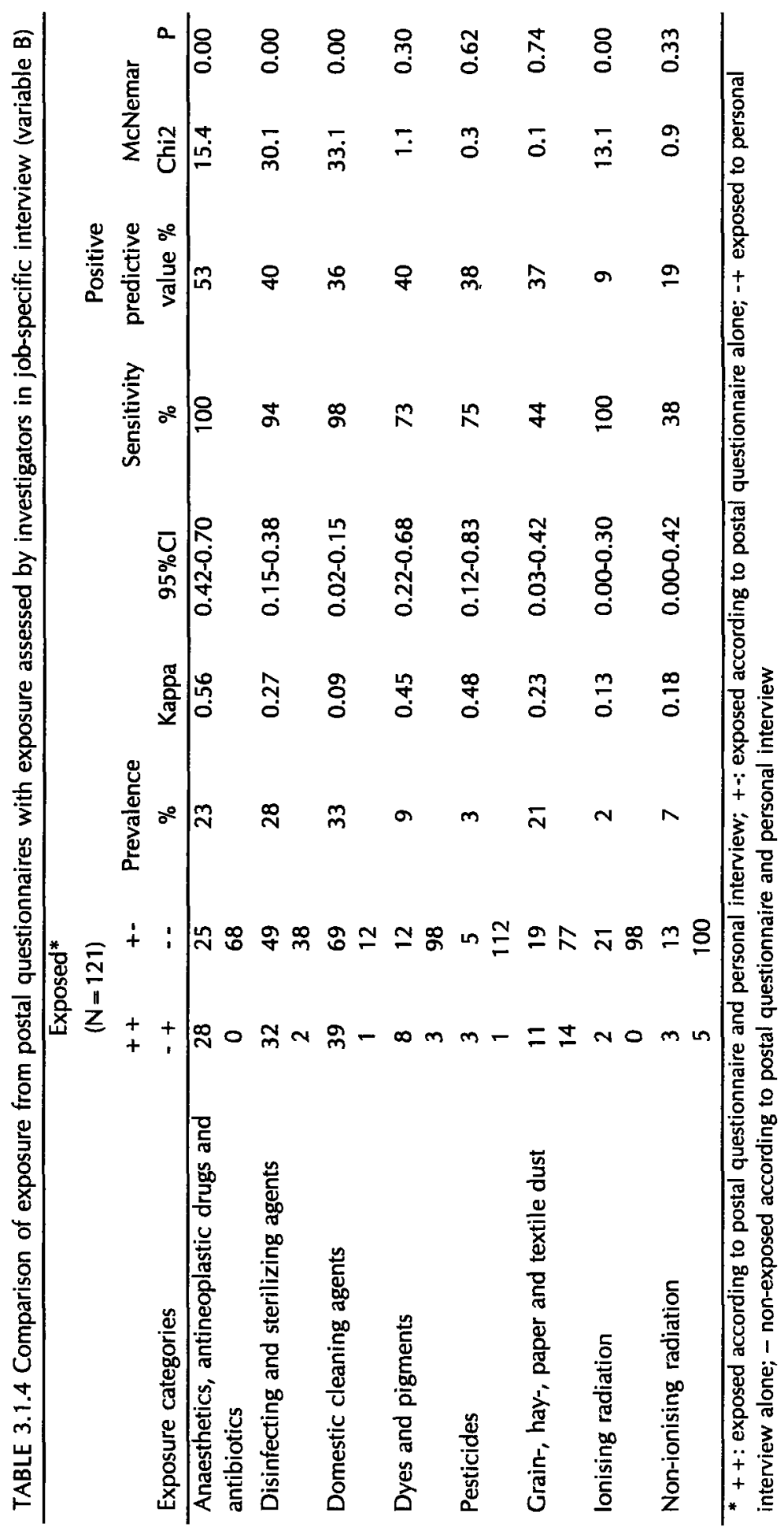


The fifth columns in Tables 3.1.3 and 3.1.4 show that the positive predictive values ranged between $9 \%$ and $63 \%$. In all exposure categories the positive predictive value was low and lower than the sensitivity. The difference was significant with McNemar's test for half of the categories. Overreporting in the questionnaire was thus common. The highest positive predictive values were found for anaesthetics and drugs $(62 \%)$, cleaning agents $(60 \%)$, and pesticides $(63 \%)$, when the postal questionnaire was compared with the self reported interview data (Figure C). However, in concordance with the results of the $\boldsymbol{K}$ coefficients, these positive predictive values decreased considerably when the questionnaire was compared with the interview data assessed by an investigator $(53 \%, 36 \%$, and $38 \%$ respectively). This indicates that sometimes women may have reported exposures consistently in the questionnaire and the interview, whereas these exposures seemed to be non-existent or negligible when the frequency of exposure and the use of protective devices were taken into account. As a result, these women were classified as non-exposed in the data assessed by the investigator.

\section{Discussion}

In population based case-control studies, personal job specific interviews with expert exposure assessment are considered a valid means of data collection, which is usually preferred over self administered questionnaires. In the second phase of our study on spina bifida and parental occupation, detailed information on exposure and frequency of exposure was gathered by means of such interviews. Because the exposure prevalence was low, however, exposure categories had to be clustered and exposure levels were dichotomised. Consequently, we wondered if the simple questionnaires which we used in the first phase of the study would have yielded the same results as the job specific interviews.

The results from this comparative study show that, overall, low to moderate agreement exists between data on occupational exposures from postal questionnaires and from interviews. Some exposure categories that we inquired about in our study on spina bifida were not defined identically in the questionnaire and the interview and are not presented in this paper. Within the exposure categories for which exact comparisons could be made, large differences in reporting accuracy and degree of overreporting and underreporting existed. It must be noted however, that $95 \% \mathrm{Cls}$ of the measures of validity and agreement of some exposure categories were wide, due to the small study population and low prevalences of exposure for these exposure categories. In general, sensitivities were high, indicating that only a few exposed people were missed when using the postal questionnaire. For dust and non-ionising radiation, however, underreporting was more common. This might be due to the fact that people do not realise their exposure to these agents without detailed prompting. 

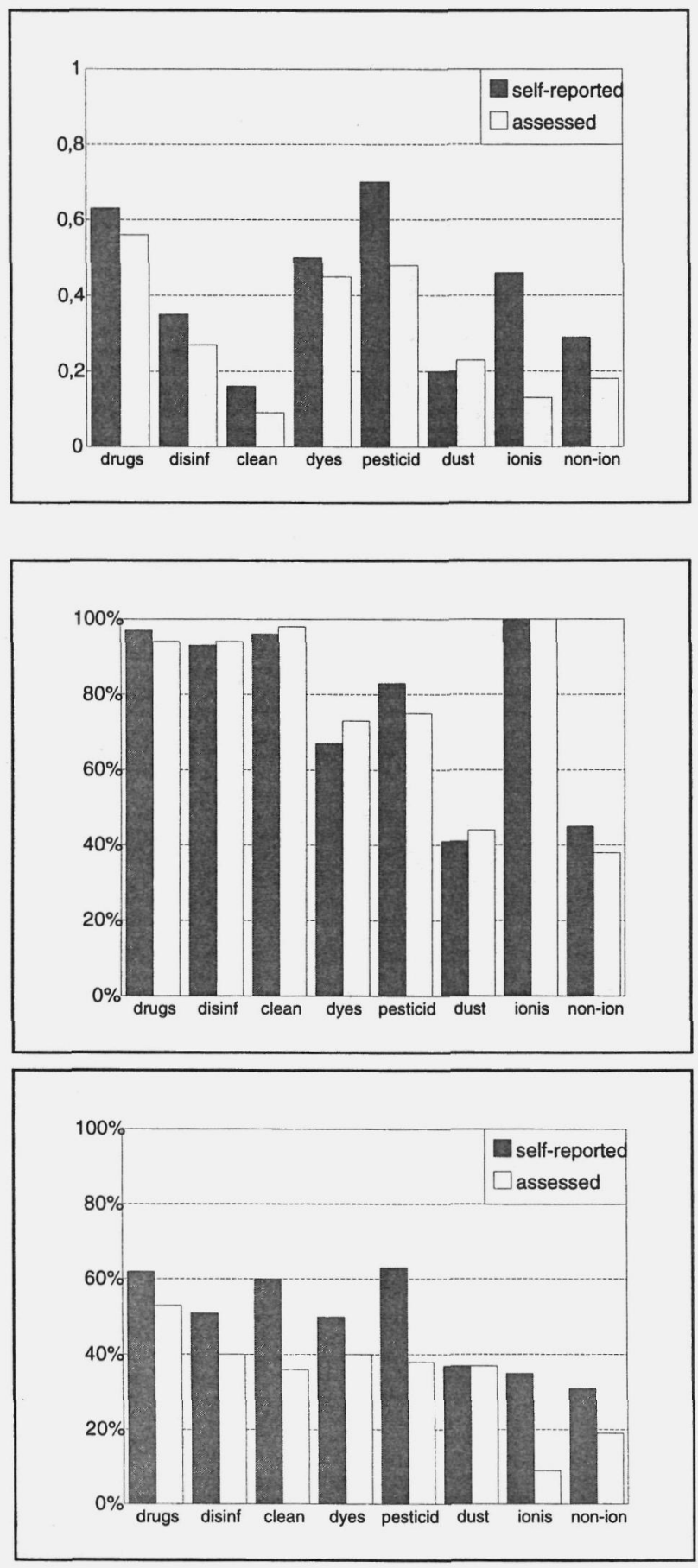

Figure A $\kappa$ coefficients of questionnaire vs interview information: self reported data as a gold standard (dark bars) compared with investigator assessed data as a gold standard (light bars)

Figure B Sensitivity of questionnaire vs interview information: self reported data as a gold standard compared with investigator assessed data as a gold standard

Figure C Positive predictive values of questionnaire vs interview information: self reported data as a gold standard compared with investigator-assessed data as a gold standard 
The results also suggest low positive predictive values and thus much overreporting in the postal questionnaire. In particular, exposure to cleaning agents and dust, which are common domestic exposures, was heavily overreported. The questionnaire may not have clearly indicated that the questions concerned only work exposures. Also, some women may have considered household cleaning agents and dust as workplace exposures. However, typical occupationally used agents, such as agents used by healthcare workers (anaesthetics, antineoplastic drugs, and antibiotics) and by agricultural workers (pesticides) show better agreement. Although differences in prevalences of exposure existed between the exposure categories in our study, they cannot totally explain the differences in the $\kappa$ coefficients found.

In this study, we made two comparisons: daata from postal questionnaires versus self reported data from interviews (variable $A$ ), and data from postal questionnaires versus data from an interview assessed by an investigator (variable B). The difference between the two comparisons is determined by the exposure assessment by the investigators based on the self reported information combined with task descriptions, the frequency of exposure, and the use of protective devices. In practice, this meant that the self reported data were primarily adjusted by elimination of very low or infrequent exposures. As most of the potential exposures were asked for in the interview, no additional exposures were inferred from the interview information. This explains the finding of higher positive predictive values when the data from the postal questionnaire were compared with the self reported data as opposed to the exposure data assessed by the investigator.

In considering the validity of this study, it must be noted that the exposures occurred one to 14 years before data collection. It was expected that early exposures would be reported less accurately than recent exposures, so we stratified our analyses according to early (eight to 14 years ago) and recent exposure (one to seven years ago). The results for the eight exposure categories were randomly higher or lower in one or the other period. Also, the periods we referred to in the two methods were not exactly the same. In the questionnaire, one year before birth was used as a proxy for the period of interest as opposed to the two months around conception in the personal interview. However, the effect of this discrepancy is considered to be small as most women do not stop working immediately when they find out that they are pregnant. For five out of the 121 women, we found an occupation around conception that differed from the occupation that was reported in the questionnaire. In three instances the women had stopped working; the two other women were mistaken about the time period when filling in the questionnaire. It is unlikely that these women account for most of the disagreement between the two methods of assessment.

Considering the possibility of information bias in case-control studies, it might be expected that differences in reporting exist between cases and controls. Therefore, 
we stratified our analyses on agreement and validity according to case-control status. As the $k$ coefficients, sensitivities, and positive predictive values for the eight exposure categories were randomly higher or lower for cases compared with controls, we think that no evidence for differential misclassification of information exists. However, numbers in subgroups were small, leading to unstable estimates.

For efficiency reasons only people with occupations with a high potential for exposure were selected for an interview. Although this interviewed study population of 121 women was of primary interest in the present study, it was not representative of the total study population regarding the prevalence of exposure. In the total study population with a lower prevalence of exposure, the cell distributions in the contingency table would shift towards a less symmetric distribution of agreement, leading to a lower $\kappa \cdot{ }^{14,15}$ The effect of variation in the disagreements, which is likely to occur when the sensitivity and specificity remains the same, is smaller. In addition, the positive predictive value decreases with decreasing prevalence of exposure.

Few studies have examined different methods of exposure assessment used in population based case-control studies. Eskenazi and Pearson compared questionnaires with clinical interviews and suggested that self administered questionnaires can be used to obtain valid information on occupation and occupational exposure from pregnant women. ${ }^{10}$ However, the time between initial and subsequent data collection in their study averaged three weeks, and the period of interest was at most nine months before data collection. Most investigators express a preference for more detailed and job specific methods of data collection. ${ }^{1-5}$

In conclusion, we found that the use of postal questionnaires has a high potential for misclassification, although results differ between the various categories of chemical agents. Therefore, self administered questionnaires are not an alternative for job and task specific interviews combined with assessment of exposure by an occupational hygienist. We argue that job and task specific interviews should be performed whenever possible in population based case-control studies which examine exposures that must be assessed retrospectively. If other methods such as postal questionnaires are used, overestimation of exposure might occur. It should be noted that when exposure prevalences are low, overreporting resulting in a decrease in positive predictive value has a larger influence on the validity and the power of the study than underreporting of exposure..$^{16,17}$

\section{References}

1 Goldberg $M$, Hémon D. Occupational epidemiology and assessment of exposure. Int J Epidemiol 1993;22 (suppl 2):S5-S9.

2 Gérin $M$, Siemiatycki J, Kemper $H$, Bégin D. Obtaining occupational exposure histories in epidemiologic case-control studies. J Occ Med 1985;27:420-426.

3 Gérin $M$, Siemiatycki J. The occupational questionnaire in retrospective epidemiologic 
studies: Recent approaches in community-based studies. Appl Occup Environ Hyg 1991;6:495-501.

4 Stewart W, Stewart P. Occupational case-control studies: I. Collecting information on work histories and work-related exposures. Am J Ind Med 1994;26:297-312.

5 Stewart P, Stewart W. Occupational case-control studies: II. Recommendations for exposure assessment. Am J Ind Med 1994;26:313-326.

6 Rona RJ, Mosbech J. Validity and repeatability of self-reported occupational and industrial history from patients in EEC countries. Int J Epidemiol 1989;18:674-679.

7 Baumgarten M, Siemiatycki J, Gibbs G. Validity of work histories obtained by interview for epidemiologic purposes. Am J Epidemiol 1983;118:583-591.

8 Joffe $M$. Validity of exposure data derived froma structured questionnaire. Am J Epidemiol 1992;135:564-570.

9 Teschke K, Kennedy SM, Olshan AF. Effect of different questionnaire formats on reporting of occupational exposures. Am J Ind Med 1994;26:327-337.

10 Eskenazi B, Pearson K. Validation of a self-administered questionnaire for assessing occupational and environmental exposures of pregnant women. Am J Epidemiol 1988;128:1117-1129.

11 Blatter BM, Roeleveld N, Zielhuis GA, Mullaart RA, Gabreëls FJM. Spina bifida and parental occupation. Epidemiol 1996;7:188-193.

12 Blatter BM, Roeleveld N, Zielhuis GA, Gabreëls FJM, Verbeek ALM. Maternal occupational exposure during pregnancy and the risk of spina bifida. Occup Environ Med 1996;53:80-86.

13 Cohen J. A coefficient of agreement for nominal scales. Psychological Measurement 1960;20:37-46.

14 Armstrong BK, White E, Saracci R. Monographs in Epidemiology and Biostatistics vol 21. Principles of exposure measurement in epidemiology. Oxford: Oxford University press, 1992;109.

15 Lantz C, Nebenzahl E. Behavior and interpretation of the $\kappa$ statistic: resolution of the two paradoxes. J Clin Epidemiol 1996;49:431-434.

16 Stewart WF, Correa-Villaseñor $A$. False positive exposure errors and low exposure prevalence in community-based case-control studies. Appl Occup Environ Hyg 1991;6:534-540.

17 Hemminki K, Lindbohm ML, Kyyrönen P. Validity aspects of exposure and outcome data in reproductive studies. J Occ Environ Med 1995;37:903-907. 
CHAPTER 3.2

\title{
HOSPITAL OR POPULATION REFERENTS IN A STUDY OF CONGENITAL MALFORMATIONS?
}

\author{
N Roeleveld, BM Blatter, E Welp \\ Submitted for publication
}

\begin{abstract}
In case-referent studies, hospital-based referent groups are often used to avoid recall bias, but they may cause selection bias. To choose the best referent group in a study on spina bifida and parental occupation, the potential for selection bias and recall bias was evaluated. Information from self-administered questionnaires was compared between 246 hospital-based referent children with a cerebral trauma or meningitis and 651 population referents. 'Objective' variables (e.g., education and occupation) were used to assess selection bias and 'subjective' variables (e.g., lifestyle factors and occupational exposures) to assess recall bias. The hospital-based referent group was selected towards a lower level of education, blue collar or agricultural occupations, and living in rural areas, clearly resulting in selection bias in the odds ratios. No indications for recall bias were found for the lifestyle factors smoking and alcohol use. For a number of 'common' occupational exposures, overreporting by case parents seems to occur, leading to odds ratios inflated by recall bias when a population-based referent group is used. As selection bias may have a greater impact on the study results than recall bias, a populationbased referent group would be preferred for studies on congenital defects and parental occupation.
\end{abstract}

In case-referent studies of congenital malformations, hospital-based referent groups are often used to guarantee comparibility of information between cases and referents in order to avoid recall bias. ${ }^{1-4}$ However, this may introduce selection bias in the study if the referent disorder is associated with the exposure under study. ${ }^{5-7}$ Therefore, it is not obvious whether to choose a hospital-based or a population-based referent group in any specific etiologic study of congenital malformations.

When population referents are used, recall bias might result from differential recall of exposure by parents of cases and referents. Case parents are assumed to search more thoroughly for possible causes of their child's condition and therefore to be more likely to report exposures than equally exposed parents of healthy 
referents. ${ }^{1,8}$ Differential overreporting by case parents will lead to an overestimate of the odds ratio. A similar bias would arise if referent parents underreported exposures. Alternatively, bias resulting from case mothers failing to report exposure or referent mothers overreporting has been mentioned as an explanation for negative associations or bias towards the null value., ${ }^{9,10}$ Although expressions of concern about possible effects of recall bias are frequently found in the literature, ${ }^{8,11-13}$ little empirical evidence exists to support these concerns. Only one study of congenital malformations has clearly identified recall bias, ${ }^{3}$ but the conclusions of this study have been questioned. ${ }^{5,13}$ In other studies on reproductive defects no evidence for recall bias could be found. .,15-18 $^{2}$

Despite this, hospital-based referent groups are recommended for studies on congenital defects as a means of reducing recall bias. ${ }^{1,3,19}$ Moreover, a greater motivation to participate in the study is expected of parents of hospital referents, which would result in a higher response rate compared to population referents. ${ }^{1,4}$ As hospital referents are usually more readily available than population referents, it may also be more convenient and less expensive to enroll a hospital-based referent group. ${ }^{4}$

The disadvantage of using a hospital-based referent group in studies of congenital malformations is a considerable risk of selection bias. ${ }^{5-7,20,21}$ This would occur if the hospital-based referent group was not representative of the study base from which the cases were derived for exposure and possible confounders. The referent disorders may have an unknown association with the exposure under study or the referents may be admitted to a particular hospital for different reasons than the cases. Both phenomena could lead to substantial selection bias in the study results, which could be greater than any recall bias that would occur with a population-based referent group. ${ }^{5-7}$

In order to choose the best referent group in a study on spina bifida and parental occupation, the potential for selection bias and recall bias as well as feasibility issues were evaluated by comparing information from a self-administered questionnaire between a hospital-based and a population-based referent group. In addition, the risk estimates calculated with one or the other referent group were compared to assess the impact of selection bias and/or recall bias on the study results.

\section{Population and methods}

The study was attached to a larger study on spina bifida and parental occupation performed in The Netherlands. ${ }^{22}$ A subsample of 253 cases was available at the time the validity study was conducted. The cases were born between January 1, 1980 and December 31, 1991 and were diagnosed with spina bifida aperta (International Classification of Diseases (ICD-9) codes 741.0 and 741.9) in two university hospitals 
and one regional hospital in The Netherlands. We selected two different referent groups consisting of children from the catchment areas of the hospitals and born in the same time period as the cases. The hospital-based referent group included 404 children who had been born healthy, but had experienced a cerebral trauma (ICD-9 codes $800,801,851-854$ ) or meningitis during early childhood. They were diagnosed and/or treated in the hospitals in which the cases were identified. By means of extensive hospital record review, children with birth defects or diseases potentially associated with occupational exposure of the parents were excluded. The populationbased referent group included 914 children sampled from 27 municipal registries in The Netherlands. They were frequency matched to the cases on geographical location and on size of the municipality in four categories.

Each parent of cases and referents was sent a self-administered questionnaire, accompanied by a letter from the investigators and a letter from one of their child's physicians (cases and hospital referents) or from a municipal administrator (population referents). The questionnaire included general questions about age and education of the parents, parity, and gender of the child; questions on lifestyle factors, such as smoking, alcohol use, and medical drug use; questions about the living environment; and questions concerning occupational title, tasks, and daily activities at work. Information on occupational exposures was gathered by means of a checklist with 17 exposure categories. For ease of completion, all questions referred to a point in time exactly one year before the birth of the index child.

We evaluated the response rates in the case and referent groups and the participation of hospitals and municipalities to address feasibility issues and to find indications for selective non-response. In order to detect other potential sources of bias, we compared the information from the hospital-based referent group with the information from the population-based referent group. The potential for selection bias was assessed by evaluating differences in the proportions of the answer categories of 'objective' variables, such as education, occupation, and place of residence of the parents. These variables are assumed to be reported accurately when the time period of interest is small. ${ }^{13}$ We also compared the occupational distributions of the two referent groups with the occupational distribution of the general population in the same age range (25-44 years) and the same geographical areas as registered by the Central Bureau for Statistics (CBS) in The Netherlands. ${ }^{23}$ To identify the potential for recall bias, we looked at differences in the proportions of the answer categories of 'subjective' variables for which differential recall may be expected: lifestyle factors, such as smoking and alcohol use, living environment, and occupational exposures.

In order to assess the impact of using one or the other referent group on the final study results, we calculated odds ratios (OR) with 95\% confidence intervals $(95 \% \mathrm{Cl})$ for spina bifida using the hospital-based referent group and the populationbased referent group separately in univariate analyses. Logistic regression analyses 
were performed to correct the results of the 'subjective' variables for potential confounding by obvious selection factors found in the analyses of the 'objective' variables.

\section{Results}

Of the 34 municipalities asked to provide a sample of children for the populationbased referent group, $27(79.4 \%)$ participated. Two municipalities refused, one had a too lengthy procedure, and four were excluded because of high sampling costs. The response rate was higher among population referents $(71.2 \%, \mathrm{~N}=651)$ than among hospital referents $(60.9 \%, N=246)$, but not as high as among cases $(84.2 \%, N=213)$. When asked whether they wanted to participate in a potential further study, the parents of population referents appeared to be more willing to do so than the parents of hospital referents $(71.6 \%$ and $64.7 \%$ of initial response, respectively).

\section{Selection bias}

The potential for selection bias was evaluated using the 'objective' background variables listed in Table 3.2.1. As expected, approximately half $(50.9 \%)$ of the population-based referent group consisted of boys, compared to $63.4 \%$ of the hospital-based referent group. For level of education, there also was a discrepancy between the two groups. The parents of population referents seem to have a higher education (approximately $70 \%$ compared to $60 \%$ above 9 th grade). This leads to odds ratios around unity when the hospital-based referent group is used, whereas inverse relationships between spina bifida and level of education are observed with the population-based referent group $\left(\mathrm{OR}_{\text {mother }}=0.5,95 \% \mathrm{Cl}\right.$ : $0.4-0.7 ; \mathrm{OR}_{\text {father }}=0.6$, 95\% $\mathrm{Cl}: 0.4-0.9$ ). A higher percentage of hospital referents lived in rural areas

TABLE 3.2.1 Background variables evaluated for potential selection bias

\begin{tabular}{lcccccccc}
\hline & Cases \% & referents \% & \multicolumn{2}{c}{ Population } & \multicolumn{2}{c}{ Cases vs hospi- } & \multicolumn{2}{c}{ Cases vs popula- } \\
Background variables & $(\mathrm{N}-213)$ & $(\mathrm{N}-246)$ & $(\mathrm{N}-651)$ & OR & $95 \% \mathrm{Cl}$ & OR & $95 \% \mathrm{Cl}$ \\
\hline Gender of child - male & 44.6 & 63.4 & 50.9 & 0.5 & $0.3-0.7$ & 0.8 & $0.6-1.1$ \\
Primiparity & 49.5 & 38.6 & 41.2 & 1.6 & $1.1-2.3$ & 1.4 & $1.0-1.9$ \\
Education mother $>$ 9th grade & 56.6 & 59.6 & 71.8 & 0.9 & $0.6-1.3$ & 0.5 & $0.4-0.7$ \\
Education father $>$ 9th grade & 58.0 & 62.8 & 68.4 & 0.8 & $0.5-1.2$ & 0.6 & $0.4-0.9$ \\
Living in rural area & 16.4 & 18.7 & 10.8 & 0.9 & $0.5-1.4$ & 1.6 & $1.1-2.5$ \\
Living in free-standing house & 35.7 & 39.8 & 31.2 & 0.8 & $0.6-1.2$ & 1.2 & $0.9-1.7$ \\
\hline
\end{tabular}


(19.7\% compared to $10.8 \%$ of population referents) and in free-standing houses $(39.8 \%$ versus $31.2 \%)$. This indicates oversampling of hospital referents or undersampling of population referents from rural areas, which would distort a potential relationship between spina bifida and agricultural occupations. When population referents are used, an association is found between spina bifida and living in rural areas $\left(\mathrm{OR}_{\text {population }}=1.6,95 \% \mathrm{Cl}: 1.1-2.5\right)$, which is not apparent when the hospital-based referent group is used $\left(\mathrm{OR}_{\text {hospital }}=0.9,95 \% \mathrm{Cl}\right.$ : $\left.0.5-1.4\right)$.

The same pattern can be seen in Table 3.2.2, which lists the occupational distribution of the fathers. The proportion of agricultural workers was higher among hospital referents than among population referents $(10.0 \%$ versus $4.4 \%)$, leading to a decreased risk of spina bifida $\left(O R_{\text {hospital }}=0.4,95 \% \mathrm{Cl}: 0.2-0.9\right)$. In contrast, the proportion of professionals, teachers, and social workers was higher in the population-based referent group ( $30.5 \%$ versus $21.4 \%$ ), which is in accordance with the higher level of education. For professionals, the risk of spina bifida calculated with the population referents seems to be decreased $\left(\mathrm{OR}_{\text {population }}=0.5,95 \% \mathrm{Cl}: 0.3-0.8\right)$. Correction for level of education increased this odds ratio slightly $\left(\mathrm{OR}_{\mathrm{adj}}=0.7\right.$, $95 \% \mathrm{Cl}: 0.4-1.1)$. The proportions of blue collar workers were higher among the hospital referents for most industrial categories, except for metal and electrical workers. The two referent groups were similar for fathers working in administrative, sales, and service jobs. Compared to the occupational distribution according to the $\mathrm{CBS}{ }^{23}$ the population-based referent group proved to be a good representation of the general population in the same age range in the regions where the hospitals were located. Among the hospital referents, agricultural workers appear to be oversampled $(10.0 \%$ versus $5.1 \%$ in CBS statistics), whereas the proportion of professionals,

TABLE 3.2.2 Paternal occupational distribution evaluated for potential selection bias

\begin{tabular}{lccccccc}
\hline & $\begin{array}{c}\text { Cases \% } \\
\text { Paternal occupation }\end{array}$ & $\begin{array}{c}\text { referents \% } \\
(\mathrm{N}=213)\end{array}$ & \multicolumn{2}{c}{$\begin{array}{c}\text { Population } \\
\text { referents \% }\end{array}$} & \multicolumn{2}{c}{$\begin{array}{c}\text { Cases vs hospi- } \\
\text { tal referents }\end{array}$} & \multicolumn{2}{c}{$\begin{array}{c}\text { Cases vs popula- } \\
\text { tion referents }\end{array}$} \\
\hline Professionals & 9.9 & 10.9 & 17.5 & 0.9 & $0.5-1.6$ & 0.5 & $0.3-0.8$ \\
Teachers and social workers & 10.3 & 10.5 & 13.0 & 1.0 & $0.5-1.8$ & 0.8 & $0.5-1.3$ \\
Administrative workers & 12.2 & 10.9 & 11.3 & 1.1 & $0.6-2.0$ & 1.1 & $0.7-1.8$ \\
Sales and service workers & 8.5 & 12.1 & 10.0 & 0.7 & $0.4-1.2$ & 0.8 & $0.5-1.4$ \\
Agricultural workers & 4.2 & 10.0 & 4.4 & 0.4 & $0.2-0.9$ & 1.0 & $0.4-2.1$ \\
Metal and electrical workers & 13.6 & 8.8 & 13.6 & 1.6 & $0.9-3.0$ & 1.0 & $0.6-1.6$ \\
Printers, painters, plastic and & 4.7 & 4.2 & 3.1 & 1.1 & $0.5-2.8$ & 1.5 & $0.7-3.3$ \\
paper workers & & & & & & & \\
Other industrial workers & 11.3 & 8.8 & 7.0 & 1.3 & $0.7-2.4$ & 1.7 & $1.0-2.8$ \\
Construction workers & 8.9 & 6.3 & 5.6 & 1.5 & $0.7-3.0$ & 1.6 & $0.9-2.9$ \\
Transportation workers & 12.2 & 13.8 & 9.9 & 0.9 & $0.5-1.5$ & 1.3 & $0.8-2.1$ \\
Unemployed & 4.2 & 3.8 & 4.5 & 1.1 & $0.4-2.9$ & 0.9 & $0.4-2.0$ \\
\hline
\end{tabular}


teachers, and social workers was lower than expected $(21.4 \%$ versus $27.2 \%)$.

The maternal occupational distributions of the two referents groups were very similar and in accordance with the occupational distribution of the CBS. ${ }^{23}$ Almost half of the mothers $(49.6 \%$ of hospital referents and $47.9 \%$ of population referents) were housewives. Again, the population-based referent group contained slightly more professionals, teachers, and social workers $(23.8 \%$ versus $21.6 \%)$ and the hospitalbased referent group more jobs for lower educated women $(18.7 \%$ versus $15.1 \%)$. Only for cleaners $(3.7 \%$ of hospital referents and $1.5 \%$ of population referents) did the odds ratios appear to be influenced by the selection of the referent group $\left(\mathrm{OR}_{\text {hospital }}=0.8,95 \% \mathrm{Cl}: 0.4-1.4\right.$ and $\left.\mathrm{OR}_{\text {population }}=2.6,95 \% \mathrm{Cl}: 1.0-6.6\right)$.

\section{Recall bias}

Potential recall bias was evaluated using the 'subjective' variables listed in Tables 3.2.3 through 3.2.5. For the lifestyle factors smoking and alcohol use no indications for recall bias by differential overreporting or underreporting were found for either parent (Table 3.2.3). Concerning the environmental factors, only the percentages of parents who reported living close to a chemical plant differed considerably between the two referent groups and between referents and cases, leading to an odds ratio

TABLE 3.2.3 Parental lifestyle factors and environmental factors evaluated for potential recall bias

\begin{tabular}{|c|c|c|c|c|c|c|c|}
\hline & \multirow[t]{2}{*}{ Cases $\%$} & \multirow[t]{2}{*}{$\begin{array}{l}\text { Hospital } \\
\text { referents \% }\end{array}$} & \multirow[t]{2}{*}{$\begin{array}{l}\text { Population } \\
\text { referents \% }\end{array}$} & \multicolumn{2}{|c|}{$\begin{array}{l}\text { Cases vs hospi- } \\
\text { tal referents }\end{array}$} & \multicolumn{2}{|c|}{$\begin{array}{l}\text { Cases vs popu- } \\
\text { lation referents }\end{array}$} \\
\hline & & & & OR & $95 \% \mathrm{Cl}$ & OR & $95 \% \mathrm{Cl}$ \\
\hline Paternal lifestyle factors & $(N-213)$ & $(N-239)$ & $(N-639)$ & & & & \\
\hline Smoking & 53.1 & 53.8 & 49.9 & 1.0 & $0.7-1.4$ & 1.1 & $0.8-1.6$ \\
\hline Alcohol use & 85.9 & 83.1 & 83.1 & 1.2 & $0.7-2.1$ & 1.2 & $0.8-1.9$ \\
\hline Alcohol use $>2$ days/week & 35.2 & 31.2 & 36.9 & 1.2 & $0.8-1.8$ & 0.9 & $0.6-1.3$ \\
\hline Maternal lifestyle factors & $(N-213)$ & $(N-246)$ & $(N=651)$ & & & & \\
\hline Smoking & 45.5 & 47.4 & 42.5 & 0.9 & $0.6-1.3$ & 1.1 & $0.8-1.6$ \\
\hline Alcohol use & 48.4 & 56.0 & 52.3 & 0.7 & $0.5-1.1$ & 0.9 & $0.6-1.2$ \\
\hline Alcohol use $>2$ days/week & 11.3 & 11.1 & 11.8 & 1.0 & $0.6-1.8$ & 0.9 & $0.6-1.6$ \\
\hline Environmental factors & $(N=213)$ & $(N=239)$ & $(N-639)$ & & & & \\
\hline Heavy traffic in vicinity & 38.0 & 41.4 & 37.9 & 0.9 & $0.6-1.3$ & 1.0 & $0.7-1.4$ \\
\hline Chemical plant in vicinity & 11.3 & 7.1 & 4.1 & 1.7 & $0.9-3.2$ & 3.0 & $1.7-5.3$ \\
\hline Pesticide spraying in vicinity & 16.4 & 17.6 & 13.5 & 0.9 & $0.5-1.6$ & 1.3 & $0.8-2.0$ \\
\hline
\end{tabular}


TABLE 3.2.4 Paternal occupational exposures evaluated for potential recall bias

\begin{tabular}{|c|c|c|c|c|c|c|c|}
\hline \multirow[b]{2}{*}{ Paternal occupational exposure } & \multirow{2}{*}{$\begin{array}{l}\text { Cases \% } \\
(N=204)\end{array}$} & \multirow{2}{*}{$\begin{array}{l}\text { Hospital } \\
\text { referents \% } \\
(\mathrm{N}=230)\end{array}$} & \multirow{2}{*}{$\begin{array}{l}\text { Population } \\
\text { referents \% } \\
(\mathrm{N}-610)\end{array}$} & \multicolumn{2}{|c|}{$\begin{array}{l}\text { Cases vs hospi- } \\
\text { tal referents }\end{array}$} & \multicolumn{2}{|c|}{$\begin{array}{l}\text { Cases vs popu- } \\
\text { lation referents }\end{array}$} \\
\hline & & & & OR & $95 \% \mathrm{Cl}$ & OR & $95 \% \mathrm{Cl}$ \\
\hline Pesticides & 13.3 & 16.4 & 9.1 & 0.8 & $0.4-1.4$ & 1.5 & $0.9-2.6$ \\
\hline Fertilizers & 9.8 & 19.4 & 9.1 & 0.5 & $0.3-0.8$ & 1.1 & $0.6-1.9$ \\
\hline Domestic cleaning agents & 49.2 & 48.9 & 39.2 & 1.0 & $0.7-1.5$ & 1.5 & $1.1-2.1$ \\
\hline Organic solvents & 46.5 & 47.9 & 45.6 & 0.9 & $0.6-1.4$ & 1.0 & $0.7-1.4$ \\
\hline Paint, printing ink, and glue & 56.6 & 57.1 & 49.1 & 1.0 & $0.7-1.5$ & 1.4 & $1.0-1.9$ \\
\hline Dyes and pigments & 13.5 & 15.5 & 13.5 & 0.9 & $0.5-1.5$ & 1.0 & $0.6-1.7$ \\
\hline Paint thinners and removers & 47.0 & 41.2 & 35.0 & 1.3 & $0.9-1.9$ & 1.7 & $1.2-2.3$ \\
\hline $\begin{array}{l}\text { Heavy metals (e.g lead, } \\
\text { cadmium) }\end{array}$ & 14.6 & 15.8 & 17.6 & 0.9 & $0.5-1.6$ & 0.8 & $0.5-1.3$ \\
\hline Other metals (e.g. zinc, iron) & 41.3 & 36.3 & 36.7 & 1.2 & $0.8-1.9$ & 1.2 & $0.9-1.7$ \\
\hline Welding fumes & 28.9 & 29.5 & 26.2 & 1.0 & $0.6-1.5$ & 1.1 & $0.8-1.6$ \\
\hline Fuel and exhaust fumes & 47.6 & 49.3 & 41.6 & 0.9 & $0.6-1.4$ & 1.3 & $0.9-1.8$ \\
\hline $\begin{array}{l}\text { Anesthetics, cytostatics, } \\
\text { antibiotics }\end{array}$ & 6.0 & 7.5 & 7.5 & 0.8 & $0.4-1.7$ & 0.8 & $0.4-1.6$ \\
\hline $\begin{array}{l}\text { Disinfectants and sterilizing } \\
\text { agents }\end{array}$ & 18.9 & 23.5 & 16.9 & 0.8 & $0.5-1.2$ & 1.1 & $0.7-1.8$ \\
\hline lonizing radiation & 10.8 & 5.1 & 8.6 & 2.2 & $1.0-4.8$ & 1.3 & $0.7-2.2$ \\
\hline Non-ionizing radiation & 9.5 & 12.4 & 14.4 & 0.7 & $0.4-1.4$ & 0.6 & $0.4-1.1$ \\
\hline Dust (e.g. paper, textile, hay) & 26.0 & 29.5 & 24.1 & 0.8 & $0.5-1.3$ & 1.1 & $0.8-1.6$ \\
\hline Asbestos and glass fibers & 30.0 & 22.0 & 21.7 & 1.5 & $1.0-2.4$ & 1.5 & $1.1-2.3$ \\
\hline
\end{tabular}

above unity for either of the referent groups $\left(\mathrm{OR}_{\text {hospital }}=1.7,95 \% \mathrm{Cl}\right.$ : $0.9-3.2$ and $\mathrm{OR}_{\text {population }}=3.0,95 \% \mathrm{Cl}: 1.7-5.3$ ). The differences found for pesticide spraying in the vicinity coincide with the larger number of hospital referents living in rural areas and having agricultural occupations.

As can be seen in Table 3.2.4, a larger proportion of fathers of hospital referents also reported occupational exposure to pesticides and fertilizers $(16.4 \%$ and $19.4 \%$ compared to $9.1 \%$ of population referents). As a result, the hospital-based odds ratio for fertilizers $\left(\mathrm{OR}_{\text {hospital }}=0.5,95 \% \mathrm{Cl}: 0.3-0.8\right)$ points towards a protective effect. On the other hand, the hospital-based odds ratio for ionizing radiation seems to be increased $\left(O R_{\text {hospital }}=2.2,95 \% \mathrm{Cl}: 1.0-4.8\right)$, due to the relatively low number of professional workers. For most other categories, the distributions of reported exposure are very similar between the two referent groups, with the exception of 'common' exposures such as domestic cleaning agents $(48.9 \%$ versus $39.2 \%)$, paint, printing ink, and glue $(57.1 \%$ versus $49.1 \%)$, paint thinners $(41.2 \%$ versus $35.0 \%)$, and fuel and exhaust fumes $(49.3 \%$ versus $41.6 \%)$. For these agents, the odds ratios calculated with the hospital referents vary around unity, but the population-based 
odds ratios are greater than one $\left(\mathrm{OR}_{\text {cleaning agents }}=1.5,95 \% \mathrm{Cl}\right.$ : $1.1-2.1 ; \mathrm{OR}_{\text {paint }}=1.4$, $95 \% \mathrm{Cl}: 1.0-1.9 ; \mathrm{OR}_{\text {paint thinner }}=1.7,95 \% \mathrm{Cl}: 1.2-2.3 ;$ and $\mathrm{OR}_{\text {exhaust fumes }}=1.3,95 \% \mathrm{Cl}$ : 0.9-1.8). These odds ratios did not change substantially when level of education, living in rural areas, and the occupational distribution were included in the analyses as potential confounders. Irrespective of the referent group used, an increased risk of spina bifida seems to exist for exposure to asbestos and glass fibers $\left(O R_{\text {hospital / popula }}\right.$ tion $=1.5,95 \% \mathrm{Cl}: 1.0-2.4$ ).

To avoid comparisons of imprecise estimates, Table 3.2 .5 lists only the maternal occupational exposures which were reported by more than $5 \%$ of working mothers of cases and referents. Only the reporting of 'common' exposures seems to differ between the two referent groups. The proportion of hospital referents is higher than the proportion of population referents for exposure to domestic cleaning agents $(75.4 \%$ versus $53.8 \%)$, organic solvents $(26.4 \%$ versus $19.9 \%)$, fuel and exhaust fumes $(21.6 \%$ versus $9.7 \%)$, disinfectants and sterilizing agents $(42.2 \%$ versus $32.4 \%)$, and dust $(26.6 \%$ versus $20.8 \%$ ). The population-based odds ratios are substantially increased for domestic cleaning agents $(\mathrm{OR}=2.1,95 \% \mathrm{Cl}: 1.3-3.4)$, fuel and exhaust fumes $(\mathrm{OR}=1.6,95 \% \mathrm{Cl}: 0.8-3.1)$, and dust $(\mathrm{OR}=1.6,95 \% \mathrm{Cl}: 1.0-2.7)$. These odds ratios did not change when correction for confounding by level of education and living in rural areas was performed. For disinfectants and sterilizing agents a hospital-based odds ratio below unity is seen $\left(\mathrm{OR}_{\text {hospital }}=0.5,95 \% \mathrm{Cl}\right.$ : 0.3 0.9) and for exposure to medical drugs both odds ratios are below unity $\left(\mathrm{OR}_{\text {hospital }}=0.6,95 \% \mathrm{Cl}: 0.3-1.2\right.$ and $\left.\mathrm{OR}_{\text {population }}=0.5,95 \% \mathrm{Cl}: 0.3-1.0\right)$.

TABLE 3.2.5 Maternal occupational exposure evaluated for potential recall bias

\begin{tabular}{lcccccccc}
\hline & Cases \% & referents \% & Population & \multicolumn{2}{c}{ Cases vs hos- } & \multicolumn{2}{c}{ Cases vs popu- } \\
refents $\%$ & pital referents & \multicolumn{2}{c}{ lation referents } \\
Maternal occupational exposure & $(\mathrm{N}-105)$ & $(\mathrm{N}=124)$ & $(\mathrm{N}=339)$ & $\mathrm{OR}$ & $95 \% \mathrm{Cl}$ & $\mathrm{OR}$ & $95 \% \mathrm{Cl}$ \\
\hline Domestic cleaning agents & 70.9 & 75.4 & 53.8 & 0.8 & $0.4-1.4$ & 2.1 & $1.3-3.4$ \\
Organic solvents & 25.8 & 26.4 & 19.9 & 1.0 & $0.5-1.8$ & 1.4 & $0.8-2.4$ \\
Paint, printing ink, and glue & 32.7 & 37.6 & 32.9 & 0.8 & $0.5-1.4$ & 1.0 & $0.6-1.6$ \\
Dyes and pigments & 11.6 & 7.1 & 8.9 & 1.7 & $0.7-4.4$ & 1.3 & $0.6-2.8$ \\
Paint thinners and removers & 20.6 & 16.8 & 16.9 & 1.3 & $0.6-2.6$ & 1.3 & $0.7-2.2$ \\
Fuel and exhaust fumes & 14.9 & 21.6 & 9.7 & 0.6 & $0.3-1.3$ & 1.6 & $0.8-3.1$ \\
Anesthetics, cytostatics, & 11.0 & 18.1 & 18.9 & 0.6 & $0.3-1.2$ & 0.5 & $0.3-1.0$ \\
antibiotics & & & & & & & \\
Disinfectants and sterilizing & 26.7 & 42.2 & 32.4 & 0.5 & $0.3-0.9$ & 0.8 & $0.5-1.3$ \\
agents & & & & & & & \\
lonizing radiation & 7.0 & 8.6 & 10.2 & 0.8 & $0.3-2.2$ & 0.7 & $0.3-1.5$ \\
Non-ionizing radiation & 7.1 & 6.8 & 8.6 & 1.1 & $0.4-3.0$ & 0.8 & $0.3-1.9$ \\
Dust (e.g. paper, textile, hay) & 29.7 & 26.6 & 20.8 & 1.2 & $0.6-2.1$ & 1.6 & $1.0-2.7$ \\
\hline
\end{tabular}




\section{Discussion}

The present study was conducted to make an informed decision about the best referent group in an etiologic study on spina bifida and parental occupation, based on validity and feasibility issues. As no gold standard is available for choosing a referent group, both the hospital-based referent group and the population-based referent group were initially assumed to be a representative sample of the population from which the cases originated. However, we found large differences between the two referent groups for several variables. Apart from chance variation, these differences indicate differential recall by hospital and population referents and/or selection in one or both of the referent groups, caused by the sampling frame and/or by selective non-response. As a result, the odds ratios are potentially biased by selection bias and/or recall bias.

\section{Selection bias}

Because the hospital referents were diagnosed in the same hospitals as the cases and none of the hospitals was a specialized center for spina bifida or for the referent disorders, there is no reason to suspect selection bias by hospital. The population referents were frequency matched to the cases on geographical area and size of the municipality, which also precludes selection bias. The non-participation of municipal registries $(20.6 \%)$ seems to be random. However, as the non-response rates in the hospital-based and the population-based referent group were $39.1 \%$ and $28.8 \%$, respectively, selective non-response cannot be excluded. Among the hospital referents, for instance, higher educated parents may have considered the study not applicable if their child had had only a minor cerebral trauma.

This selective non-response would partly explain the lower proportion of parents with a higher education among the hospital referents compared to the population referents. Another explanation would be that the referent disorders in this study (cerebral trauma and meningitis) are more prevalent in families with a lower socioeconomic status, for which level of education below 10th grade is a proxy in The Netherlands. In the literature, an inverse relationship is described between spina bifida and socioeconomic status. ${ }^{24,25}$ The decreased population-based odds ratios for spina bifida and level of education are in accordance with the literature, but the hospital-based odds ratios around unity are not. Therefore, selection towards a lower level of education is highly likely for the hospital-based referent group. Using this referent group may lead to biased odds ratios for spina bifida and parental occupation because of the correllation between occupation and level of education.

This is well illustrated by the occupational distributions of the parents in this study. The distribution of paternal occupations for the population-based referent group is very similar to the distribution in the general population of the same geographical areas, whereas the hospital referents seem to be undersampled for 
professional jobs, teachers, and social workers and oversampled for blue collar workers. As a result, the decreased population-based odds ratio for professionals and the increased odds ratios for some industrial workers are obscured when the hospital-based referent group is used. For the maternal occupational distributions, the same education-related pattern can be seen, but the odds ratios are not greatly influenced. Only the potential association between spina bifida and mothers working as cleaners $\left(O R_{\text {population }}=2.6\right.$. $\left.95 \% \mathrm{Cl}: 1.0-6.6\right)$ would not be identified with the hospital-based referent group.

The hospital-based referent group is clearly oversampled for paternal agricultural occupations and for living in rural areas, which may be due to an association between living in or around a farm and experiencing a cerebral trauma or meningitis. A study in the United States published after the start of this study, found that preschool farm children were particularly liable to experience head and neck trauma and injuries resulting from falls. ${ }^{26}$ As a result of selection bias, the hospital-based odds ratio indicates a protective effect of paternal agricultural occupation, whereas others find either no effect or an increased risk of spina bifida. ${ }^{27-29}$ For the mothers, the numbers of agricultural workers were too small to draw any conclusions.

Although the hospital-based referent group was carefully chosen and selected by extensive medical record review to exclude children with birth defects or diseases potentially related to parental occupation, selective non-response and oversampling of parents with a level of education below 10th grade, blue collar or agricultural occupations, and living in rural areas seem to have occurred. This was due to unsuspected associations between the above variables and the referent dișorders. As a result, selection bias would occur in the associations between spina bifida and parental occupation if this hospital-based referent group were to be used.

\section{Recall bias}

For the evaluation of recall bias we assumed that the hospital referents would overreport and underreport much the same way as the cases, but different from the population referents. Although lifestyle factors, such as smoking and alcohol use, are often reported inaccurately, there are no indications for differential reporting leading to recall bias in this study. These results are in accordance with the study of Mackenzie and Lippman $^{8}$ and show that even with simple questions relatively reliable data can be obtained for these lifestyle factors. This is not true for the environmental factor 'chemical plant in the vicinity', where we see large differences in reporting between cases $(11.3 \%)$, hospital referents $(7.1 \%)$, and population referents $(4.1 \%)$. This may be due to overreporting by case parents who suspect an association between environmental pollution and spina bifida, but chance or a true association cannot be ruled out as explanations for the increased odds ratios.

Information on occupational exposures was gathered by means of a simple 
checklist, providing ample opportunity for overreporting by parents who are searching for an explanation of their child's condition. However, large differences in proportions between the cases and the population referents are only observed for 'common' exposures which are easily overreported, such as domestic cleaning agents and fuel and exhaust fumes for both parents; paint, printing ink, glue, and paint thinners for fathers; and dust for mothers. For most of these exposure categories, the proportions of cases and hospital referents were comparable, which might indicate that the hospital-based referent group was well chosen to avoid recall bias. On the other hand, it might reflect the previously described selection towards industrial workers and cleaners in the hospital-based referent group, which would obscure true associations between spina bifida and the above-mentioned occupational exposures. However, as the population-based odds ratios did not change when the selection factors were included in the analyses, recall bias is a more likely explanation for the increased odds ratios found for these 'common' occupational exposures, given that they were not due to true associations with spina bifida.

Selection factors rather than recall seem to play a role in the decreased hospitalbased odds ratios for maternal exposure to disinfectants and sterilizing agents and for paternal exposure to fertilizers. The former could be due to the higher proportion of cleaners and the latter to the higher proportion of agricultural workers among the hospital referents. Because of lack of a gold standard, it is impossible to judge whether the decreased odds ratios for maternal exposure to medical drugs and the increased odds ratios for paternal exposure to pesticides, ionizing. radiation, and asbestos and glass fibers are caused by selection bias, recall bias, real effects, or chance.

Although the hospital-based referent group was chosen to avoid recall bias, some recall bias may be present in the hospital-based odds ratios for environmental and occupational factors. With the population-based referent group, however, recall bias is more likely to occur in the associations between spina bifida and parental occupational exposures, especially when a simple questionnaire is used. The latter seems to yield unbiased estimates for smoking and alcohol use.

\section{Feasibility}

One of the reasons for choosing a hospital-based referent group is the easy access to referents. ${ }^{4}$ In this study, however, the extensive medical record review necessary to select eligible referents was very costly and time-consuming and the quality of the records was not always adequate. Moreover, discussions with the hospitals over ethical issues caused considerable delay. In contrast, most municipalities rapidly consented to provide us with a sample of population referents at low or no cost. Contrary to expectation, the hospital referents in this study had a lower response rate than the population referents. Therefore, there are no compeling feasibility arguments 
for choosing a hospital-based referent group when a sample of the general population can be relatively easily obtained.

\section{Conclusion}

Contrary to other studies, ${ }^{8,15-18}$ this study showed that recall bias can influence the results of a study on congenital malformations, such as spina bifida, and parental occupational exposure obtained by a self-administered questionnaire. However, recall bias cannot be totally avoided by using a hospital-based referent group. Because the referent disorders need to be nonassociated with parental occupation, children with other congenital malformations are usually not eligible., ${ }^{6,11}$ Children with acquired defects, such as were included in this study, are already far from the ideal hospital-based referent group, because the parents will not be focused on things that happened during pregnancy as much as case parents. This study also confirms that there is a considerable chance of selection occurring in a hospitalbased referent group leading to selection bias, ${ }^{5-7}$ which may distort possible associations between congenital defects and occupational and environmental exposures. As selection bias seems to have a greater impact on the study results than recall bias, a population-based referent group would be preferred for studies of congenital defects and parental occupation, and possibly for other reproductive epidemiologic studies. To minimize recall bias when a population-based referent group is used, data collection methods must be chosen that will permit complete and accurate exposure assessment. ${ }^{8,13}$

\section{References}

1 Rothman KJ. Modern Epidemiology. Boston: Little, Brown \& Company, 1986.

2 Louik C, Mitchell AA, Werler MM, Hanson JW, Shapiro S. Maternal exposure to spermicides in relation to certain birth defects. N Eng J Med 1987;317:474-478.

3 Werler MM, Pober BR, Nelson K, Holmes LB. Reporting accuracy among mothers of malformed and nonmalformed infants. Am J Epidemiol 1989;129:415-421.

4 Wacholder S, Silverman DT, McLaughlin JK, Mandel JS. Selection of controls in casecontrol studies. II. Types of controls. Am J Epidemiol 1992;135:1029-1041.

5 Swan SH, Shaw GM. Re: reporting accuracy among mothers of malformed and nonmalformed infants. Letter. Am J Epidemiol 1990;131:935-936.

6 Swan SH, Shaw GM, Schulman J. Reporting and selection bias in case-control studies of congenital malformations. Epidemiology 1992;3:356-363.

7 Drews C, Greenland S, Flanders WD. The use of restricted controls to prevent recall bias in case-control studies of reproductive outcomes. Ann Epidemiol 1993;3:86-92.

8 Mackenzie SG, Lippman A. An investigation of report bias in a case-control study of pregnancy outcome. Am J Epidemiol 1989;129:65-75.

9 Mills JL, Rhoads GG, Simpson JL, Cunningham GC, Conley MR, Lassman MR, Walden ME, Depp OR, Hoffman HJ, and the NICHD Neural Tube Defects Group. The 
absence of a relation between the periconceptional use of vitamins and neural-tube defects. N Engl J Med 1989;321:430-435.

10 Ahlborg GA. Validity of exposure data obtained by questionnaire. Scand J Work Environ Health 1990;16:284-288.

11 Janerich DT, Polednak AP. Epidemiology of birth defects. Epidemiologic Rev 1983;5:16-37.

12 Raphael K. Recall bias: a proposal for assessment and control. Int J Epidemiol 1987; 16:167-170.

13 Coughlin SS. Recall bias in epidemiologic studies. J Clin Epidemiol 1990;43:87-91.

14 Berg AT. Re: reporting bias among mothers of malformed and non-malformed infants (Letter). Am J Epidemiol 1990;131:936-947.

15 Klemetti A, Saxen L. Prospective versus longitudinal approach in the search for environmental causes of malformation. Am J Public Health 1967;57:2071-2075.

16 Zierler S, Rothman KJ. Congenital heart disease in relation to maternal use of Bendectin and other drugs in early pregnancy. N Engl J Med 1985;313:347-352.

17 Feldman Y, Koren G, Mattice D, Shear H, Pellegrini E, MacLeod SM. Determinants of recall and recall bias in studying drug and chemical exposure in pregnancy. Teratology 1989;40:37-45.

18 Drews CD, Kraus JF, Greenland S. Recall bias in a case-control study of sudden infant death syndrome. Int J Epidemiol 1990;19:405-411.

19 Roeleveld N, Kiemeney L, Schattenberg G, Peer P. Information bias in a case-referent study on mental retardation and parental occupation: colleagues as dual respondents. Epidemiology 1990;1:292-297.

20 West DW, Schuman KL, Lyon JL, Robison LM, Allred R. Differences in risk estimation from a hospital and a population-based case-control study. Int J Epidemiol 1984;13:235-239.

21 Kleinbaum DG, Kupper LL, Morgenstern H. Epidemiologic Research, principles and quantitative methods. New York: Van Nostrand Reinhold Company, 1982.

22 Blatter BM, Roeleveld N, Zielhuis GA, Mullaart RA, Gabreëls FIM. Spina bifida and parental occupation. Epidemiology 1996;7:188-193.

23 Central Bureau for Statistics. Arbeidskrachtentelling 1985. Den Haag: Staatsuitgeverij, 1987.

24 Elwood JM, Elwood JH. Epidemiology of anencephalus and spina bifida. Oxford: Oxford University Press, 1980.

25 Little J, Elwood JH. Socio-economic status and occupation. In: Elwood JM, Little J, Elwood JH, editors. Epidemiology and control of neural tube defects. Monographs in Epidemiology and Biostatistics. Vol. 20. Oxford: Oxford University Press, 1992;456520.

26 Stueland D, Layde P, Lee BC. Agricultural injuries in children in central Wisconsin. J Trauma 1991;31:1503-1509.

27 Balarajan R, McDowall M. Congenital malformations and agricultural workers (Letter). Lancet 1983;l:1112-1113.

28 McDonald AD, McDonald JC, Armstrong B, Cherry NM, Nolin AD, Robert D. Fathers' 
occupation and pregnancy outcome. Br J Ind Med 1989;46:329-333.

29 Hammond FG, Canache MF. Some epidemiological aspects of neural tube defects in Barquisimeto, Venezuela (Abstract). Am J Hum Genet 1991;49 (suppl.):470. 


\title{
CHAPTER 4
}

\section{SPINA BIFIDA AND PARENTAL OCCUPATION}

\author{
BM Blatter, N Roeleveld, GA Zielhuis, RA Mullaart, FJM Gabreëls \\ Epidemiology 1996;7:188-193 \\ with the permission of Epidemiology Resources Inc.
}

\begin{abstract}
To examine the association between parental occupation and spina bifida in offspring, we conducted a multicentre case-referent study in The Netherlands. Cases were children with spina bifida aperta from nine different hospitals throughout the country; the referent group comprised population-based referents who were randomly drawn from municipal birth registries. All children were born between 1980 and 1992. We collected data using postal questionnaires for both parents with questions about occupational title, industry, daily occupational activities and a number of potential confounders. We were able to include 353 cases and 1,329 referents in the analyses. We found increased risks for maternal agricultural occupations [odds ratio $(\mathrm{OR})=5.6,95 \%$ confidence interval $(\mathrm{Cl})$ : 1.8 17.8] and for cleaning women $(O R=1.9,95 \% \mathrm{Cl}$ : 0.9-3.9). For the fathers, we saw increased odds ratios for welders $(O R=2.1,95 \% \mathrm{Cl}: 0.6-7.0)$ and transport workers $(O R=1.4,95 \% \mathrm{Cl}$ : 0.9-2.1).
\end{abstract}

Several studies have reported a relation between neural tube defects and socioeconomic status. ${ }^{1-3}$ Since Smithells et $\mathrm{al}^{4}$ investigated the association between socioeconomic classes, vitamin levels, and neural tube defects, epidemiologic research into the role of vitamins, and folic acid in particular, has increased. Several observational and intervention studies have provided evidence for a protective effect of periconceptional multivitamins containing folic acid and of folic acid supplements alone ${ }^{5-7}$ As the classification of socioeconomic status is primarily based on occupation, however, the presence of potential teratogens in the work environment could be an additional explanation for the differential prevalence rates of neural tube defects between socioeconomic classes. Maternal occupational exposure before conception and up to the 28th day of embryonic development could have a direct effect on the morphogenesis of the neural tube. Indirect exposure of the mother could result from carry-home exposure of the father. Paternal chemical occupational exposure could 
theoretically result in genetic damage to germ cells ${ }^{8}$ and might introduce teratogenic substances in the seminal fluid at conception or later during embryonic development. $^{9}$

Studies specific to neural tube defects and parental occupation have been scarce; most studies include congenital anomalies in general or central nervous system defects including neural tube defects. ${ }^{10}$ Such studies have shown an increased risk of central nervous system defects among women working in industry, construction, transport and communication [odds ratio $(O R)=2.0$ ], ${ }^{11,12}$ and among women exposed to organic solvents. ${ }^{13}$ An increased risk of spina bifida was reported among women working in dental offices. ${ }^{14}$ Studies on fathers have shown an increased risk of central nervous system defects for painters, ${ }^{15}$ of developmental defects for workers in the food and beverage industries and in agriculture, ${ }^{16}$ of neural tube defects for fathers exposed to low-level radiation, ${ }^{17}$ and of spina bifida for agricultural workers [observed/expected (O/E) ratio: $1.3 .^{18}$

Studies that focused on neural tube defects in particular or included larger numbers of cases with a neural tube defect have revealed an increased risk of spina bifida for women working as nurses $(O R=2.2),{ }^{19}$ hairdressers $(13 \%$ vs $1.3 \%$ in controls) ${ }^{20}$ and farmers $(8 \%$ vs $0 \%$; OR $=7.1)$. $^{20,21}$ Among men, a threefold increased risk was found for painters, for both spina bifida and anencephaly. ${ }^{22-24}$ Other studies showed an increased risk for printers [relative risk $(R R)=6.7$ ], transport and communication workers $(R R=1.7),{ }^{22}$ farmers $(32 \%$ vs $13 \%)$, and bricklayers $(20 \%$ vs $5 \%),{ }^{20}$ In contrast, analyses of a cluster of neural tube defects in California did not show any association with occupational title. ${ }^{25}$

Except for Brender and Suarez, ${ }^{24}$ who focused on pesticides and solvents, all investigators looked at a broad range of occupations. Few studies had more than 300 cases, ${ }^{21,23,24}$ and most studies had relatively limited data on occupational title, derived from birth registries. These limitations probably contributed to inconsistencies in the results.

The purpose of the present multicenter case-referent study, which used selfassessed occupational titles, is to identify clearly the maternal or paternal occupations that are associated with an increased risk of having a child with spina bifida.

\section{Population and methods \\ Population}

The cases were liveborn children with spina bifida aperta (International Classification of Diseases (ICD-9) ${ }^{26}$ Codes 741.0 and 741.9) who were born between January 1 , 1980 , and December 31, 1992. We identified a total of 470 cases in six university hospitals (with a specialized "spina bifida team"), one regional hospital, and two rehabilitation centers in the Netherlands. All cases had a clinically confirmed 
diagnosis of spina bifida. In six out of the nine participating hospitals, the researchers reviewed the medical records to verify the diagnosis and thus reduce misclassification on the outcome variable. Where no record review could be performed owing to privacy regulations, we relied on the physicians' assessment of the diagnosis.

We obtained a population-based referent group, consisting of 1,894 children who were recruited through stratified random samples from birth registries of 45 municipalities in the Netherlands. All referent children were born between January 1 , 1980 and December 31, 1992. To guarantee a similar geographical distribution, we chose municipalities from the catchment areas of the hospitals. Referents were frequency matched to the cases on catchment area and size of the municipality in four categories.

\section{Data collection}

We approached parents by mail with a letter from one of their child's physicians in the spina bifida team or from a municipal administrator, accompanied by a letter from the investigators, a brochure with information, and a questionnaire for each parent. The latter included questions about occupational title, industry, tasks, and daily occupational activities. Questions about potentially confounding variables, such as maternal age, parity, smoking and drinking habits, vitamin and medical drug use, and family history of neural tube defects, as well as some general background variables, such as marital status and length of pregnancy, were also included. For ease of completion, all questions referred to one date of interest as a proxy for the period around conception. We defined this date as the date of birth of the index child minus 1 year.

We coded the occupations according to the International Labour Office (ILO) classification of occupations, ${ }^{27}$ based on the information on function and tasks available in the questionnaire. For instance, we coded a nurse who indicated that she only had administrative tasks as head of a nursing department. We coded students as having the occupations for which they studied. In the few instances that participants had more than one job, we classified them as having the job with the highest potential for chemical exposure.

\section{Analysis}

In the analysis, we grouped occupational titles with the largest possible specificity, taking account of the numbers in the strata. If splitting the occupations into smaller, more specific categories did not yield differential results, we concentrated several occupations into the main cluster to which belonged. We calculated odds ratios (OR) for the different occupational groups using the nonexposed occupations as reference category, which included clerical and managerial workers, teachers, artists, social 
workers, household personnel, and shop assistants. Among mothers, housewives made up $58 \%$ of the reference category.

We included as confounding factors those that changed the ORs for occupation by $10 \%$ or more in the univariate analyses. If a risk factor occurred in no more than 10 persons, we excluded the respondents with this risk factor from the adjusted analyses to avoid unstable estimates.

\section{Results}

The response rate for the postal questionnaire was $79 \%$ for case parents and $72 \%$ for referent parents. We found little difference in response rate between mothers and fathers. There were 21 cases and 48 referents for whom we could not obtain current addresses. Information on 353 children with spina bifida and 1,329 population-based referent children was available for the statistical analyses.

The distribution of the potentially confounding factors among the mothers is presented in Table 4.1; the distribution among the fathers is shown in Table 4.2.

Initially, we included a positive family history of neural tube defects, alcohol use, smoking, maternal oral contraceptive use, use of ovulation-stimulating agents, parity, and fetal loss in the univariate analyses as potential confounders. We did not include maternal and paternal education in these analyses.

The final model for the occupation of the mothers included a positive family history of the father and use of ovulation-stimulating agents as confounders. The final model regarding the fathers included a positive family history of the father and maternal oral contraceptive use as confounders. We treated maternal use of vitamin $A$, use of antiepileptic a-gents, diabetes mellitus, diagnosis of homocysteinemia, and consanguinity (first or second cousins) as restriction variables, as these risk factors occurred rarely. A total of 34 records were excluded.

The results concerning maternal occupation are shown in Table 4.3. After adjustment for confounding, we found an increased OR of 5.6 for women working in agricultural occupations [95\% confidence interval $(\mathrm{Cl}): 1.8-17.8$ ]. Four case mothers had been working in crop and stock farming, two mothers in poultry farming, one in market gardening, one in mushroom cultivation and two in other agricultural occupations. Of the referents, two mothers had been working in crop and stock farming, one in plant and flower growing, and two in another agricultural occupation. If both parents worked in agriculture, the odds ratio was 19.7: of the 10 agricultural case mothers, five had a husband with an agricultural occupation; of the five referent mothers, one had an agricultural husband. When all of the housewives whose husbands were self-employed farmers were included in the 'agricultural worker' category, the crude OR fell from 7.9 to $1.7(95 \% \mathrm{Cl}: 1.0-3.1)$. 
TABLE 4.1 Distribution of maternal background variables in cases and referents

\begin{tabular}{|c|c|c|}
\hline Maternal characteristics & $\begin{array}{l}\text { Cases \% } \\
(N=349)\end{array}$ & $\begin{array}{c}\text { Referents \% } \\
(\mathrm{N}=1324)\end{array}$ \\
\hline \multicolumn{3}{|l|}{ Education* } \\
\hline Low & 37.1 & 29.2 \\
\hline Middle & 45.5 & 48.7 \\
\hline High & 17.4 & 22.2 \\
\hline \multicolumn{3}{|l|}{ Residence } \\
\hline Apartment & 18.6 & 20.7 \\
\hline House with garden & 51.0 & 53.7 \\
\hline Villa/farmhouse & 30.4 & 25.6 \\
\hline \multicolumn{3}{|l|}{ Living environment } \\
\hline Urban & 51.0 & 45.8 \\
\hline Suburban & 33.8 & 38.5 \\
\hline Rural & 15.2 & 15.7 \\
\hline Alcohol use (at least 1 glass/week) & 48.6 & 54.0 \\
\hline Smoking (at least 1 cigarette/day) & 38.7 & 41.2 \\
\hline Other child with NTD & 2.6 & 0.2 \\
\hline Family history of NTD+ & 4.6 & 1.3 \\
\hline Consanguinity (1st or 2 nd cousin) & 0.9 & 0.5 \\
\hline Primiparity & 45.4 & 43.3 \\
\hline Age at birth (average) & 28.1 yrs & 28.5 yrs \\
\hline \multicolumn{3}{|l|}{ Vitamin use } \\
\hline Multivitamins & .6 .0 & 3.0 \\
\hline Vit $A$ & 0.3 & 0.2 \\
\hline Vit B & 1.2 & 2.1 \\
\hline Other/unknown & 2.6 & 2.7 \\
\hline Oral contraceptive use & 37.4 & 33.1 \\
\hline Ovulation stimulating drugs & 5.2 & 3.1 \\
\hline Use of anti-epileptics $¥$ & 0.6 & 0.3 \\
\hline Diabetes mellitus & 0.5 & 0.2 \\
\hline Homocysteinaemia§ & 0.9 & 0.2 \\
\hline Fetal loss (ever had) & 22.0 & 25.0 \\
\hline
\end{tabular}

* Low: comparable with up to grade 9; middle: comparable with grades 10-14; high: comparable with grade 15 and higher

† First or second degree: parents, siblings, grandparents, uncles and aunts

₹ Valproic acid or carbamazepine

$\S$ Assessed by asking in the questionaire: 'Were you ever diagnosed with homocysteinaemia?' 
TABLE 4.2 Distribution of paternal background variables in cases and referents

\begin{tabular}{lcc}
\hline Paternal characteristics & $\begin{array}{c}\text { Cases \% } \\
(\mathrm{N}=350)\end{array}$ & $\begin{array}{c}\text { Referents \% } \\
(\mathrm{N}=1293)\end{array}$ \\
\hline Education* & & 29.4 \\
Low & 36.2 & 37.6 \\
Middle & 37.6 & 33.0 \\
High & 26.2 & 84.8 \\
Alcohol use (at least 1 glass/week) & 83.3 & 47.2 \\
Smoking (at least 1 cigarette/day) & 48.1 & 1.1 \\
Family history of NDTt & 5.7 & \\
\hline
\end{tabular}

* Low: comparable with up to grade 9; middle: comparable with grades 10-14; high: comparable with grade 15 and higher

† First or second degree: parents, siblings, grandparents, uncles and aunts

We also found an elevated risk $(\mathrm{OR}=1.9,95 \% \mathrm{Cl}$ : 0.9-3.9) for cleaners. Since part-time work is very common among cleaners, the analyses were stratified into women who had been working for more than 10 hours per week and women who had been working 0-10 hours per week. The adjusted ORs for these strata were 2.7 (95\% Cl: $1.2-6.2)$ and $0.7(95 \% \mathrm{Cl}: 0.1-3.3)$, respectively.

In Table 4.4, we present the results for paternal occupations. After adjustment, we observed increased $\mathrm{ORs}$ for welders $(\mathrm{OR}=2.1,95 \% \mathrm{Cl}: 0.6-7.0)$ and for transport workers $(O R=1.4,95 \% \mathrm{Cl}$ : $0.9-2.1)$. The latter $O R$ was primarily attributable to the transport workers other than truck drivers. The other ORs for fathers were close to unity.

TABLE 4.3 Maternal occupation and risk of spina bifida aperta

\begin{tabular}{lccccc}
\hline Occupation & $\begin{array}{c}\text { Cases } \\
(\mathrm{N}=349)\end{array}$ & $\begin{array}{c}\text { Refs } \\
(\mathrm{N}=1324)\end{array}$ & OR $_{\text {crude }}$ & OR $_{\text {adj }}{ }^{*}$ & $95 \% \mathrm{Cl}$ \\
\hline Health care workers & 40 & 183 & 0.9 & 0.9 & $0.6-1.3$ \\
$\quad$ Nurses & 12 & 69 & 0.7 & 0.7 & $0.4-1.4$ \\
$\quad$ Nurse aid & 16 & 53 & 1.2 & 1.2 & $0.7-2.2$ \\
$\quad$ Other health care workers & 12 & 61 & 0.8 & 0.8 & $0.4-1.5$ \\
Cleaners & 13 & 23 & 2.2 & 1.9 & $0.9-3.9$ \\
Hairdressers & 3 & 13 & 0.9 & 0.7 & $0.2-3.2$ \\
Industry and transport workers & 15 & 44 & 1.3 & 1.5 & $0.8-2.8$ \\
Agricultural workers & 10 & 5 & 7.9 & 5.6 & $1.8-17.8$ \\
Non-exposed reference category & 268 & 1056 & & & \\
\hline
\end{tabular}

* Adjusted for a positive family history of the father and use of ovulation stimulating agents by logistic regression. Restriction for maternal use of vitamin $A$, antiepileptics, diabetes, diagnosis of homocysteinaemia and consanguinity 
TABLE 4.4 Paternal occupation and risk of spina bifida aperta

\begin{tabular}{lccccc}
\hline Occupation & $\begin{array}{c}\text { Cases } \\
(\mathrm{N}=347)\end{array}$ & $\begin{array}{c}\text { Refs } \\
(\mathrm{N}=1293)\end{array}$ & $\mathrm{OR}_{\text {crude }}$ & $\mathrm{OR}_{\text {adj }}{ }^{*}$ & $95 \% \mathrm{Cl}$ \\
\hline Health care workers & 13 & 68 & 0.7 & 0.7 & $0.4-1.4$ \\
Professional/technical personnel & 27 & 144 & 0.7 & 0.8 & $0.5-1.2$ \\
Food, drink and tobacco workers & 6 & 21 & 1.1 & 1.3 & $0.5-3.4$ \\
Engineering and electrical workers & 42 & 142 & 1.1 & 1.1 & $0.8-1.7$ \\
$\quad$ Engineers and metal workers & 10 & 36 & 1.1 & 1.1 & $0.5-2.2$ \\
$\quad$ Mechanics & 25 & 83 & 1.2 & 1.2 & $0.7-2.0$ \\
$\quad$ Plumbers & 2 & 15 & 0.5 & 0.6 & $0.1-2.5$ \\
$\quad$ Welders & 5 & 8 & 2.4 & 2.1 & $0.6-7.0$ \\
Painters & 5 & 20 & 1.0 & 1.0 & $0.4-2.7$ \\
Plastic/paper workers and printers & 9 & 27 & 1.3 & 1.2 & $0.5-2.8$ \\
Other industrial workerst & 23 & 83 & 1.1 & 1.1 & $0.6-1.8$ \\
Transport workers & 42 & 113 & 1.4 & 1.4 & $0.9-2.1$ \\
$\quad$ Truck drivers & 13 & 38 & 1.3 & 1.1 & $0.6-2.3$ \\
$\quad$ Other transport workers & 29 & 75 & 1.5 & 1.5 & $0.9-2.5$ \\
Constuction workers & 25 & 84 & 1.1 & 1.1 & $0.7-1.8$ \\
$\quad$ Carpenters & 10 & 37 & 1.0 & 1.0 & $0.5-2.1$ \\
Other constuction workers & 15 & 47 & 1.2 & 1.2 & $0.7-2.3$ \\
Agricultural workers & 17 & 61 & 1.1 & 1.0 & $0.5-1.8$ \\
Non-exposed reference category & 138 & 530 & & & \\
\hline Adjust for a positiv fanty history
\end{tabular}

*Adjusted for a positive family history of the father and maternal oral contraceptive use by logistic regression. Restriction for maternal use of vitamin A, antiepileptics, diabetes, diagnosis of homocysteinaemia and consanguinity

† Among others general foremen, metal founders, chemical process workers, textile, glass, and pottery workers

\section{Discussion}

Our findings indicate increased risks of having a child with spina bifida for male welders and transport workers, for female cleaners and especially for women working in agricultural occupations. We did not observe a difference between cases and referents concerning type of agricultural work associated with specific tasks or chemicals that might be reponsible for the increased risk.

Theoretically, selection bias may have resulted from restriction of the study to liveborn cases. No information was available on women who had an induced abortion after antenatal screening that indicated a neural tube defect in the fetus. Antenatal screening, however, was not routinely offered in the Netherlands during the study period. Therefore, mainly more highly educated women, among whom occupational exposure was less frequent, had an abortion after antenatal screening. Nevertheless, even if 50 such women were included in the study population, the 
effect on the results would be marginal. The crude odds ratio for mothers in agricultural occupations, for example, would change from 7.9 to 6.6. On the other hand, resstriction to liveborn cases may have led to underestimation of the effects, owing to the so-called 'inverse dose-response relation'. As reproductive endpoints can be-viewed as a continuum, a very high exposure could result in early fetal loss, whereas a lower one might result in a congenital malformation recognized at birth. ${ }^{28}$

The use of population-based referents does not cause selection bias in this study, as there is no selective referral pattern due to socioeconomic or other risk factors for spina bifida in the Netherlands. Virtually all cases of spina bifida that occur in a specific region are referred to a hospital with a specialized spina bifida team. These are the hospitals that we included. As the referents were randomly sampled from the general population, stratified by size of municipalities in the catchment area of each hospital, we expect the case and referent populations to be similar with respect to extraneous risk factors for spina bifida.

We used occupational titles in this study, although these can only serve as crude indicators of occupational exposure. To make the job titles more reliable, we used information on tasks and daily activities to fine-tune the coding. Nonetheless, nondifferential misclassification may have occurred. Although such misclassification usually causes biases toward the null value, if it concerns a nominal variable with numerous categories like occupational title, bias away from the null could occur. ${ }^{29}$ In this study, misclassification may have occurred if women who worked on their husband's farm called themselves housewives and were incorrectly assigned to the noexposure category. As a result, the odds ratios might have been biased towards the null. On the other hand, when every housewife whose husband was a self-employed farmer was included in the 'agricultural worker' category, the crude OR fell from 7.9 to $1.7(95 \% \mathrm{Cl}: 1.0-3.1)$, probably because of misclassification by inclusion of nonexposed women in the agriculture exposure category. The same mechanism could explain the increase of the OR for cleaners from 1.9 to 2.7 when restricting the analyses to women who worked more than 10 hours per week.

As a proxy for the period around conception, we used a date 1 year before the date of birth. Although differential misclassification is not very likely, as the mean length of pregnancy differed only slightly between cases and referents, nondifferential misclassification could have occurred if the occupation of the parent 1 year before birth was not the same as the occupation in the first month of pregnancy. Nevertheless, as the workforce in The Netherlands is relatively stable, this misclassification is expected to be uncommon. On the other hand, questions referring to the period before the woman knows that she is pregnant may result in more valid estimates of exposures such as smoking and drinking behavior in the first month of pregnancy than questions about the pregnancy period itself. 
Self-reported information on occupational titles concerning a short time period is not likely to be liable to information bias. Also, a comparison of the populationbased referents from our study with a hospital-based referent group showed similar frequency distributions of the other variables for which information bias would be more likely, such as smoking and drinking habits and other life-style factors (manuscript in preparation). We found multivitamin and vitamin use to be higher among cases than among referents, even among parents without a positive family history for neural tube defects. As an adverse effect of vitamin use is not expected, this could point to the presence of information bias, induced by the recent publicity about prenatal vitamin use. As folic acid was not added to multivitamin supplements in The Netherlands during the study period, ${ }^{30}$ a preventive effect of vitamin use was not expected either.

We did not control for differences in nutrition, which we assumed to be fairly homogeneous in the Netherlands. Small differences that might exist could not have been detected by means of a self-administered dietary history, and therefore, nutrition was not included in the questionnaire. Since women working in agriculture probably eat more rather than less green leaf vegetables than the general population, the increased risk for women in agricultural occupations cannot easily be explained by a vitamin or folic acid deficiency. Although the level of education of the parents was not distributed equally among the cases and referents, we decided not to correct for this variable to avoid overadjustment. As education is not an independent risk factor for spina bifida, but an indicator for socioeconomic status and occupation, the ORs for occupation might have been unjustly corrected toward the null value. Moreover, other indicators for socioeconomic status, such as residence and living environment, did not differ substantially between the cases and referents. Socioeconomic differences in the Netherlands are small relative to most other countries.

No published study on maternal occupation exceeds ours in size. The only larger study, by Olshan et al., ${ }^{23}$ involved paternal occupation and was register-based. Although Ericson et al. ${ }^{21}$ concluded that no association could be found for any type of occupation, they did find an odds ratio of 7.1 for mothers in agricultural occupations, for which they did not present a confidence interval (1.4-35.2) because only seven cases and two referents had an agricultural occupation (B. Källén, personal communication, 1994). A small-scale study in Venezuela ${ }^{20}$ showed different frequencies of maternal agricultural occupations among 76 cases of neural tube defects $(8 \%)$ and 76 controls $(0 \%)$. The authors found that $32 \%$ of the case fathers had an agricultural occupation, compared with $13 \%$ of the referent fathers. A study in England on congenital malformations among offspring of agricultural workers showed that 'gardeners and groundsmen' had increased $\mathrm{O} / \mathrm{E}$ ratios of 1.2 for spina bifida and $\mathbf{1 . 2}$ for anencephaly, whereas 'agricultural workers' had an increased ratio 
of 1.3 for spina bifida. ${ }^{18}$ In the latter two studies, an effect is seen for exposure of the father that was not found in the present study. Neither the literature nor our study give insight into the type of agricultural work or the specific exposures that could lead to an increased risk for spina bifida.

Increased odds ratios have been reported for solvent-exposed workers. ${ }^{15,22,23}$ The absence of this effect among mothers in our study might be explained by the low doses handled or by the small number of women in the Netherlands who are occupationally exposed to solvents in industrial settings. The increased risk found for cleaners might reflect working with solvents in heavy-duty cleaning jobs. An increased risk of neural tube defects was recently observed for exposure to glycol ethers, which are sometimes used by cleaners. ${ }^{31}$

The increased risk of spina bifida that we found for welders has not been reported before, although sperm quality and fertility seem to be reduced among welders, ${ }^{32,33}$ and increased risks have been found for childhood cancers. ${ }^{34,35}$ Fedrick reported an increased risk of anencephaly for transport and communication workers, ${ }^{22}$ who were mainly drivers of road vehicles.

\section{Acknowledgements}

We are most obliged to the Spina Bifida Teams of the University Hospital Groningen (JH Begeer), the University Hospital of the Free University (CA Kurk), the University Hospital Rotterdam (PC) de Laat), the Maartensclinic Rehabilitation Centre (M) Poelma), the Elisabeth Hospital Tilburg (IA Rammeloo), the Roessingh Rehabilitation Center (M Stroo), the University Hospital Amsterdam (JW Weber), and the University Hospital Utrecht $(\mathrm{H}$ van Wieringen). Furthermore, we thank Annelies Pellegrino for her practical support, and I Copius Peereboom-Stegemann and PWJ Peters for their critical comments on an earlier version of the manuscript. We also owe special thanks to all the parents for their participation in the study.

\section{References}

1 Nevin NC, Johnston WP, Merrit JD. Influence of social class on the risk of recurrence of anencephalus and spina bifida. Dev Med Child Neurol 1981;23:155-159.

2 Elwood JM, Elwood JH. Epidemiology of anencephalus and spina bifida. Oxford: Oxford University Press, 1980.

3 Little J, Elwood JH. Socioeconomic status and occupation. In: Elwood JM, Little J, Elwood JH, eds. Epidemiology and Control of Neural Tube Defects. Monographs in Epidemiology and Biostatistics. vol 20. Oxford: Oxford University Press, 1992;456520.

4 Smithells RW, Sheppard S, Schorah CJ. Vitamin deficiencies and neural tube defects. Arch Dis Child 1976;51:944-950.

5 Slattery ML, Janerich DT. The epidemiology of neural tube defects: a review of 
dietary intake and related factors as etiologic agents. Am J Epidemiol 1991;133:526540.

6 Wald N, Sneddon J, Frost C, Stone R. Prevention of neural tube defects: results of the Medical Research Council Vitamin Study. Lancet 1991;338:131-137.

7 Czeizel AE, Dudas I. Prevention of the first occurrence of neural tube defects by periconceptional vitamin supplementation. N Engl J Med 1992;327:1832-1835.

8 Brown NA. Are offspring at risk from their father's exposure to toxins? Nature 1985;316:110.

9 Hales BF, Smith S, Robaire B. Cyclophosphamide in the seminal fluid of treated males: transmission to females by mating and effect on pregnancy outcome. Toxicol and Appl Pharmacol 1986;84:423-430.

10 Blatter BM, van der Star $M$, Roeleveld N. Review of neural tube defects: risk factors in parental occupation and the environment. Environ Health Perspect 1994;102:140145.

11 Hemminki K, Mutanen P, Luoma K, Saloniemi I. Congenital malformations by the parental occupation in Finland. Int Arch Occup Environ Health 1980;46:93-98.

12 Hemminki K, Mutanen P, Saloniemi I, Luoma K. Congenital malformations and maternal occupation in Finland: multivariate analysis. J Epidemiol Community Health 1981;35:5-10.

13 Holmberg PC, Nurminen $M$. Congenital defects of the central nervous system and occupational factors during pregnancy. A case-referent study. Am J Ind Med 1980;1: 167-176.

14 Sikorski R, Juszkiewicz T, Paszkowski T, Sprengier-Juszkiewicz T. Women in dental surgeries: reproductive hazards in occupational exposure to metallic mercury. Int Arch Occup Environ Health 1987;59:551-557.

15 Olsen J. Risk of exposure to teratogens amongst laboratory staff and painters. Dan Med Bull 1983;30:24-28.

16 McDonald AD, McDonald JC, Armstrong B, Cherry NM, Nolin AD, Robert D. Fathers' occupation and pregnancy outcome. $\mathrm{Br} J$ Ind Med 1989;46:329-333.

17 Sever LE, Gilbert ES, Hessol NA, Mclntyre JM. A case-control study of congenital malformations and occupational exposure to low-level ionizing radiation. Am J Epidemiol 1988; 127:226-242.

18 Balarajan R, McDowall $M$. Congenital malformations and agricultural workers (Letter). Lancet 1983;I:1112-1113.

19 Matte TD, Mulinare J, Erickson JD. Case-control study of congenital defects and parental employment in health care. Am J Ind Med 1993;24:11-23.

20 Hammond FG, Canache MF. Some epidemiological aspects of neural tube defects in Barquisimeto, Venezuela (Abstract). Am J Hum Genet 1991;49 (suppl.):470.

21 Ericson A, Källén B, Löfkvist E. Environmental factors in the etiology of neural tube defects: a negative study. Environ Res 1988;45:38-47.

22 Fedrick J. Anencephalus in the Oxford Record Linkage Study Area. Dev Med Child Neurol 1976;18:643-656. 
23 Olshan AF, Teschke K, Baird PA. Paternal occupation and congenital anomalies in offspring. Am J Ind Med 1991;20:447-475.

24 Brender CJ, Suarez L. Paternal occupation and anencephaly. Am J Epidemiol 1990;131:517-521.

25 Hearey CD, Harris JA, Usatin MS, Epstein DM, Ury HK, Neutra RR. Investigation of a cluster of anencephaly and spina bifida. Am J Epidemiol 1984;120:559-564.

26 World Health Organization. International Classification of Diseases, 9th revision. Geneva: World Health Organization, 1977.

27 International Labour Office. International Standard Classification of Occupations (revised ed.) 1968. Geneva: ILO Publications, 1978.

28 Selevan SG, Lemasters GK. The dose-response fallacy in human reproductive studies of toxic exposures. / Occup Med 1987;29:451-454.

29 Wacholder S, Dosemeci M, Lubin JH. Blind assignment of exposure does not always prevent differential misclassification. Am J Epidemiol 1991;134:433-437.

30 Cornel MC, de Jong-van den Berg LTW, Steegers-Theunissen RPM, ten Kate LP. Foliumzuur voor alle fertiele vrouwen? Ned Tijdschr Geneeskd 1993;137:12831285.

31 Ha MC, Cordier S, Danache B, Bergeret A, Mandereau L, Bruno F. Congenital malformations and occupational exposures to glycol ethers: a European collaborative case-control study (Abstract). Tenth International Symposium on Epidemiology in Occupational Health, Como, Italy, 1994.

32 Mortensen JT. Risk for reduced sperm quality among metal workers, with special reference to welders. Scand J Work Environ Health 1988; 14:27-30.

33 Bonde JP, Hansen KS, Levine RJ. Fertility among Danish male welders. Scand J Work Environ Health 1990;16:315-322.

34 Olshan AF, Breslow NE, Daling JR, Falletta JM, Grufferman S, Robison LL, Waskerwitz M, Hammond GD. Wilms' tumor and paternal occupation. Cancer Res 1990;50:3212-3217.

35 Bunin GR, Petrakova A, Meadows AT, Emanuel BS, Buckley JD, Woods WG, Hammond GD. Occupations of parents of children with retinoblastoma: a report from the Children's Cancer Study Group. Cancer Res 1990;50:7129-7133. 


\title{
CHAPTER 5
}

\section{HETEROGENEITY OF SPINA BIFIDA}

\author{
BM Blatter, AB Lafeber, PWJ Peters, N Roeleveld, ALM Verbeek, FJM Gabreëls
}

Teratology (accepted for publication)

\begin{abstract}
Splitting birth defects into dysmorphologically homogeneous groups might improve the ability to detect a genetic risk factor or teratogenic exposure. With regard to spina bifida, recent studies suggest that etiologic heterogeneity exists within the group of spina bifida, although exogeneous risk factors have been sparsely evaluated for subgroups. In the present study, 210 spina bifida patients were classified into relatively homogeneous groups, based on retrospective information on appearance and functional aspects of the lesion abstracted from medical records of the patients. We compared high with low spina bifida, and open with closed spina bifida, and investigated whether risk factors for spina bifida, such as maternal age, anti-epileptic drug use, parental occupation, and genetic factors, were specifically associated with these homogeneous subclasses. For these comparisons, a referent group of 671 children was used. Although classifying spina bifida into homogeneous subclasses presented some difficulties and numbers were small, this study provides some evidence for different risk profiles for subclasses of spina bifida. The sex ratio, the proportion of miscarriages of siblings, and maternal age did not differ among the different subclasses of spina bifida. However, children with a positive family history of neural tube defects (NTDs) had a higher risk of high spina bifida $(\mathrm{OR}=6.3,95 \% \mathrm{Cl}$ : $1.7-19.2)$ than of low spina bifida $(\mathrm{OR}=2.1,95 \% \mathrm{Cl}: 1.0-4.2)$. Siblings with NTDs were more common in cases with high spina bifida and cases with open spina bifida. A strongly increased risk of high spina bifida was found for male welders $(O R=12.1,95 \% C l: 1.5-64.2)$, whereas the risk of low spina bifida was much lower $(\mathrm{OR}=1.6,95 \% \mathrm{Cl}$ : $0.2-7.9)$. For mothers with agricultural occupations, a strongly increased risk was observed for open spina bifida $(O R=14.3$, 95\%Cl: 2.9-77.7), whereas none of 107 cases with closed spina bifida had a mother with an occupation in agriculture. Due to small numbers, the results must be interpreted with caution.
\end{abstract}




\section{Introduction}

Neural tube defects (NTD) have been studied extensively and have been associated with many factors, such as maternal age, geography, socioeconomic status, occupation, maternal vitamin intake, illness, medication use, and family history of neural tube defects. ${ }^{1}$ Nevertheless, few aspects of the underlying mechanisms have been unraveled. ${ }^{2}$ In etiologic studies, anencephaly and spina bifida are often separated, because of a supposed etiologic difference between these two types of NTD. In addition, recent studies suggest that heterogeneity exists within the group of spina bifida. $^{3-6}$ Splitting spina bifida into dysmorphologically homogeneous groups might improve the ability to detect a teratogenic exposure, ${ }^{7,8}$ which may have implications for the prevention of spina bifida. However, the criteria for subclassification inferred from possibly distinct pathogenetic mechanisms are still unclear.

In many studies, cases are divided into isolated and nonisolated or multiple spina bifida, based on the presence and nature of accompanying abnormalities. ${ }^{6,9-11} \mathrm{~A}$ classification based on the anatomic site of the lesion originates from the idea that there are two different processes, neurulation and canalization, which are involved in neural tube formation. ${ }^{46,12-14}$ Neurulation consists of fusion of the neural folds, whereas canalization, also called secondary neurulation, comprises the formation of vacuoles in between the undifferentiated caudal cell mass. ${ }^{15}$ Although the exact vertebral level that indicates the junction between the two different processes is unknown, Lemire calculated that posterior neuropore closure, completing neurulation, occurs between the 11th thoracal vertebral level and the 4th lumbar vertebral level. ${ }^{15}$ This suggests that defects resulting from disturbance in the process of neurulation are located above the site of closure of the posterior neuropore, and are therefore called 'high' defects, whereas 'low' defects may be due to a disturbance in canalization. ${ }^{12}$ Most investigators have chosen to use the 12 th thoracic vertebra as the junction between high and low defects. ${ }^{4,11,12}$

Lemire also states that neural tube defects arising during neurulation are clinically apparent by being open, that is, leaving nervous tissue exposed. ${ }^{16}$ In contrast, postneurulation or canalization defects are skin-covered because embryonic ectoderm covers the surface of the embryo during canalisation. Lemire includes anencephaly, craniorrhachischisis and meningomyelocele in the 'open' category, and classifies meningocele and spina bifida occulta as 'closed' lesions. Saddler, however, also considers meningomyelocele a skin covered defect. ${ }^{17}$ Only a few investigators have used the classification of 'open' or 'closed' lesions to identify etiologic differences between these forms of spina bifida.,

In order to contribute to the ongoing discussion about a possible heterogeneity of spina bifida, we investigated whether exogeneous risk factors and genetic susceptibility factors for spina bifida, obtained by questionnaire, were specifically associated with homogeneous subclasses of spina bifida, based on retrospective information that was available in the medical records of the cases. 


\section{Population and methods}

\section{Population}

Cases were 273 children with spina bifida, diagnosed in three hospitals in The Netherlands, who were live-born between January 1, 1980 and December 31, 1992. The referentgroup consisted of 907 children who were also born between January 1 , 1980 and December 31, 1992, derived from the general population. They were obtained through random samples from municipal birth registries in the regions where the cases originated.

\section{Data collection}

In order to discriminate between different subclasses of spina bifida, information on anamnesis, diagnosis, appearance, severity, site of the lesion, surgery, neurological deficits, and the presence of other abnormalities was abstracted from the medical records of the patients using a standardized form. Based on this information, spina bifida cases were classified in three different ways. Firstly, they were classified into 'isolated' and 'nonisolated' spina bifida, based on the presence and nature of accompanying abnormalities. Cases were 'isolated' if spina bifida occurred solely or in association with malformations that were considered secondary to the neural tube defect. Spina bifida cases were classified as 'nonisolated' if they had another unrelated birth defect, such as a congenital heart defect, cleft lip or cleft palate, renal agenesis, exomphaly, hypospadia or uterine abnormality, anorectal atresia, diaphragmatic hernia, horseshoe kidney, Meckel's diverticulum, accessory spleen, or nonrotation of the gut. ${ }^{11}$ Secondly, the spina bifida cases were classified by level of the defect. High defects were those in which the upper extent of the defect was estimated as lying above the 12th thoracic vertebra, or those described as thoracal or thoracolumbar. 'Low' defects were those in which the upper extent of the defect was below the 11th thoracic vertebra. Thirdly, we divided the cases into 'open' and 'closed' lesions according to type of spina bifida: rachischisis (all defects with neural tissue exposed on the surface) was defined as 'open' spina bifida, whereas meningomyelocele, meningocele and spina bifida occulta were defined as 'closed' spina bifida. Several data from the medical records were combined to make this distinction. Absence of the skin, visibility of normal or degenerated neural tissue, and severe motor and sensor defects were considered to be indications for 'open' spina bifida.

Information on risk factors for spina bifida had been collected by means of a postal questionnaire that was sent to both parents of cases and referents in 1992. Data were gathered on maternal age, diabetes mellitus, use of anti-epileptic agents, use of oral contraceptives and ovulation stimulating agents, fetal loss, occupation of both parents, consanguinity (first cousins or second cousins), and family history of neural tube defects. Eventually the information on family history of neural tube 
defects that was used in the analyses was obtained from the postal questionniare and from the medical record: if a relative with a neural tube defect was reported in either questionnaire or medical record, a person was appointed to the exposed category. All other data concerning risk factors were obtained from the questionnaire; no other items were obtained from medical records or vital statistics.

\section{Analyses}

Descriptive analyses were performed on the clinical characteristics of every subclass of spina bifida. Next, odds ratios (OR) with $95 \%$ confidence intervals $(95 \% \mathrm{Cl})$ were calculated to compare the spina bifida subclasses with the referent group regarding the association with risk factors. As many of the calculations involved small numbers, mid-P exact confidence limits were calculated by means of the computer program EXACT. ${ }^{18}$ Multivariate analyses were performed to adjust the ORs for all other risk factors. ORs were compared between subclasses to investigate if some risk factors were specifically associated with a single subclass.

\section{Results}

Response rates for cases and referents were $84 \%$ and $74 \%$, respectively. Nineteen medical records could not be used or traced, reducing the study population to 210 cases and 671 referents.

Only $7(3.3 \%)$ nonisolated spina bifida cases were observed. The accompanying congenital malformations were anal atresia $(n=3)$, congenital heart defects $(n=3)$, and Duane's syndrome. Six of these patients had low spina bifida, whereas the site of the defect of the other case was unknown. Two had open and four had closed lesions. Because the numbers in these subclasses are too small to investigate associations with possible risk factors, this classification is not taken into account in the further analyses.

TABLE 5.1 Level (high / low) versus appearance (open / closed) of spina bifida

\begin{tabular}{lcrrrrr}
\hline & \multicolumn{2}{c}{ Open $(\mathrm{N}=66)$} & \multicolumn{2}{c}{ Closed $(\mathrm{N}=107)$} & \multicolumn{2}{c}{ Unknown $(\mathrm{N}=37)$} \\
& $\mathrm{N}$ & $\%$ & $\mathrm{~N}$ & $\%$ & $\mathrm{~N}$ & $\%$ \\
\hline High $(\mathrm{N}=24)$ & 10 & 15.2 & 9 & 8.4 & 5 & 13.5 \\
Low $(\mathrm{N}=173)$ & 55 & 83.3 & 90 & 84.1 & 28 & 75.7 \\
Unknown $(\mathrm{N}=13)$ & 1 & 1.5 & 8 & 7.5 & 4 & 10.8 \\
\hline
\end{tabular}

Separating cases into high and low spina bifida yielded 24 cases $(11.4 \%)$ with high spina bifida and $173(82.4 \%)$ with a low defect (Table 5.1). The level of the lesion of 13 cases $(6.2 \%)$ was unknown. Sixty-six $(31 \%)$ had open spina bifida, 
whereas $107(51 \%)$ had closed spina bifida. For many cases, information on diagnoses or definitions in the medical record were contradictory or information on the appearance of the lesion was insufficient. Therefore, 37 cases $(17.6 \%)$ could not be classified into open or closed spina bifida. There was little correlation between the two classifications: of the defects that were considered open, $15 \%$ were classified as high and $83 \%$ were classified as low spina bifida; of the defects that were considered to be closed, $8 \%$ were classified as high and $84 \%$ as low.

TABLE 5.2 Clinical characteristics of the spina bifida subclasses of two classifications, based on information in the medical record of the patient

\begin{tabular}{|c|c|c|c|c|c|c|c|c|c|c|}
\hline \multirow[b]{3}{*}{ Information in medical record } & \multicolumn{10}{|c|}{ Spina bifida subclasses } \\
\hline & \multicolumn{2}{|c|}{$\begin{array}{l}\text { High } \\
(N=24)\end{array}$} & \multicolumn{2}{|c|}{$\begin{array}{c}\text { Low } \\
(N=173)\end{array}$} & \multicolumn{2}{|c|}{$\begin{array}{c}\text { Open } \\
(N=66)\end{array}$} & \multicolumn{2}{|c|}{$\begin{array}{c}\text { Closed } \\
(N=107)\end{array}$} & \multicolumn{2}{|c|}{$\begin{array}{c}\text { Unknown } \\
(N=37)\end{array}$} \\
\hline & $\mathbf{N}$ & $\%$ & $N$ & $\%$ & $\mathbf{N}$ & $\%$ & $\mathbf{N}$ & $\%$ & $\mathrm{~N}$ & $\%$ \\
\hline Open defect & 16 & 67 & 102 & 59 & 61 & 92 & 37 & 35 & 23 & 62 \\
\hline Meninges visiblet & 11 & 46 & 38 & 22 & 28 & 42 & 15 & 14 & 6 & 16 \\
\hline Neural tissue visible $\neq$ & 6 & 25 & 25 & 14 & 26 & 39 & 4 & 4 & 2 & 5 \\
\hline Totally skin covered§ & 3 & 13 & 51 & 30 & 3 & 5 & 55 & 51 & 1 & 3 \\
\hline Partly skin covered§ & 8 & 33 & 43 & 25 & 26 & 39 & 21 & 20 & 5 & 14 \\
\hline Swelling / celeq & 5 & 21 & 65 & 38 & 11 & 17 & 56 & 52 & 6 & 16 \\
\hline Motor neurological leg defect & 18 & 75 & 100 & 58 & 63 & 96 & 29 & 27 & 32 & 87 \\
\hline Sensor neurological leg defect & 15 & 63 & 123 & 71 & 63 & 96 & 49 & 46 & 31 & 84 \\
\hline Knee reflex absent & 12 & 50 & 50 & 29 & 41 & 62 & 12 & 11 & 11 & 30 \\
\hline Achillestendon reflex absent & 9 & 38 & 95 & 55 & 50 & 76 & 36 & 34 & 22 & 60 \\
\hline Sphincter ani reflex absent & 6 & 25 & 93 & 54 & 49 & 74 & 35 & 33 & 19 & 51 \\
\hline Hydrocephalus & 18 & 76 & 121 & 70 & 62 & 94 & 46 & 43 & 35 & 95 \\
\hline Arnold-Chiari llf & 11 & 46 & 28 & 16 & 21 & 32 & 9 & 8 & 9 & 24 \\
\hline $\begin{array}{l}\text { * Open or closed appearance not } \\
+ \text { Visibility of meninges not ment } \\
\text { ₹ Visibility of neural tissue not me } \\
\text { \$ Skin coverage not mentioned in } \\
\text { I Presence or absence of swelling }\end{array}$ & tio & in & of & & cord & & & & & \\
\hline
\end{tabular}

Some clinical characteristics of the subclasses of spina bifida are presented in Table 5.2. The number of cases with unknown level of defect was considered too small $(n=13)$ to present separately; the clinical description of the 37 cases with unknown classification of open or closed is given in the last column. Large prevalence differences between high and low spina bifida were found for visibility of meninges 
( $46 \%$ compared to $22 \%$ ), complete skin coverage (13\% compared to $30 \%$ ), and the presence of Arnold-Chiari malformation ( $46 \%$ compared to $16 \%$ ). As the classification into open or closed spina bifida was based on a combination of some of the characteristics displayed in Table 5.2, such as absence of the skin, visibility of normal or degenerated neural tissue, and severe motor and sensor defects, it is not surprising that the frequencies of these characteristics differed between open and closed spina bifida, and that information about these characteristics within the group with unknown type of spina bifida was lacking. Still, it is noteworthy that $35 \%$ of the defects that were classified as closed were described in the medical record as an open defect. In $94 \%$ of the cases with open spina bifida, hydrocephalus was present, compared to $43 \%$ of closed spina bifida cases. Arnold-Chiari malformation was present in $32 \%$ of the cases with open spina bifida, whereas only $8 \%$ of the children with closed defects had Arnold-Chiari malformation.

In Tables 5.3 and 5.4, we present ORs with exact 95\% confidence intervals of the associations between potential risk factors and the different subclasses of spina bifida, calculated by means of comparison with a referent group. The prevalence of some risk factors was very low, which sometimes resulted in very large confidence intervals. As maternal diabetes occurred in only one case, it was excluded from the table. ORs were not calculated if in one of both case groups zero or one case was exposed. As the adjusted ORs did not differ from the crude ORs, the crude ORs are presented in the tables.

Concerning the level of the defect (Table 5.3), the risk of both high and low spina bifida was slightly lower for males than for females $(O R=0.7$ and $O R=0.8$, respectively). A positive family history of neural tube defects appears to be a risk factor for both subclasses of spina bifida, but the $O R$ for high spina bifida $(O R=6.3$ ) was stronger than the $O R$ for low spina bifida $(O R=2.1)$. If only siblings with a neural tube defect were considered, the difference between the odds ratios of both subclasses increased $\left(\mathrm{OR}_{\text {high }}=60.7,95 \% \mathrm{Cl}: 4.4-1791 ; \mathrm{OR}_{\mathrm{low}}=7.8,95 \% \mathrm{Cl}: 0.6-230\right)$. Finally, the occupations for which the OR of high spina bifida was much higher than the OR of low spina bifida were in industry or transport for mothers, and health care, welders and construction for fathers. However, it should be noted that in all comparisons, confidence intervals were overlapping. For many factors ORs could not be calculated with regard to high spina bifida because of small numbers.

In Table 5.4, the risk factors for open and closed spina bifida are presented. Open spina bifida was associated in particular with the occurrence of siblings with NTDs (OR $=31.8$ ), whereas none of 107 cases with closed spina bifida had a sibling with NTD. Women who had used oral contraceptives within three months before conception show a slightly decreased risk fôr open spina bifida, whereas the risk of closed spina bifida was slightly increased. Differing ORs were observed for maternal cleaning occupations $(O R=4.3$ compared with $O R=1.9)$. For mothers working in 
TABLE 5.3 Risk factors for high and low spina bifida

\begin{tabular}{|c|c|c|c|c|c|c|c|}
\hline & \multicolumn{3}{|c|}{$\begin{array}{l}\text { High spina bifida } \\
(N=24)\end{array}$} & \multicolumn{3}{|c|}{$\begin{array}{l}\text { Low spina bifida } \\
(N=173)\end{array}$} & \multirow{2}{*}{$\begin{array}{c}\text { Referents } \\
(\mathrm{N}=671) \\
\mathrm{N}\end{array}$} \\
\hline & $\mathbf{N}$ & OR* & $95 \% \mathrm{Cl}$ & $\mathbf{N}$ & OR* & $95 \% \mathrm{Cl}$ & \\
\hline Male sex & 10 & 0.7 & $0.3-1.6$ & 77 & 0.8 & $0.6-1.1$ & 341 \\
\hline Family history of NTDst & 4 & 6.3 & 1.7-19.2 & 12 & 2.1 & $1.0-4.2$ & 24 \\
\hline Sibling with NTD & 2 & 60.7 & 4.4-1791 & 2 & 7.8 & $0.6-230$ & 1 \\
\hline Fetal loss of siblings & 4 & 0.7 & $0.2-1.9$ & 33 & 0.8 & $0.5-1.2$ & 153 \\
\hline \multicolumn{8}{|l|}{ Maternal age } \\
\hline $21-30$ & $\begin{array}{c}2 \\
18\end{array}$ & 1.0 & ref & 122 & 1.0 & ref & 469 \\
\hline $31-35$ & 4 & 0.6 & $0.2-1.8$ & 40 & 0.9 & $0.6-1.4$ & 163 \\
\hline$>36$ & 0 & - & & 6 & 1.0 & $0.4-2.3$ & 24 \\
\hline Oral contraceptives & 9 & 1.2 & $0.5-2.9$ & 68 & 1.3 & $0.9-1.8$ & 228 \\
\hline Ovulation stimulants & 0 & - & & 7 & 1.0 & $0.4-2.2$ & 28 \\
\hline Antiepileptic agents & 0 & - & & 2 & 2.6 & $0.3-17.6$ & 3 \\
\hline \multicolumn{8}{|l|}{ Maternal occupation $¥$} \\
\hline Nurses & 2 & 1.7 & $0.3-6.3$ & 3 & 0.3 & $0.1-1.0$ & 35 \\
\hline Nurse aids & 1 & - & & 10 & 2.2 & $1.0-4.9$ & 18 \\
\hline Other health care & 0 & - & & 4 & 0.5 & $0.2-1.5$ & 28 \\
\hline Cleaners & 1 & - & & 7 & 2.8 & $1.0-7.5$ & 10 \\
\hline Hairdressers & 0 & - & & 3 & 1.7 & $0.4-6.4$ & 7 \\
\hline Industrial / transport & 3 & 4.2 & $0.9-14.0$ & 4 & 0.7 & $0.2-1.9$ & 22 \\
\hline Agricultural & 0 & - & & 4 & 5.3 & $1.1-28.3$ & 3 \\
\hline \multicolumn{8}{|l|}{ Paternal occupation $\ddagger$} \\
\hline Health care & 4 & 3.1 & $0.9-8.9$ & 3 & 0.3 & $0.1-0.8$ & 41 \\
\hline Professional / technical & 0 & - & & 14 & 0.7 & $0.4-1.3$ & 73 \\
\hline Food, drink, tobacco & 1 & - & & 2 & 0.8 & $0.1-3.2$ & 10 \\
\hline Metal workers & 0 & - & & 8 & 1.3 & $0.5-2.8$ & 25 \\
\hline Mechanics & 3 & 1.9 & $0.4-5.9$ & 14 & 1.1 & $0.8-2.3$ & 48 \\
\hline Welders & 2 & 12.1 & $1.5-64.2$ & 2 & 1.6 & $0.2-7.9$ & 5 \\
\hline Plumbers & 0 & - & & 2 & 0.6 & $0.1-2.6$ & 12 \\
\hline Painters & 0 & - & & 3 & 1.7 & $0.4-6.4$ & 7 \\
\hline Plastic, paper, printers & 1 & - & & 5 & 1.5 & $0.4-3.8$ & 13 \\
\hline Other industrial & 1 & - & & 13 & 1.5 & $0.7-2.8$ & 35 \\
\hline Transport & 2 & 0.9 & $0.1-3.4$ & 21 & 1.4 & $0.8-2.3$ & 62 \\
\hline Construction & 6 & 5.4 & $1.9-14.0$ & 12 & 1.2 & $0.6-2.4$ & 39 \\
\hline Agricultural & 0 & - & & 4 & 0.9 & $0.3-2.4$ & 18 \\
\hline
\end{tabular}

* ORs not directly calculable from numbers in table because of differing numbers of missing values

† First or second grade family members of the child

₹ ORs of occupations with potential for chemical or physical exposure, compared with all other occupations 
TABLE 5.4 Risk factors for open and closed spina bifida subclasses

\begin{tabular}{|c|c|c|c|c|c|c|c|}
\hline & \multicolumn{3}{|c|}{$\begin{array}{l}\text { Open spina bifida } \\
\qquad(N=66)\end{array}$} & \multicolumn{3}{|c|}{$\begin{array}{l}\text { Closed spina bifida } \\
\qquad(N=107)\end{array}$} & \multirow{2}{*}{$\begin{array}{c}\text { Referents } \\
(\mathrm{N}=671) \\
\mathrm{N}\end{array}$} \\
\hline & $\mathbf{N}$ & $\mathrm{OR}^{*}$ & $95 \% \mathrm{Cl}$ & $N$ & OR* & $95 \% \mathrm{Cl}$ & \\
\hline Male sex & 33 & 1.0 & $0.6-1.6$ & 42 & 0.6 & $0.4-0.9$ & 341 \\
\hline Consanguinity† & 2 & 5.2 & $0.7-29.6$ & 0 & - & & 4 \\
\hline Family history of NTDsł & 7 & 3.2 & $1.2-7.6$ & 7 & 2.0 & $0.8-4.5$ & 24 \\
\hline Sibling with NTD & 3 & 31.8 & $3.3-838$ & 0 & - & & 1 \\
\hline Fetal loss of siblings & 13 & 0.8 & $0.4-1.5$ & 20 & 0.8 & $0.5-1.3$ & 153 \\
\hline \multicolumn{8}{|l|}{ Maternal age } \\
\hline$\leq 20$ & 2 & 1.6 & $0.2-6.4$ & 6 & 2.9 & $1.0-7.8$ & 13 \\
\hline $21-30$ & 46 & 1.0 & ref & 74 & 1.0 & ref & 469 \\
\hline $31-35$ & 15 & 0.9 & $0.5-1.7$ & 23 & 0.9 & $0.5-1.5$ & 163 \\
\hline$>36$ & 3 & 1.3 & $0.3-4.0$ & 4 & 1.1 & $0.3-2.9$ & 24 \\
\hline Oral contraceptives & 15 & 0.6 & $0.3-1.0$ & 47 & 1.6 & $1.0-2.4$ & 228 \\
\hline Ovulation stimulants & 1 & - & & 4 & 0.9 & $0.3-2.5$ & 28 \\
\hline \multicolumn{8}{|l|}{ Maternal occupation§ } \\
\hline Nurses & 2 & 0.6 & $0.1-2.1$ & 3 & 0.5 & $0.1-1.6$ & 35 \\
\hline Nurse aids & 4 & 2.3 & $0.7-6.7$ & 6 & 2.2 & $0.8-5.4$ & 18 \\
\hline Other health care & 2 & 0.7 & $0.1-2.6$ & 1 & - & & 28 \\
\hline Cleaners & 4 & 4.3 & $1.1-13.6$ & 3 & 1.9 & $0.4-6.7$ & 10 \\
\hline Hairdressers & 2 & 3.0 & $0.4-13.6$ & 1 & - & & 7 \\
\hline Industrial / transport & 0 & - & & 5 & 1.4 & $0.5-3.7$ & 22 \\
\hline Agricultural & 4 & 14.3 & $2.9-77.7$ & 0 & - & & 3 \\
\hline \multicolumn{8}{|l|}{ Paternal occupation§ } \\
\hline Health care & 1 & - & & 5 & 0.8 & $0.3-1.8$ & 41 \\
\hline Professional / technical & 6 & 0.8 & $0.3-1.9$ & 8 & 0.7 & $0.3-1.4$ & 73 \\
\hline Food, drink, tobacco & 2 & 2.1 & $0.3-8.7$ & 1 & - & & 10 \\
\hline Engineers, metal & 3 & 1.2 & $0.3-3.8$ & 5 & 1.3 & $0.4-3.2$ & 25 \\
\hline Mechanics & 8 & 1.8 & $0.8-3.8$ & 6 & 0.8 & $0.3-1.8$ & 48 \\
\hline Welders & 1 & - & & 2 & 2.5 & $0.3-13.0$ & 5 \\
\hline Painters & 0 & - & & 3 & 2.7 & $0.6-10.5$ & 7 \\
\hline Plastic, paper, printers & 2 & 1.6 & $0.2-6.3$ & 3 & 1.5 & $0.3-4.9$ & 13 \\
\hline Other industrial & 5 & 1.5 & $0.5-3.7$ & 7 & 1.3 & $0.5-2.8$ & 35 \\
\hline Transport & 7 & 1.2 & $0.5-2.6$ & 15 & 1.6 & $0.9-2.9$ & 62 \\
\hline Construction & 6 & 1.6 & $0.6-3.8$ & 10 & 1.7 & $0.8-3.4$ & 39 \\
\hline Agricultural & 5 & 1.9 & $0.6-4.8$ & 2 & 0.4 & $0.1-1.6$ & 28 \\
\hline
\end{tabular}

* ORs not directly calculable from numbers in table because of differing numbers of missing values

t First cousins or second cousins

₹ First or second grade family members of the child

$\$$ ORs of occupations with potential for chemical or physical exposure, compared with all other occupations 
agricultural occupations a strongly increased risk of open spina bifida was observed $(O R=14.3)$, whereas none of the 107 mothers of children with closed spina bifida worked in agriculture.

\section{Discussion}

In this study, classification of spina bifida into homogeneous subclasses of 'open' and 'closed' lesions was feasible but difficult, as the necessary information to classify the defects was not uniformly interpretable and often lacking. We found little correlation between the classifications into high or open, versus low or closed spina bifida. Some of the genetic and exogeneous risk factors for spina bifida seem to be specifically associated with one type of spina bifida, but risk estimates are imprecise due to small numbers. In particular, high spina bifida and open spina bifida were associated with risk factors such as the occurrence of spina bifida in siblings or other family members, maternal agricultural occupation, and paternal occupation as a welder.

We found that only three percent of the spina bifida cases had a multiple or nonisolated character, which was much lower than in other studies. ${ }^{5,6,8}$ Part of this difference can be explained by the fact that syndromes, such as Meckel's syndrome, were excluded from our study population beforehand. Also, the proportion of cases with high spina bifida $(14 \%)$ was somewhat lower than in previous studies., ${ }^{5,612}$ Lack of information in the medical records used is one possible explanation for this discrepancy. More importantly, our study population, mainly derived from pediatric units, consisted only of live-born children with inclusion of all forms of spina bifida, whereas most other studies included fetal deaths but excluded patients with spina bifida occulta. Shaw et al. showed that the proportion of multiple defects in fetal deaths was much higher than in livebirths. ${ }^{6}$ Exclusion of ten children who died after birth in one of the participating hospitals might have contributed to the underrepresentation of nonisolated spina bifida as well.

The definitions of high and low spina bifida in our study and in the abovementioned studies are based on a closure site of the posterior neuropore between the 11th thoracal and the 4th lumbar vertebral level. ${ }^{15}$ Studies of Muller and $\mathrm{O}^{\prime}$ Rahilly ${ }^{19}$ and Nievelstein et al. ${ }^{20}$ suggest that closure occurs between the second sacral and the fifth sacral vertebral level. If this second sacral junction is the correct level that distinguishes neurulation from canalization, huge misclassification has occurred in our study, which makes the results uninterpretable. According to the latter definition, the number of low spina bifida cases in our study would decrease from 173 to 24 . Additional analyses showed that this large shift of cases from low to high spina bifida indeed would affect the results of the study. For instance, the odds ratios for family history of neural tube defects would change from 6.3 for high and 2.1 for low spina bifida to 2.3 for high and 4.0 for low spina bifida. The odds ratios for siblings with a neural tube defect would change from 60.7 and 7.8 to 15.8 and 
zero (no cases). VanAllen et al. recently suggested a multi-site neural tube closure model. ${ }^{21}$ Although this model might be plausible, it cannot easily be studied in our relatively small study population. Information on the exact site of the lesion by radiographic measurements was only known for a small part of our cases. Therefore, we used the site of the skin defect that was reported in the medical record to classify the case group into high and low defects, which may have introduced misclassification.

In most studies, no distinction was made between open and closed defects as the information on the appearance of the defect was often unknown or uninterpretable. ${ }^{7}$ For the same reason in our study, 37 cases could not be classified. No pictures of the defects were available in the medical records and contradictory characteristics were sometimes used to describe a defect. Dolk and Seller concluded from a survey of European pathologists that there was often marked variation in the descriptions of photographs of neural tube defects and that the division between open and closed in terms of skin or membrane covering needs to be clearly defined. ${ }^{22}$ For instance, 'meningomyelocele' appears to be a very confusing term. Saddler describes this form of spina bifida as a defect caused by nonfusion of some vertebrae, whereas only rachischisis is described as nonfusion of the neural folds. ${ }^{17}$ Lemire, however, considers meningomyelocele as an open neurulation defect, also named myeloschisis. ${ }^{15}$ Therefore, our classification into open and closed defects was not based on these diagnoses alone but also on the appearance of the lesion, such as visibility of neural tissue and skin, and neurological aspects. The classification into open and closed might also have been hampered by the fact that an open defect can be caused by rupture of the skin during birth, and a closed defect by reepithelialisation of an open defect before or after birth. ${ }^{22}$

According to Lemire, defects that result from disturbance in the process of neurulation are located above the site of closure of the posterior neuropore, and are therefore called 'high' defects. ${ }^{15}$ In addition, he states that neurulation defects clinically present themselves as open defects with neural tissue exposed to the surface, ${ }^{16}$ implying that high spina bifida defects are open and low defects are closed. However, there was little correlation between the two classifications in our study and in other studies, 5,6 which may imply that the underlying mechanisms of neurulation and canalization are not directly deducible from a clinical presentation as open or closed.

Our study is also limited by the small number of cases in some of the subclasses of spina bifida and the low prevalences of several risk factors, resulting in imprecise estimates of effect. Some findings may thus be caused by chance. Theoretically, the loss of statistical power due to the selection of smaller case groups can be more than offset by the higher odds ratios expected in these subgroups. ${ }^{8}$ However, as most of the confidence intervals of the ORs we compared were overlapping, 
results must be interpreted cautiously. As the risk factors were retrospectively gathered from the parents in this case-referent study, information bias must be regarded as a potential limitation of the study. Whether this results in overreporting or underreporting, cannot easily be inferred.

In contrast with most other investigators, we evaluated both genetic susceptibility factors and environmental risk factors in this study. We found that infants with high spina bifida were far more likely to have family members in the first or second degree with a neural tube defect than infants with low spina bifida, which is consistent with observations in other studies. ${ }^{4,5}$ We observed slightly more females in high (sex ratio of 0.7 ) than in low (0.8) spina bifida (not presented), which largely corresponds with findings from the literature. ${ }^{4,5,14,23}$ However, Seller observed a much larger excess of females in high spina bifida (sex ratio 0.4 ) and a large male excess for low spina bifida (sex ratio 3.0 ). ${ }^{13}$

The proportion of miscarriages of siblings was similar among high and low spina bifida in our study. This was also observed by Hall et al., ${ }^{4}$ but not by Garabedian and Fraser ${ }^{14}$ nor Toriello and Higgins, ${ }^{12}$ who found higher proportions of fetal loss among siblings of cases with high spina bifida. No specific association was seen between maternal age and any subclass of spina bifida in our study, which was comparable to other studies. ${ }^{46}$ Furthermore, we found some variability in risk estimates for other characteristics. Women working in industrial occupations had a higher risk of high spina bifida than low spina bifida; fathers working as a welder had a higher risk of high spina bifida than low spina bifida. These characteristics have not been studied by others.

As mentioned before, the subclassification of open and closed spina bifida has rarely been studied. Therefore, our findings can be compared only with observations from Park et al. ${ }^{5}$ and Shaw et al. ${ }^{6}$ Infants with open spina bifida more often had family members with a neural tube defect than infants with closed spina bifida; maternal age did not differ between open and closed spina bifida. This is consistent with the literature., The variability we found for other risk factors such as oral contraceptive use shortly before conception and parental occupation could not be compared with findings from the literature.

Although our classification of spina bifida into subclasses according to site and type of defect, based on retrospectively gathered data, probably involved misclassification and numbers were small, our findings present some indications that spina bifida subclasses differ according to specific risk factors. Some differences in risks were found for occupational factors, but the largest variability was observed in genetic susceptibility factors, such as having a positive family history of neural tube defects. Research on the pathogenetic mechanisms of spina bifida has not yet provided any criteria that can be used for case definition or classification in epidemiologic studies. However, our findings suggest that researchers should try to form 
homogeneous subclasses to investigate etiologic factors of these subclasses of spina bifida, probably providing better clues to their etiology.

\section{Acknowledgements}

This study was financially supported by the Prinses Beatrix Fonds. We would like to thank the staff of the participating hospitals and dr. RA Mullaart, dr. RPM SteegersTheunissen, prof. dr. GA Zielhuis, and prof. dr. B Källén for their critical comments on the manuscript.

\section{References}

1 Elwood JM, Little J, Elwood JH. Epidemiology and control of neural tube defects. Oxford: Oxford University Press, 1992.

2 Sever LE. Looking for causes of neural tube defects: Where does the environment fit in? Environ Health Persp 1995;103 (suppl 6):165-171.

3 Holmes LB, Driscoll, SG, Atkins L. Etiologic heterogeneity of neural tube defects. N Engl I Med 1976;294:365-369.

4 Hall JG, Friedman JM, Kenna BM, Popkin J, Jawanda M, Arnold W. Clinical, genetic and epidemiological factors in neural tube defects. Am J Hum Genet 1988;43:827837.

5 Park $\mathrm{CH}$, Stewart W, Khoury MJ, Mulinare J. Is there etiologic heterogeneity between upper and lower neural tube defects? Am J Epidemiol 1992;136:1493-1501.

6 Shaw GM, Jensvold NG, Wasserman CR, Lammer EJ. Epidemiologic characteristics of phenotypically distinct neural tube defects among 0.7 million California births, 19831987. Teratology 1994;49:143-149.

7 Dolk $H$, De Wals $P$, Gillerot $Y$, Lechat MF, Ayme S, Cornel M, Cuschieri A, Garne E, Goujard J, Laurence KM, Lillis D, Lys F, Nevin N, Owens J, Radic A, Stoll C, Stone D, Ten Kate L. Heterogeneity of neural tube defects in Europe: The significance of site of defect and presence of other major anomalies in relation to geographic differences in prevalence. Teratology 1991;44:547-559.

8 Khoury MJ, Moore CA, James LM, Cordero JF. The interaction between dysmorphology and epidemiology: methodologic issues of lumping and splitting. Teratology 1992;45:133-138.

9 Khoury MJ, Erickson JD, James LM. Etiologic heterogeneity of neural tube defects: Clues from epidemiology. Am J Epidemiol 1982;115:538-548.

10 Windham GC, Bjerkedal T. Secular trends of neural tube defects by demographic subgroups in Norway, 1967-81. NIPH Annals 1982;2:57-67.

11 Seller MJ, Kalousek DM. Neural tube defects: Heterogeneity and homogeneity. Am J Med Genet Suppl 1986;2:77-87.

12 Toriello HV, Higgins JV. Possible Causal Heterogeneity in spina bifida cystica. Am J Med Genet 1985;21:13-20.

13 Seller MJ. Neural tube defects and sex ratios. Am J Med Genet 1987;26:699-707.

14 Garabedian BH, Fraser FC. Upper and lower neural tube defects: An alternate 
hypothesis. J Med Genet 1993;30:849-851.

15 Lemire RJ, Loeses JD, Leech RW, Ellsworth CA. Normal and abnormal development of the human nervous system. Hagerstown, Maryland: Harper \& Row Publishers, 1975;54-83.

16 Lemire RJ. Neural Tube Defects. JAMA 1988;259:558-562.

17 Sadler TW. Langman's medische embryologie. Tiende, herziene druk. Utrecht/Antwerpen: Bohn, Scheltema \& Holkema, 1988;352-390.

18 Martin D, Austin H. An efficient program for computing conditional maximum likelihood estimates and exact confidence limits for a common odds ratio. Epidemiol $1991 ; 2: 359-62$.

19 Müller F, O'Rahilly R. The development of the human brain, the closure of the caudal neuropore, and the beginning of secondary neurulation at stage 12. Anat Embryol 1987;176:413-430.

20 Nievelstein RAJ, Hartwig NG, Vermeij-Keers C, Valk J. Embryonic development of the mammalian caudal neural tube. Teratology 1993;48:21-31.

21 Van Allen MI, Kalousek DK, Chernoff GF, Juriloff D, Harris M, McGillivray BC, Yong SL, Langlois S, McLeod PM, Chitayat D, Redman JM, Wilson RD, McFadden D, Pantzar J, Ritchie S, Hall JG. Evidence for multi-site closure of the neural tube in humans. Am J Med Genet 1993;47:723-743.

22 Dolk H, Seller MJ. Neural tube defects: A survey of lesion descriptions made by different European pathologists. J Med Genet 1993;30:942-946.

23 Källén B, Cocchi G, Knudsen LB, Castilla EE, Robert E, Daltveit AK, Lancaster PL, Mastroiacovo $\mathrm{P}$. International study of sex ratio and twinning of neural tube defects. Teratology 1994;50:322-331. 
CHAPTER 6 REGISTRY-BASED STUDIES IN EUROPE 


\title{
CHAPTER 6.1
}

\section{SPINA BIFIDA AND PARENTAL OCCUPATION IN A SWEDISH REGISTER-BASED STUDY}

\author{
BM Blatter, N Roeleveld \\ Scand J Work Env Hea 1996;22:433-437 \\ with the permission of the Scand J Work Environ Health
}

\begin{abstract}
Objectives To gather more evidence on a possible relation between spina bifida and agricultural and other occupations of parents, a register-based linkage study was conducted in Sweden.

Methods Four hundred eighty-two cases of spina bifida in infants born between 1976 and 1991 were identified from the Swedish Register of Congenital Malformations. Nine hundred and sixty-four referents without spina bifida were selected from the Medical Birth Register and matched for year of birth of the child, maternal age, and parity. Information on occupation was obtained from the Medical Birth Register from 1983 on, and from the census, which is performed every fifth year.

Results A slightly increased odds ratio (OR) was observed for women in agricultural occupations $[\mathrm{OR}=1.8,95 \%$ confidence interval $(95 \% \mathrm{Cl})$ 0.8-4.2]. For all women who had an agricultural occupation or lived on a farm, the OR was 2.2 (95\% Cl: 1.3-3.8). The OR values of most of the other occupational groups were close to unity.

Conclusions The results suggest an increased risk of spina bifida for the infants of women in agricultural occupations, but do not provide insight into any specific occupational risk factors.
\end{abstract}

\section{Introduction}

As spina bifida exhibits a strong variation by socioeconomic status in several countries, ${ }^{1}$ a search for environmental causes is indicated. Since classifications of socioeconomic status are primarily based on occupation, the presence of potential teratogens in the work environment may be an explanation for the differential prevalence rates by socioeconomic class, in addition to differing life-style factors. Maternal occupational exposure around conception and up to the 28th day of embryonic development could have a direct effect on the morphogenesis of the neural tube. Paternal chemical occupational exposure could theoretically result in genetic damage to germ cells ${ }^{2}$ and 
introduce teratogenic substances in the seminal fluid at conception or later during embryonic development. ${ }^{3,4}$

Studies specific to neural tube defects and parental occupation have been scarce. Most studies include congenital anomalies in general or defects of the central nervous system (CNS) as a group, including neural tube defects. In these studies, some associations have been found for women working in industry, construction, transport and communication, ${ }^{5,6}$ dental surgeries, ${ }^{7}$ nursing ${ }^{8}$ and for women exposed to organic solvents. ${ }^{9}$ Studies on fathers yielded increased risks for painters, ${ }^{10}$ agricultural workers, ${ }^{11}$ workers in the food, beverage, wood and textile industries, ${ }^{12}$ and fathers exposed to low-level radiation. ${ }^{13}$

Studies that focussed on neural tube defects in particular or as one of the main categories of congenital defects have revealed increased risks for women working as hairdressers ${ }^{14}$ and farmers ${ }^{14,15}$ and for men working as painters, ${ }^{16-18}$ printers, decorators, transport and communication workers, ${ }^{16}$ plastic production workers, ${ }^{18}$ and farmers and bricklayers. ${ }^{14}$ It should be stressed, however, that except for male painters and male and female agricultural workers, very few findings have been repeated in two or more studies.

Recently, we conducted a case-referent study on spina bifida and parental occupation in the Netherlands. Postal questionnaires and personal interviews were used to collect data on occupation and occupational exposure, respectively. Increased risks were suggested for fathers working as a welder or transport worker, for cleaningwomen, and especially for women working in agriculture $(\mathrm{OR}=5.6,95 \% \mathrm{Cl}: 1.8-17.8){ }^{19}$ However, no association was found between spina bifida and maternal pesticide use or any other agriculture-related exposure, but the numbers of exposed workers were small. ${ }^{20}$ A Finnish study did not find an association between pesticide use and central nervous system defects, either. ${ }^{21}$

To gather more evidence about a potential relation between spina bifida and parental agricultural occupations, we conducted a register-based case-referent study. Furthermore, we also evaluated the risk of other occupations with a potential for chemical or physical exposure.

\section{Subjects and methods}

\section{Subjects}

The subjects were identified from the Swedish Register of Congenital Malformations. ${ }^{22}$ This register became compulsory in 1965 and covers live births, stillbirths, and prenatally diagnosed malformations from all of Sweden from 1973 on. Using the unique personal identification number of the mother or the child or both, the register was linked with the Medical Birth Register, which covers all live births and stillbirths in 
Sweden from 1973 on. The maternal identification numbers and birthdate of the children identify whether the same case appears in both registers.

In this study, 482 infants with spina bifida aperta (International Classification of Diseases (ICD-9) codes 741.0 and 741.9$)^{23}$ were included. Because occupational information was not available for every year of birth of the children, we could only include children born in 1976, 1981, or between 1983 and 1991. As a consequence of the linking procedure, only live births and stillbirths have been included in our study. For each case, two referents without spina bifida were selected from the Medical Birth Register, matched for year of birth of the child, maternal age in five-year classes, and parity (first, second, third, and fourth or subsequent child). As a result, 964 referents were included.

\section{Data collection}

Information on occupation was obtained from two sources. The first source of occupational information was the census, which was linked with the Medical Birth Register. Performed every fifth year, the census provides a large amount of information on each individual in Sweden. Census information on maternal and paternal occupation is coded centrally by Statistics Sweden using the Nordic Classification of Occupations. In this case-referent study the three-digit code was used. Because of a special interest in agriculture and the fact that farming occupations may be underreported by women, we also abstracted information on housing, particularly living on a farm, from the census. Census information from 1975 was used for infants born in 1976, from 1980 for infants born in 1981, and from 1985 for infants born in 1985 or 1986. Information on paternal occupations was only available in the census from 1985, which was linked with births in 1985 and 1986.

The second source of occupational information was the Medical Birth Register, which has been collecting information on maternal occupation since 1983. The occupational information in the Medical Birth Register is based on interviews performed by midwives at the first visit of the pregnant woman to the maternity health service, usually at weeks 10-12. The actual occupation of the woman is recorded verbatim. In the present study, this information was translated into the three-digit code of the Nordic Classification of Occupations for infants who were born between 1983 and 1991. The coding was done without knowledge of the case-referent status of the child.

To assess whether someone had an occupation with potential exposure to chemical or physical agents, we primarily used the census information on occupation. As more detailed information on occupation is gathered in the census, it is more often precise and complete. When no census information was available, the occupational information in the Medical Birth Register was used. Table 6.1.1 shows the distribution of cases and referents according to year of birth and the source of information that was used to assess the occupation of the mothers in that specific year of birth. Census 
information was used for one-third of all the cases and referents; the Medical Birth Register was used in all other cases. The table also shows the years in which information on housing, smoking, socioeconomic status (SES), and geographic area was available.

TABLE 6.1.1 Cases and referents by year of birth and source of information on occupation, socioeconomic status, housing, smoking, and geographic area. (MBR = Medical Birth Register)

\begin{tabular}{lcclllll}
\hline \multirow{2}{*}{ Year of birth } & Cases & Referents & \multicolumn{5}{c}{ Source of information } \\
\cline { 5 - 8 } & $(\mathrm{N})$ & $(\mathrm{N})$ & $\begin{array}{l}\text { Maternal } \\
\text { Occupation }\end{array}$ & SES & Housing & Smoking & $\begin{array}{l}\text { Geographic } \\
\text { area }\end{array}$ \\
\hline 1976 & 46 & 92 & census & - & census & - & MBR \\
1981 & 41 & 82 & census & - & census & - & MBR \\
1983 & 38 & 76 & MBR & - & - & MBR & MBR \\
1984 & 41 & 82 & MBR & - & - & MBR & MBR \\
1985 & 48 & 96 & census & census & census & MBR & MBR \\
1986 & 53 & 106 & census & census & census & MBR & MBR \\
1987 & 66 & 132 & MBR & - & - & MBR & MBR \\
1988 & 41 & 82 & MBR & - & - & MBR & MBR \\
1989 & 54 & 108 & MBR & - & - & MBR & MBR \\
1990 & 52 & 104 & MBR & - & - & MBR & MBR \\
1991 & 2 & 4 & MBR & - & - & MBR & MBR \\
Total & 482 & 964 & & & & & \\
\hline
\end{tabular}

\section{Analysis}

Matched univariate analyses were done for the triplets of the cases and referents, odds ratios (OR) being calculated by means of Mantel-Haenszel estimates with $95 \%$ confidence intervals. ${ }^{24}$ We included smoking in three classes (no smoking, 0-10 cigarettes, $>10$ cigarettes), socioeconomic status in four classes (blue collar workers, middle-class white collar workers, academics and executives, and farmers) and geographic area in five classes (southeast, south, southwest, middle, and north) as potential confounders. The subjects whose status was unknown due to lack of data were not excluded from the analyses but were insteas included as a separate category.

\section{Results}

Table 6.1.2 presents the distributions of the maternal agricultural occupations and other selected maternal occupations with potential for chemical exposure. Of the case mothers, 130 were housewives and $339(70 \%)$ worked outside the home, compared with 230 and $708(73 \%)$, respectively, of the reference mothers. The remaining mothers were students or had occupations that could not be classified. 
TABLE 6.1.2 Number of cases and referents and Mantel-Haenszel odds ratios with $95 \%$ confidence intervals $(95 \%, \mathrm{Cl})$ for maternal occupational categories with potential for exposure to chemical or physical agents.

\begin{tabular}{|c|c|c|c|c|}
\hline Occupation & $\begin{array}{c}\text { Cases } \\
(\mathrm{N}=482)\end{array}$ & $\begin{array}{l}\text { Referents } \\
(\mathrm{N}=964)\end{array}$ & $\overline{\mathrm{OR}}$ & $95 \% \mathrm{Cl}$ \\
\hline Agricultural workers & 10 & 11 & 1.8 & $0.8-4.2$ \\
\hline All agricultural women* & 32 & 30 & 2.2 & 1.3-3.6 \\
\hline Nurses & 16 & 29 & 1.1 & $0.6-2.1$ \\
\hline Nurse aids & 52 & 119 & 0.9 & $0.6-1.2$ \\
\hline Other health care workers & 18 & 49 & 0.7 & $0.4-1.3$ \\
\hline Cleaners & 16 & 28 & 1.2 & $0.6-2.1$ \\
\hline Hairdressers & 1 & 9 & 0.2 & $0.0-1.4$ \\
\hline Industry and transport workers & 22 & 43 & 1.0 & $0.6-1.7$ \\
\hline Printing, paper and plastic workers & 6 & 7 & 1.7 & $0.6-5.0$ \\
\hline Non-exposed occupations and housewives & 334 & 650 & - & - \\
\hline
\end{tabular}

* Exposed: maternal agricultural occupation or living on a farm

An increased risk was observed for women in agricultural occupations $(O R=1.8$, $95 \% \mathrm{Cl}: 0.8-4.2$ ). Five case mothers and seven reference mothers were working proprietors in agriculture, two case mothers were livestock or poultry farm workers, two case mothers and three reference mothers were horticultural workers, and one case and one reference mother were fur-bearing animal workers. When we included all women who had an agricultural occupation or lived on a farm in the exposed category, the odds ratio increased to 2.2 (95\% Cl: $1.3-3.8)$.

Although our main interest focused on agricultural occupations, we were also able to study associations between spina bifida and some other potentially exposed occupations. A decreased odds ratio of $0.2(95 \% \mathrm{Cl}: 0.0-1.4)$ was observed for hairdressers. No effect was found for the total group of industry and transport workers $(O R=1.0)$, but when only women who worked in the printing, paper or plastic industry were considered, an increased odds ratio of 1.7 (95\% Cl: 0.6-5.0) was seen. However, the numbers were small and the confidence interval did not exclude unity. The odds ratios of all the other occupational categories were close to unity.

Only 81 case fathers and 162 reference fathers could be included in the analysis due to lack of data on paternal occupation (Table 6.1.3). Increased odds ratios were found for paternal agricultural occupations $(\mathrm{OR}=1.6,95 \% \mathrm{Cl}$ : $0.6-4.5)$, and for solventexposed fathers $(\mathrm{OR}=2.6,95 \% \mathrm{Cl}: 0.7-10.4)$. However, the $95 \%$ confidence intervals for both odds ratios did not exclude unity.

Smoking, socioeconomic status, and geographic area were included in the analyses as potential confounders. They did not confound the relation between spina bifida and maternal or paternal occupation. 
TABLE 6.1.3 Number of cases and referents and Mantel-Haenszel odds ratios with $95 \%$ confidence intervals for paternal occupational categories with potential for exposure to chemical or physical agents.

\begin{tabular}{lcccc}
\hline Occupation & $\begin{array}{c}\text { Cases } \\
(\mathrm{N}=81)\end{array}$ & $\begin{array}{c}\text { Referents } \\
(\mathrm{N}=162)\end{array}$ & OR & $95 \% \mathrm{Cl}$ \\
\hline Agricultural workers & 7 & 9 & 1.6 & $0.6-4.5$ \\
Health care & 0 & 3 & - & - \\
Transport and communication workers & 5 & 14 & 0.7 & $0.2-2.0$ \\
Industrial workers & 24 & 45 & 1.1 & $0.6-1.9$ \\
$\quad$ Printing, painting, paper and plastic workers & 5 & 4 & 2.6 & $0.7-10.4$ \\
Non-exposed occupations & 45 & 91 & - & - \\
\hline
\end{tabular}

\section{Discussion}

The results of this register-based study point to a slightly increased risk for women working in agriculture. When only women with agricultural occupations were assigned to the exposed category, an odds ratio of 1.8 was observed (95\% Cl: 0.8-4.2). However, women who perform agricultural tasks at home may call themselves housewives and may thus be misclassified with respect to exposure status. Therefore, women living on a farm were included in the exposed category as well, yielding an odds ratio of 2.2 (95\% Cl: 1.3-3.8). As information on housing was only available for births in 1976, 1981, 1985 and 1986, however, some people may still be misclassified according to this broader definition.

The rather broad category of agricultural workers that we used in this study may comprise a diversity of tasks and activities and varying chemical or physical exposures. Due to small numbers, however, it was not possible to subdivide this category into homogeneously exposed groups. As a result, random misclassification might have biased the odds ratios towards the null value.

In our study, infants with spina bifida were selected from the Register of Congenital Malformations. In this register, every diagnosis that is doubtful or unclear is checked with original hospital records. Therefore, diagnostic specificity is high. ${ }^{25}$ For spina bifida the sensitivity is estimated to be $80-90 \% .{ }^{26}$

Prenatally diagnosed malformations leading to elective abortions could not be included in the study. Theoretically this exclusion may have introduced some selection bias. However, it should be stressed that the majority of Swedish women get at least one ultrasound screening during pregnancy free of charge. As any possible effect of prenatal screening may be largest among the older mothers and in more recent periods, we stratified our analyses according to age and calendar year. No differences in odds ratios were found between mothers above 27 years of age and those 27 years of age or younger; differences between the women who gave birth before and after 1985 were also negligible. 
Because the neural tube is closed in the fourth week of pregnancy, occupational exposure in the first month of pregnancy is of interest. However, information is recorded in the Medical Birth Register at weeks 10-12 of pregnancy, and census information is collected at five-year intervals and linked with births in the following year. Therefore, occupation may have been misclassified if the recorded occupation was not the same as the occupation in the relevant period. ${ }^{27}$ As women usually do not stop working until the end of their pregnancy, we did not expect this type of misclassification to be large. Occupations could be derived from the census in one third of all cases and referents. Census information is usually not collected during pregnancy at all; however, because it is more complete and precise, census data were preferred to the Medical Birth Register. According to Ericson et al., ${ }^{28,29}$ the accuracy of census information varied between $88 \%$ and $98 \%$. The fact that information was collected before birth or even before pregnancy has the advantage that information on cases and referents with respect to exposures is comparable, and information bias is not likely.

A disadvantage of using routinely collected data is that the coding of occupations has received little attention when compared with specifically designed case-referent studies using questionnaires or interviews. In addition, a limitation of this study is that most of the other risk factors of interest, such as a family history of neural tube defects, consanguinity, dietary factors, vitamin use and use of anti-epileptic agents or ovulation stimulating agents, could not be taken into consideration in the analyses since information on these variables was not available in the Medical Birth Register or census. As a result, the odds ratios may be biased towards or away from the null value. A higher rate of consanguinity might theoretically be expected in rural populations, and such a difference might partly explain the increased odds ratio found for agriculture. However, this was not the case in our Dutch study on spina bifida and parental occupation ${ }^{19}$ and so is therefore not expected in Sweden either. Adjustment for socioeconomic status and geographic area did not change the results. In The Netherlands, the only confounder was a family history of neural tube defects.

As information on paternal occupations was only available from census data in 1985, a small number of 81 case fathers and 162 reference fathers was included in the analyses. Therefore, the confidence intervals were wide and the point estimates for the paternal occupations have to be interpreted very carefully.

In the literature, some evidence is found for an association between spina bifida and maternal agricultural occupations. Although the risk observed in our study was only slightly increased, it agrees with the results reported in the literature. In a previous study in Sweden, Ericson et al. ${ }^{15}$ stated that no statistically significant association could be found between neural tube defects and any type of occupation, even though they did find an odds ratio of 7.1 for mothers in agricultural occupations. The $95 \%$ confidence interval, which was not presented because of small numbers, ranged from 1.4 to 35.2. It is worth noting, however, that approximately one third of the cases in our study was 
probably also included in the study of Ericson et al. A small-scale study in Venezuela showed largely differing frequencies of agricultural occupations among 76 cases of neural tube defects and 76 referents: $8 \%$ compared with $0 \%$ among the mothers and $32 \%$ compared with $13 \%$ among the fathers. ${ }^{14}$ Moreover, a study in England on congenital malformations among offspring of agricultural workers showed that 'gardeners and groundsmen' had increased ratios for spina bifida, anencephaly, and facial clefts, while 'agricultural workers' had increased ratios for spina bifida and facial clefts. ${ }^{11}$ In a questionnaire-based case-referent study that we recently performed in the Netherlands, an increased risk of $5.6(95 \% \mathrm{Cl}: 1.8-17.8)$ was found for women in agricultural occupations as well. ${ }^{19}$

A specific teratogenic agent that might be responsible for the increased risk found in our study and in the literature could not be identified in this register-based study. However, directions for further and more detailed research into the association between spina bifida and maternal agricultural occupations can be inferred.

\section{Acknowledgements}

The authors are obliged to A Ericson and J Gunnarskog (bcn) from the National Board of Health and Social Welfare in Stockholm, Sweden, for the linkage of the data and to B Källen for his help with the statistical analyses and his critical comments on the manuscript. This study was financially supported by the Prinses Beatrix Fonds and The Netherlands Organization for Scientific Research (NWO).

\section{References}

1 Little \}, Elwood JH. Socioeconomic status and occupation. In: Elwood JM, Little J, Elwood JH, editors. Epidemiology and control of neural tube defects. Monographs in epidemiology and biostatistics, vol 20. Oxford: Oxford University Press, 1992:456-520.

2 Brown NA. Are offspring at risk from their father's exposure to toxins? Nature 1985;316:110.

3 Hales BF, Smith S, Robaire B. Cyclophosphamide in the seminal fluid of treated males: Transmission to females by mating and effect on pregnancy outcome. Toxicol Appl Pharm 1986;84:423-430.

4 Colie CF. Male mediated teratogenesis. Reprod. Toxicol. 1993;7:3-9.

5 Hemminki K, Mutanen P, Luoma K, Saloniemi I. Congenital malformations by the parental occupation in Finland. Int Arch Occup Environ Health 1980;46:93-98.

6 Hemminki K, Mutanen P, Saloniemi I, Luoma K. Congenital malformations and maternal occupation in Finland: multivariate analysis. J Epidemiol Community Health 1981;35: 5-10.

7 Sikorski R, Juszkiewicz T, Paszkowski T, Sprengier-Juszkiewicz T. Women in dental surgeries: reproductive hazards in occupational exposure to metallic mercury. Int Arch Occup Environ Health 1987;59:551-557. 
8 Matte TD, Mulinare J, Erickson JD. Case-control study of congenital defects and parental employment in health care. Am J Ind Med 1993;24:11-23.

9 Holmberg PC, Nurminen M. Congenital defects of the central nervous system and occupational factors during pregnancy. A case-referent study. Am J Ind Med 1980;1:167176.

10 Olsen J. Risk of exposure to teratogens amongst laboratory staff and painters. Dan Med Bull 1983;30:24-28.

11 Balarajan R, McDowall M. Congenital malformations and agricultural workers (Letter). Lancet 1983;I:1112-1113.

12 McDonald AD, McDonald JC, Armstrong B, Cherry NM, Nolin AD, Robert D. Fathers' occupation and pregnancy outcome. Br J Ind Med 1989;46:329-333.

13 Sever LE, Gilbert ES, Hessol NA, Mclntyre JM. A case-control study of congenital malformations and occupational exposure to low-level ionizing radiation. Am J Epidemiol 1988; 127:226-242.

14 Hammond FG, Canache MF. Some epidemiological aspects of neural tube defects in Barquisimeto, Venezuela. Abstract. Am J Hum Genet 1991;49, suppl., 470.

15 Ericson A, Källén B, Löfkvist E. Environmental factors in the etiology of neural tube defects: a negative study. Environ Res 1988;45:38-47.

16 Fedrick J. Anencephalus in the Oxford Record Linkage Study Area. Dev Med Child Neurol 1976;18:643-656.

17 Olshan AF, Teschke K, Baird PA. Paternal occupation and anomalies in offspring. Am $J$ Ind Med 1991;20:447-475.

18 Brender CJ, Suarez L. Paternal occupation and anencephaly. Am J Epidemiol 1990;131: 517-521.

19 Blatter BM, Roeleveld N, Zielhuis GA, Mullaart RA, Gabreëls FJM. Spina bifida and parental occupation. Epidemiology 1996;7:188-193.

20 Blatter BM, Roeleveld N, Zielhuis GA, Gabreëls FIM, Verbeek ALM. Maternal occupational exposure during pregnancy and the risk of spina bifida. Occup Environ Med 1996;53:80-86.

21 Nurminen T, Rantala K, Kurppa K, Holmberg PC. Agricultural work during pregnancy and selected structural malformations in Finland. Epidemiology 1995;6:23-30.

22 Källén B, Winberg J. Swedish register of congenital malformations. Experience with continuous registration during two years with special reference to multiple malformations. Pediatrics 1968;41:765.

23 World Health Organization. International Classification of Diseases, Ninth Revision. Geneva, Switzerland: World Health Organization, 1977.

24 Rothman KJ. Modern epidemiology. Boston: Little, Brown and Company, 1986;237-283.

25 Ericson A, Källén B, Winberg J. Surveillance of malformations a birth: a comparison of two record systems run in parallel. Int J Epidemiol 1977;6:335-341.

26 Källén B, Löfkvist E. Time trends of spina bifida in Sweden 1947-81. J Epidemiol Community Health 1984;38:103-107. 
27 Shaw GM, Gold E. Methodological considerations in the study of parental occupational exposures and congenital malformations in offspring. Scand J Work Environ Health 1988;14:344-355.

28 Ericson A, Eriksson $M$, Källén B, Westerholm P, Zetterström R. Delivery outcome of women working in laboratories during pregnancy. Arch Environ Health 1984;39:5-10.

29 Ericson A, Källén B. An epidemiological study of work with video screens and pregnancy outcome. II. A case-control study. Am J Ind Med 1986;9:459-475. 


\title{
CHAPTER 6.2
}

\section{SPINA BIFIDA AND PARENTAL OCCUPATION: RESULTS FROM THREE MALFORMATION MONITORING PROGRAMS IN EUROPE}

BM Blatter, N Roeleveld, E Bermejo, ML Martínez-Frías, C Siffel, AE Czeizel Submitted for publication

\begin{abstract}
Study objective As the evidence for an association between spina bifida and parental agricultural occupations is inconclusive, we evaluated this association and the potential associations between spina bifida and other parental occupations. Design Three register-based case-referent studies were conducted in Sweden, Spain, and Hungary. Four hundred eighty-two, 478, and 1119 cases with spina bifida were identified from the registries of congenital malformations in each country, respectively. Nine-hundred sixty-four, 434 and 1489 referent children without abnormalities were identified as referents. Information on parental occupation was available in the registries from questionnaires or interviews conducted with the parents. Occupations with a potential for physical or chemical exposure were compared with non-exposed occupations.

Main results Increased odds ratios (ORs) were observed for women in agricultural occupations in Sweden $(\mathrm{OR}=1.8,95 \% \mathrm{Cl}$ : 0.8-4.2) and in Spain $(\mathrm{OR}=2.2,95 \% \mathrm{Cl}$ : 0.8-5.9), but not in Hungary $(O R=1.1,95 \% \mathrm{Cl}$ : 0.7-1.7). A number of other occupations of mothers and fathers seem to be associated with spina bifida as well, although not always consistently.
\end{abstract}

Conclusions The results are not totally consistent but point to an increased risk of spina bifida among women in agricultural occupations.

\section{Introduction}

As the occurrence of spina bifida varies strongly with socioeconomic status in several countries, ${ }^{1}$ a search for occupational and environmental causes, next to dietary factors, seems indicated. Maternal occupational exposure before conception and up to the 28th day of postconceptional development may have a direct effect on the morphogenesis of the neural tube. Paternal occupational exposure could result in genetic damage to germ cells ${ }^{2}$ and in the presence of teratogenic substances in the 
seminal fluid, ${ }^{3,4}$ which might lead to neural tube defects also.

Studies on neural tube defects have revealed an increased risk of spina bifida for women working as nurses ${ }^{5}$ and hairdressers, ${ }^{6}$ and for agricultural workers. ${ }^{6,7}$ Among men a threefold increased risk was found for painters, both for spina bifida and anencephaly. ${ }^{8-10}$ Other studies showed an increased risk of spina bifida for printers, transport and communication workers, ${ }^{8}$ agricultural workers, bricklayers, ${ }^{6}$ welders, electronic equipment operators, policemen, and vehicle manufacturers." It should be stressed that except for male painters and male and female agricultural workers, very few findings have been repeated in two or more studies.

Recently, we conducted a case-referent study on spina bifida and parental occupation in The Netherlands. ${ }^{12}$ Increased risks were observed for fathers working as a welder $(O R=2.1$ ) or transport worker $(O R=1.4)$, for cleaning women $(O R=1.9$ ), and particularly-for women working in agriculture $(O R=5.6,95 \% \mathrm{Cl}$ : $1.8-17.8)$. However, no associations were found between spina bifida and maternal pesticide use or any other agriculture-related exposure, but numbers of exposed were small. ${ }^{13}$ A Finnish study did not find an association between pesticide use and central nervous system defects either. ${ }^{14}$

To get more support for the hypothesis of a relation between agricultural occupations and spina bifida, data were used from registries that were members or former members of the International Clearinghouse for Birth Defects Monitoring Systems. ${ }^{15}$ Three studies were conducted in Sweden, Spain, and Hungary, with some differences in methodology, study population and data collection. In addition to agricultural occupations, we also evaluated associations with other parental occupations that were previously associated with spina bifida.

\section{Population and methods}

European registries for congenital malformations were selected from the International Clearinghouse for Birth Defects Monitoring Systems 1991 membership list, based on the following criteria:

- case-referent design of the registry or the possibility to collect information on suitable referent children

- relatively large number of cases with spina bifida included in registry

- information on parental occupation available in registry

Of the four registries that fulfilled these criteria, the registries of Seden, Spain and Hungary participated in this study.

\section{Sweden}

Subjects were identified from the Swedish Registry of Congenital Malformations. ${ }^{16}$ This registry, which is compulsory, includes all live born and stillborn children with malformations, as well as prenatally diagnosed malformations from all of Sweden 
from 1973 onwards. Using the unique personal identification number of the mother and the child, the registry was linked with the census and with Medical Birth Registry, which covers all live births and stillbirths in Sweden from 1973 onwards.

In this study, 482 infants with spina bifida aperta (International Classification of Diseases $^{17}$ (ICD-9) codes 741.0 and 741.9) born in 1976, 1981, or between 1983 and 1991 were included, as occupational information could only be collected for those years of birth. As a consequence of the linkage with the Medical Birth Registry, only live births and stillbirths could be included. For each case, two referents without spina bifida were selected from the Medical Birth Registry, matched on year of birth of the child, maternal age in five-year classes, and parity.

Information on parental occupation and the potential confounders smoking, socioeconomic status and geographical region was obtained from the census and the Medical Birth Registry. Performed every fifth year, the census provides information on each individual in Sweden. For the mothers, we used information from the census of 1975, 1980, 1985, and 1990 for children born in the following year. Information on occupations of the father was only available in the census from 1985, which was linked with births in 1985 and 1986. In the Medical Birth Registry, information on maternal occupation had been collected since 1983 during interviews performed by midwives at the first visit of the pregnant woman to the maternity health service, usually at weeks 10 through 12 . The information on occupation was coded into the three-digit code of the Nordic Classification of Occupations. To assess someone's job title for the present case-referent study, the census information was used when available. For the other birth years, the Medical Birth Registry was used.

Matched univariate analyses were done for the triplets of cases and referents, calculating odds ratios (OR) by means of Mantel-Haenszel estimates with $95 \%$ confidence intervals, ${ }^{18}$ comparing every index occupation with all the other occupations. Due to limited availability of information, only smoking, socioeconomic status and geographical region could be included as potential confounders in the multivariate analysis.

\section{Spain}

Data were derived from the Spanish Collaborative Study of Congenital Malformations (ECEMC), which is a hospital-based surveillance system of case-referent design. For each case, the next non-malformed infant of the same sex born in the same hospital is selected as a referent. Between 1976 and 1980, only live births were recorded; from 1980 onwards, stillborn children with malformations were also included in the registry. Given that in most instances no comparable referent children could be found for stillborn cases, referent babies were only selected for liveborn cases. Detailed descriptions of the ECEMC methodology have been published previously. ${ }^{19,20}$ 
For this study, we identified 478 children with spina bifida who were born between 1976 and 1993. Of these cases, 32 were stillborn. The specific diagnoses were identified by the staff of the ECEMC and clinical geneticists, by carefully analyzing a large amount of clinical information. Referents were 434 liveborn healthy children.

Mothers of cases and referents were interviewed by the same physicians within three days after birth, to gather information on, among others, family history, maternal alcohol use and smoking, chronic diseases, use of medical drugs and vitamin supplements, and maternal and paternal occupation. The time period that the questions on exposure generally referred to was the total gestational period and not specifically the period around conception. Occupations were coded by the staff of the ECEMC, using a detailed coding system. Grouping of the occupational codes was performed in a manner comparable to the Dutch case-referent study. ${ }^{12}$

Both crude and adjusted odds ratios with $95 \%$ confidence intervals were calculated. Homemakers, clerical and managerial workers, teachers, household personnel and shop assistants were defined as nonexposed occupations and were used as the reference category. With regard to the mothers, housewives made up $82 \%$ of the reference category. Adjusted odds ratios were calculated in univariate analyses, including maternal age, parity, smoking, use of valproic acid, fetal loss, and a positive family history for neural tube defects as potential confounders one by one. Only those variables that changed the crude odds ratio substantially (more than $10 \%$ ) were included in the final multivariate analyses.

\section{Hungary}

The Hungarian data were derived from the Hungarian Case Control Surveillance of Congenital Abnormalities (HCCSCA). ${ }^{21,22}$ Notification of congenital abnormalities is obligatory and is done by obstetricians, paediatricians, and pathologists. Information is collected on all malformed stillborn and live-born cases diagnosed from birth to the age of 1 year. Prenatally diagnosed and electively aborted malformed fetuses have also been registered in recent years. Before 1989, two referent children without an abnormality were matched to every case according to sex, birthweek, and parents' residence. Since 1989, three referents are matched to one case, because non-reponse appeared to be much higher among referent parents. For this study, we identified 1119 cases with spina bifida and 1489 referent children, all born between 1980 and 1992.

In the Hungarian registry, a postal questionnaire is sent to mothers of malformed babies and referents within one month after being reported to the registry. The questionnaire requests data on medical drug use and diseases, as well as on workplace, occupation, social class, age, parity, and family history. The questions on exposure refer to the total time period during pregnancy. Occupational data were 
coded by HCCSCA staff into main workplace categories and the official Hungarian occupational three-digit code system (FEOR). In this study, the grouping of the occupations was primarily based on this code system. Persons who were classified as having an unknown occupation or as 'other industrial workers', 'unskilled workers', or 'other physical workers' were reclassified where possible into one of the specified occupational categories according to the two-digit workplace classification.

Both crude and adjusted odds ratios with $95 \%$ confidence intervals were calculated. As in the Spanish analysis, all the nonexposed occupations, including homemakers, clerical and managerial workers, teachers, household personnel and shop assistants, were used as the reference category. Only a small part of the Hungarian reference group consisted of housewives. As a special code for housewives was not included in the FEOR, the exact proportion could not be calculated. Potential confounders were parity, maternal diabetes, use of valproic acid, ovulation stimulating agents, oral contraceptives, folic acid and vitamin A supplements, fetal loss, and a positive family history for neural tube defects. Adjusted odds ratios were calculated identically to the Spanish analysis.

\section{Results}

Limited information was available on potential confounders in Sweden. Table 6.2.1 presents the distribution of the potentially confounding factors in the Spanish and the Hungarian substudies. The two countries are hardly comparable with respect to the distributions of most variables. Case mothers were slightly older than referent mothers, which was more evident in the Spanish than the Hungarian population. Spanish case mothers smoked less than referent mothers, which was also true in the Swedish population ( $24 \%$ versus $32 \%$, respectively). In the Hungarian registry, no data were collected on smoking and alcohol use.

Tables 6.2.2-6.2.7 present the results for the maternal and paternal occupations. Occupations have been grouped in a comparable way in the 3 studies as much as possible; differences are due to varying numbers of workers in subcategories and inconsistencies in job titles. For the Swedish population, crude ORs are presented (Tables 6.2.2 and 6.2.5). The crude ORs from Spain (Tables 6.2.3 and 6.2.6) were adjusted for a positive family history of neural tube defects. In the Hungarian study population, adjustment for the factors listed in Table 6.2.1 did not change the ORs, so only crude ORs are given (Tables 6.2.4 and 6.2.7).

Increased ORs for women in agricultural occupations were found in Sweden $(O R=1.8,95 \% \mathrm{Cl}: 0.8-4.2)$ and in Spain $\left(\mathrm{OR}_{\mathrm{adj}}=2.2,95 \% \mathrm{Cl}\right.$ : 0.8-5.9), but not in Hungary $(O R=1.1,95 \% \mathrm{Cl}: 0.7-1.7)$. The overall Mantel-Haenszel $\mathrm{OR}$, stratified by country, was $1.4(95 \% \mathrm{Cl}: 1.2-1.5)$. When we included in the exposed category only those agricultural women whose husband also worked in agriculture, the $\mathrm{OR}_{\text {spain }}$ was 1.7 (95\%Cl: 0.5-6.1), the $\mathrm{OR}_{\text {Hungary }}$ was $2.0(95 \% \mathrm{Cl}$ : 0.8-4.8). In Sweden, only one case and three referents were exposed according to this definition. 
TABLE 6.2.1 Distribution of maternal characteristics in Spain and Hungary

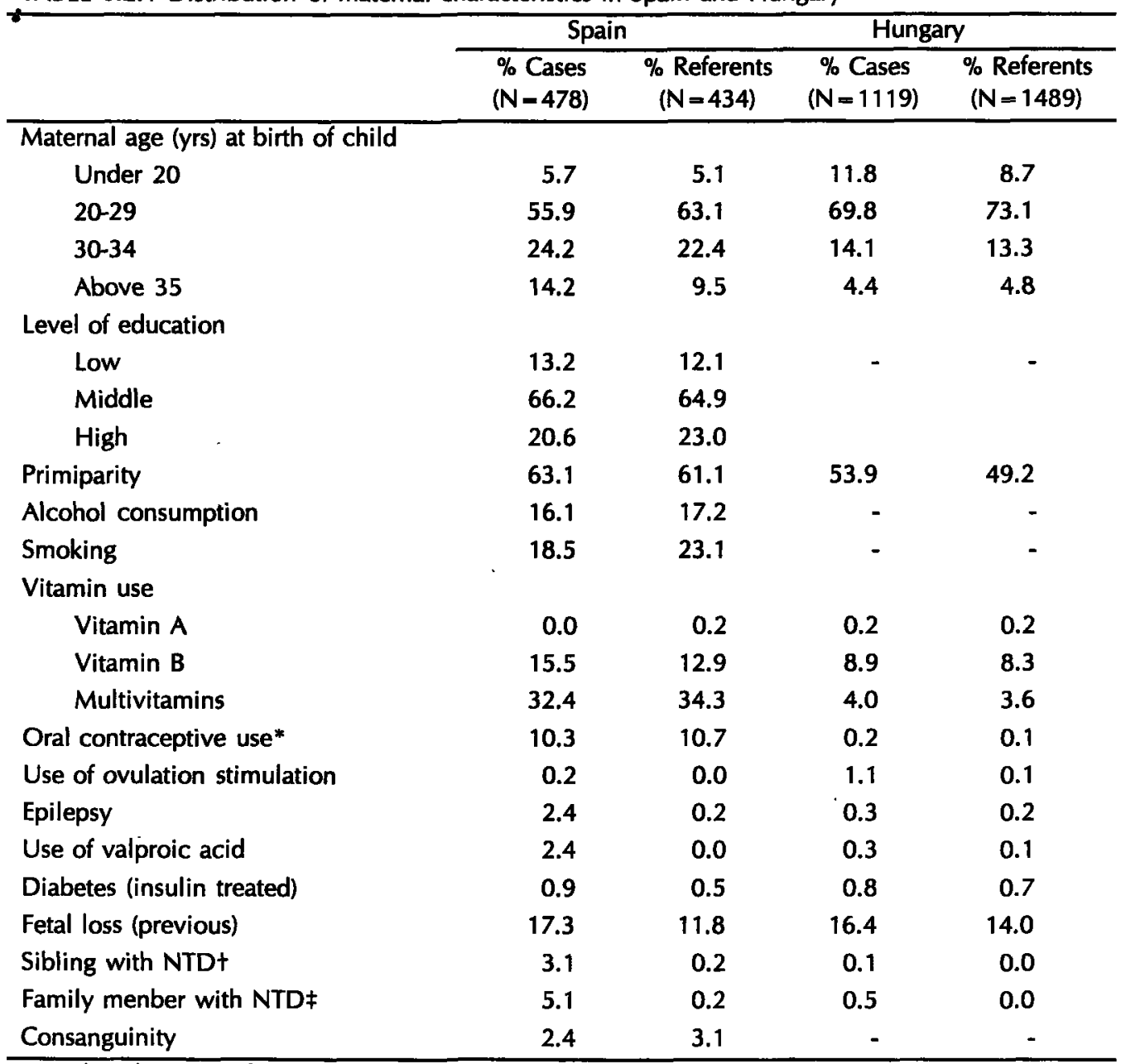

* Within three months prior to conception

+ NTD = neural tube defect

\# In Spain: first or second degree relative to the case child; in Hungary: first degree relative to the case child

An increased OR was also found for Spanish women working in health care $(\mathrm{OR}=1.9,95 \% \mathrm{Cl}=0.9-3.8)$, which was mainly due to the category of women in health care occupations other than nursing; this category included one radiology worker, two intensive care workers, one dentist and five women with occupations probably without chemical or physical exposure. 
TABLE 6.2.2 Number of cases and referents and Mantel-Haenszel odds ratios* with $95 \%$ confidence intervals for maternal occupations with potential for exposure in Sweden

\begin{tabular}{lcccc}
\hline & $\begin{array}{c}\text { Cases } \\
(\mathrm{N}=474)\end{array}$ & $\begin{array}{c}\text { Referents } \\
(\mathrm{N}=956)\end{array}$ & OR & $95 \% \mathrm{Cl}$ \\
\hline Agricultural workers & 10 & 11 & 1.8 & $0.8-4.2$ \\
Health care workers & 86 & 197 & 0.8 & $0.6-1.1$ \\
$\quad$ Nurses & 16 & 29 & 1.1 & $0.6-2.1$ \\
$\quad$ Nurse aides & 52 & 119 & 0.9 & $0.6-1.2$ \\
$\quad$ Other health care workers & 18 & 49 & 0.7 & $0.4-1.3$ \\
Cleaners & 16 & 28 & 1.2 & $0.6-2.1$ \\
Hairdressers & 1 & 9 & 0.2 & $0.0-1.4$ \\
Industry and transport workers & 22 & 43 & 1.0 & $0.6-1.7$ \\
$\quad$ Printing, paper and plastic workers & 6 & 7 & 1.7 & $0.6-5.0$ \\
Non-exposed group & 339 & 668 & & \\
\hline
\end{tabular}

* Calculated relative to all other exposed and nonexposed occupations

TABLE 6.2.3 Number of cases and referents and odds ratios for maternal occupations with potential for exposure in Spain

\begin{tabular}{lcccccc}
\hline & $\begin{array}{c}\text { Cases } \\
(\mathrm{N}=457)\end{array}$ & $\begin{array}{c}\text { Referents } \\
(\mathrm{N}=418)\end{array}$ & OR & $95 \% \mathrm{Cl}$ & OR $_{\text {adj }}{ }^{*}$ & $95 \% \mathrm{Cl}$ \\
\hline Agricultural workers & 16 & 6 & 2.6 & $1.0-6.6$ & 2.2 & $0.8-5.9$ \\
Health care workers & 22 & 12 & 1.8 & $0.9-3.7$ & 1.9 & $0.9-3.8$ \\
$\quad$ Nurses & 13 & 12 & 1.1 & $0.5-2.4$ & 1.1 & $0.5-2.4$ \\
$\quad$ Other health care workerst & 9 & 0 & - & - & - & - \\
Cleaners & 14 & 12 & 1.1 & $0.5-2.5$ & 1.0 & $0.5-2.3$ \\
Hairdressers & 4 & 3 & 1.3 & $0.3-5.9$ & 1.4 & $0.3-6.0$ \\
Industry and transport workers & 35 & 25 & 1.4 & $0.8-2.3$ & 1.2 & $0.7-2.1$ \\
$\quad$ Textile workers & 14 & 12 & 1.1 & $0.5-2.5$ & 1.1 & $0.5-2.4$ \\
$\quad$ Food industry workers & 9 & 7 & 1.3 & $0.5-3.4$ & 1.1 & $0.4-2.9$ \\
$\quad$ Other (plastic, rubber, dye) & 12 & 6 & 2.0 & $0.7-5.2$ & 1.6 & $0.6-4.4$ \\
Non-exposed reference group & 366 & 360 & & & & \\
\hline
\end{tabular}

* Adjusted for having a family member with a neural tube defect (first or second degree)

† Fisher exact test for crude association: p-value $\mathbf{- 0 . 0 0 2}$ 
TABLE 6.2.4 Number of cases and referents and odds ratios for maternal occupations with potential for exposure in Hungary

\begin{tabular}{lcccc}
\hline & $\begin{array}{c}\text { Cases } \\
(\mathrm{N}=1046)\end{array}$ & $\begin{array}{c}\text { Referents } \\
(\mathrm{N}=1419)\end{array}$ & OR & $95 \% \mathrm{Cl}$ \\
\hline Agricultural workers & 39 & 48 & 1.1 & $0.7-1.7$ \\
Health care workers & 66 & 119 & 0.8 & $0.6-1.1$ \\
Nurses & 20 & 49 & 0.6 & $0.3-1.0$ \\
Nurse aides & 12 & 24 & 0.7 & $0.3-1.4$ \\
Other health care workers & 34 & 46 & 1.0 & $0.6-1.6$ \\
Cleaners & 23 & 27 & 1.2 & $0.7-2.1$ \\
Industry and transport workers & 333 & 414 & 1.1 & $0.9-1.3$ \\
Mechanics and factory technicians & 1 & 9 & 0.1 & $0.0-1.2$ \\
Electrical workers & 18 & 17 & 1.5 & $0.8-2.9$ \\
Metalworkers & 11 & 5 & 3.0 & $1.1-8.8$ \\
Welders and solderers & 9 & 9 & 1.4 & $0.5-3.5$ \\
Paper workers and printers & 5 & 14 & 0.5 & $0.2-1.4$ \\
Textile, leather and shoe workers & 104 & 126 & 1.1 & $0.9-1.5$ \\
Food, drink and tabacco workers & 23 & 37 & 0.9 & $0.5-1.5$ \\
Construction workers & 15 & 9 & 2.3 & $1.0-5.3$ \\
Transport workers & 30 & 49 & 0.9 & $0.5-1.4$ \\
Other industrial & 64 & 64 & 1.4 & $1.0-2.0$ \\
Unskilled & 53 & 75 & 1.0 & $0.7-1.4$ \\
Non-exposed reference group & 583 & 809 & & \\
\hline
\end{tabular}

Other elevated but unstable ORs were found for Swedish women with printing, paper and plastic-producing occupations $(\mathrm{OR}=1.7,95 \% \mathrm{Cl}$ : $0.6-5.0)$ and for other industrial workers such as plastic, rubber, and dye workers in Spain $(O R=1.6$, 95\%Cl: 0.6-4.4). In Hungary, increased ORs were observed for female electrical workers $(O R=1.5,95 \% \mathrm{Cl}$ : 0.8-2.9), metalworkers (OR=3.0, 95\% Cl: 1.1-8.8), construction workers $(\mathrm{OR}=2.3,95 \% \mathrm{Cl}: 1.0-5.3)$, and other industrial workers $(\mathrm{OR}=1.4,95 \% \mathrm{Cl}: 1.0-2.0)$, but not for printing and paper workers.

The results for the paternal occupations are presented in Tables 6.2.5-6.2.7. Only 81 case fathers and 162 referent fathers could be included in the analyses in Sweden. Concerning the paternal occupations, the highest OR was found for bricklayers in Spain (OR $=2.8,95 \% \mathrm{Cl}$ : 1.4-5.4). Slightly increased ORs were found for paternal agricultural occupations in Sweden and Hungary $\left(O R_{\text {sweden }}=1.6,95 \% \mathrm{Cl}\right.$ : $0.6-4.5 ; \mathrm{OR}_{\text {Hungary }}=1.3,95 \% \mathrm{Cl}$ : 0.9-2.0), but not in Spain.

An increased OR of 2.6 was observed for the category of Swedish printers, painters, and paper and plastic workers, but the $95 \%$ confidence interval ranged from 0.7 to 10.4. In Spain, elevated ORs were also found for these occupations, 
TABLE 6.2.5 Number of cases and referents and Mantel-Haenszel odds ratios* with $95 \%$ confidence intervals for paternal occupations with potential for exposure in Sweden

\begin{tabular}{lccrr}
\hline & $\begin{array}{c}\text { Cases } \\
(\mathrm{N}=81)\end{array}$ & $\begin{array}{r}\text { Referents } \\
(\mathrm{N}=162)\end{array}$ & \multicolumn{1}{l}{ OR } & \multicolumn{1}{c}{$95 \mathrm{Cl}$} \\
\hline Agricultural workers & 7 & 9 & 1.6 & $0.6-4.5$ \\
Health care workers & 0 & 3 & - & - \\
Transport and communication workers & 5 & 14 & 0.7 & $0.2-2.0$ \\
Industrial workers & 24 & 45 & 1.1 & $0.6-1.9$ \\
Printing, painting, paper and plastic workers & 5 & 4 & 2.6 & $0.7-10.4$ \\
Non-exposed group & 40 & 87 & & \\
\hline
\end{tabular}

* Calculated relative to all other exposed and nonexposed occupations

which were divided into painters $(\mathrm{OR}=1.7,95 \% \mathrm{Cl}: 0.6-4.7)$ and printers and plastic and paper workers $(\mathrm{OR}=1.9,95 \% \mathrm{Cl}: 0.7-5.1)$. In Hungary, the number of printers and paper workers was too small to draw conclusions.

For Spanish welders we also found an increased risk, but numbers were small $(\mathrm{OR}=1.7,95 \% \mathrm{Cl}: 0.4-7.2)$. Finally, slightly increased risks were found in Hungary for other industrial workers $(\mathrm{OR}=1.3,95 \% \mathrm{Cl}$ : 0.9-1.8) and transport workers $(\mathrm{OR}=1.3,95 \% \mathrm{Cl}$ : 0.9-1.8).

TABLE 6.2.6 Number of cases and referents and odds ratios for paternal occupations with potential for exposure in Spain

\begin{tabular}{lcccccc}
\hline & $\begin{array}{c}\text { Cases } \\
(\mathrm{N}-410)\end{array}$ & $\begin{array}{c}\text { Referents } \\
(\mathrm{N}=376)\end{array}$ & OR & $95 \% \mathrm{Cl}$ & OR $^{*}{ }^{*}$ & $95 \% \mathrm{Cl}$ \\
\hline Agricultural workers & 49 & 49 & 1.0 & $0.6-1.6$ & 0.9 & $0.6-1.5$ \\
Health care workers & 7 & 7 & 1.0 & $0.3-3.0$ & 1.0 & $0.3-2.9$ \\
Transport workers & 22 & 21 & 1.1 & $0.6-2.0$ & 0.9 & $0.5-1.8$ \\
Industrial workers & 194 & 158 & 1.2 & $0.9-1.6$ & 1.2 & $0.9-1.6$ \\
$\quad$ Food, drink and tabacco workers & 20 & 14 & 1.5 & $0.7-3.0$ & 1.3 & $0.6-2.7$ \\
Engineers and metal workers & 11 & 8 & 1.4 & $0.6-3.6$ & 1.3 & $0.5-3.3$ \\
Mechanics & 28 & 34 & 0.8 & $0.5-1.5$ & 0.8 & $0.5-1.3$ \\
Welders & 6 & 3 & 2.0 & $0.5-8.1$ & 1.7 & $0.4-7.2$ \\
$\quad$ Painters & 10 & 6 & 1.7 & $0.6-4.8$ & 1.7 & $0.6-4.7$ \\
Printers, paper and plastic workers & 12 & 6 & 2.0 & $0.8-5.5$ & 1.9 & $0.7-5.1$ \\
Other industrial workers & 31 & 38 & 0.8 & $0.5-1.4$ & 0.8 & $0.5-1.4$ \\
Carpenters & 12 & 12 & 1.0 & $0.4-2.4$ & 0.9 & $0.4-2.2$ \\
Bricklayers & 37 & 13 & 2.9 & $1.5-5.6$ & 2.8 & $1.4-5.4$ \\
Other construction workers & 27 & 24 & 1.1 & $0.6-2.1$ & 1.0 & $0.5-1.8$ \\
Non-exposed reference group & 138 & 141 & & & & \\
\hline
\end{tabular}

* Adjusted for having a family member with a neural tube defect 
TABLE 6.2.7 Number of cases and referents and odds ratios for paternal occupations with potential for exposure in Hungary

\begin{tabular}{lcccc}
\hline & $\begin{array}{c}\text { Cases } \\
(\mathrm{N}=1049)\end{array}$ & $\begin{array}{c}\text { Referents } \\
(\mathrm{N}=1415)\end{array}$ & OR & $95 \% \mathrm{Cl}$ \\
\hline Agricultural workers & 78 & 82 & 1.3 & $0.9-2.0$ \\
Health care workers & 10 & 16 & 0.9 & $0.4-2.0$ \\
Transport workers & 163 & 183 & 1.3 & $0.9-1.8$ \\
Industrial workers & 605 & 803 & 1.0 & $0.8-1.4$ \\
$\quad$ Food, drink and tabacco workers & 22 & 29 & 1.1 & $0.6-2.0$ \\
Electrical workers & 77 & 95 & 1.1 & $0.8-1.7$ \\
Metalworker & 128 & 163 & 1.1 & $0.8-1.6$ \\
Mechanics & 54 & 88 & 0.9 & $0.6-1.3$ \\
Welders and solderers & 16 & 23 & 1.0 & $0.5-2.0$ \\
$\quad$ Paper workers and printers & 4 & 4 & 1.4 & $0.3-5.8$ \\
Textile and leather workers & 7 & 16 & 0.6 & $0.2-1.6$ \\
Construction workers & 120 & 190 & 0.9 & $0.6-1.3$ \\
Other industrial workers & 177 & 195 & 1.3 & $0.9-1.8$ \\
$\quad$ Unskilled/other & 100 & 202 & 0.7 & $0.5-1.0$ \\
Non-exposed reference group & 93 & 129 & & \\
\hline
\end{tabular}

\section{Discussion}

For the mothers, the main results of the Swedish and Spanish register-based substudies point to an association between spina bifida and women working in agriculture, although the widths of the confidence intervals do not rule out the possibility of chance findings. The Hungarian data do not support these findings, but reveal increased ORs for several industrial groups. The only more or less consistent finding for fathers is a possibly elevated risk for printers, painters, and paper and plastic workers in the Swedish and Spanish studies.

The inconsistency in the findings may be due to several reasons. Firstly, the odds ratios are imprecise due to low prevalences of occupations with potential exposure, so that the confidence intervals are compatible with a range of possibilities. Secondly, the quality of the occupational data may differ between the three registries. In Hungary, the coding of the occupations seemed to have received less attention than in Sweden and Spain, which probably has led to more misclassification of the data and bias toward the null. For example, according to the Hungarian FEOR occupational classification scheme, many occupations were coded as 'unknown', 'unskilled work' or 'physical work' (16\% of maternal occupations and $23 \%$ of paternal occupations). With regard to the workplace categorization, $1 \%$ of the maternal occupations and $54 \%$ of the paternal occupations were coded as 'unknown'. Few occupations were coded as 'unknown' in the Swedish and the Spanish 
registries $(4 \%)$.

Thirdly, occupational titles were used, although these can only serve as crude indicators of occupational exposure. As self-reported information on occupational titles concerning a short time period is not likely to be subject to information bias due to differential misclassification, this does not seem to be an explanation of the inconsistency in results. However, it is possible that non-differential misclassification has occurred if women who worked on their husband's farm called themselves housewives and were incorrectly assigned to the no-exposure category. As a result, the odds ratios may have been biased towards the null. In addition, some occupations may have been incorrectly assigned to the no-exposure category. For instance, teachers are likely to be exposed to some infectious agents and hyperthermia, which have been suggested by some authors as risk factors for spina bifida. $^{23}$

It is also possible that the study populations were not comparable with respect to other risk factors for spina bifida. This may be inferred from Table 6.2.1, in which the distributions of background variables of Spain and Hungary are presented. We were not able to adjust for all possible confounders in all registries, but limited control for confounding did not change the results. On the other hand, the magnitudes of the odds ratios for occupational factors depend on the magnitude of the baseline prevalence rate of spina bifida which is defined by other risk factors. This means that the same absolute effect in two populations can correspond to greatly differing relative effects. ${ }^{18}$ The baseline prevalence rate of spina bifida in Hungary $(9.1 / 10,000)$ is twice as high as in Sweden $(5.1 / 10,000)$ and Spain $(4.5 / 10,000){ }^{15}$ This may correspond with lower odds ratios in Hungary, compared to Sweden and Spain, which is observed for maternal agricultural occupations in this study.

Furthermore, one may hypothesise that the characteristics of agricultural work in terms of tasks performed, the contribution of farmers' wives in farm work, and the amount and type of pesticides used, differ between the three countries. For instance, working at an agricultural cooperation in Hungary may imply more specialisation of tasks and administrative work as well. Unfortunately, the occupational data in the registries did not give insight into possible differences in tasks, pesticide use, or type of agricultural work.

Prenatally diagnosed and aborted fetuses were included in the registry in Hungary, but not in the registries in Sweden and Spain. This may have introduced selection bias in the latter two studies, probably leading to an excess of women from lower socioeconomic classes or from rural areas in the case populations. However, it should be stressed that data were collected from 1976 onwards, when prenatal screening was not common yet. Elective abortions following antenatal screening are legal in Spain since 1985, so the effect will probably be small. In Sweden, the 
majority of women get at least one ultrasound screening during pregnancy free of charge; selection on socioeconomic status and regional differences seems negligible.

In the literature, some data support the finding of an association between spina bifida and maternal agricultural occupations. In a questionnaire-based case-referent study that we recently performed in The Netherlands, an increased risk of 5.6 (95\% Cl: $1.8-17.8)$ was found for women in agricultural occupations. ${ }^{12}$ Ericson et al $^{7}$ concluded that no statistically significant association could be found between neural tube defects and any type of occupation, but they did find an odds ratio of 7.1 for mothers in agricultural occupations. Our present study in Sweden had a small overlap with the study of Ericson et al: one third of our Swedish cases was probably included in that study also. A study in Venezuela ${ }^{6}$ showed largely differing frequencies of agricultural occupations among 76 cases of neural tube defects and 76 controls: $8 \%$ compared to none, respectively, among the mothers and $32 \%$ compared to $13 \%$ among the fathers.

Some other increased ORs that we observed in this study have been associated with spina bifida before. For instance, the increased odds ratios observed for fathers working as painters, printers, and paper and plastic workers in Sweden and Spain have been found by a number of other investigators, ${ }^{8-10}$ but the association with painters was inconclusive in a recently conducted study in Atlanta. ${ }^{11}$ In the Spanish population, we saw an increased odds ratio for fathers working as welders, which was also recently observed by Schnitzer et al. ${ }^{11}$ and Blatter et al., ${ }^{12}$ although in both studies the numbers of exposed persons were small. The increased odds ratio for bricklayers that was seen in Spain was previously found in a small-scale study in Venezuela. $^{6}$ The slightly increased risk for transport workers in Hungary was also observed by other investigators. ${ }^{8,12}$ Increased risks that were found in the literature for women working as nurses, ${ }^{5}$ hairdressers, ${ }^{6}$ and cleaners ${ }^{12}$ were not repeated in the present study.

In conclusion, the results of the three substudies are not totally consistent but suggest an increased risk of spina bifida among women in agricultural occupations. As only occupational titles could be studied, however, the study does not give more insight into the role of potentially harmful chemical agents.

\section{Acknowledgements}

We thank B Källén from the Tornblad Institute in Lund, and A Ericson and J Gunnarskog (bcn) from the National Board of Health and Welfare in Stockholm, Sweden, for their cooperation with respect to the Swedish part of the study.

\section{References}

1 Little J, Elwood JH. Socioeconomic status and occupation. In: Elwood IM, Little J, Elwood $\mathrm{JH}$, eds. Epidemiology and control of neural tube defects. Monographs in Epidemiology and Biostatistics. Vol 20: Oxford: Oxford University Press, 1992;456-520. 
2 Brown NA. Are offspring at risk from their father's exposure to toxins? Nature 1985;316:110.

3 Hales BF, Smith S, Robaire B. Cyclofosfamide in the seminal fluid of treated males: Transmission to females by mating and effect on pregnancy outcome. Toxicol Appl Pharm 1986;27:602-611.

4 Colie CF. Male mediated teratogenesis. Reprod Toxicol 1993;7:3-9.

5 Matte TD, Mulinare J, Erickson JD. Case-control study of congenital defects and parental employment in health care. Am J Ind Med 1993;24:11-23.

6 Hammond FG, Canache MF. Some epidemiological aspects of neural tube defects in Barquisimeto, Venezuela (Abstract). Am J Hum Genet 1991;49 (suppl.):470.

7 Ericson A, Källén B, Löfkvist $E$. Environmental factors in the etiology of neural tube defects: a negative study. Environ Res 1988;45:38-47.

8 Fedrick J. Anencephalus in the Oxford Record Linkage Study Area. Dev Med Child Neurol 1976;18:643-656.

9 Olshan AF, Teschke K, Baird PA. Paternal occupation and anomalies in offspring. Am J Ind Med 1991;20:447-475.

10 Brender CJ, Suarez L. Paternal occupation and anencephaly. Am J Epidemiol 1990;131:517-521.

11 Schnitzer PG, Olshan AF, Erickson JD. Paternal occupation and risk of birth defects in offspring. Epidemiology 1995;6:577-583.

12 Blatter BM, Roeleveld N, Zielhuis GA, Mullaart RA, Gabreëls FJM. Spina bifida and parental occupation. Epidemiology 1996;7:188-193.

13 Blatter BM, Roeleveld N, Zielhuis GA, Gabreëls FIM, Verbeek ALM. Maternal occupational exposure during pregnancy and the risk of spina bifida. Occup Environ Med 1996;53:80-86.

14 Nurminen T, Rantala K, Kurppa K, Holmberg PC. Agricultural work during pregnancy and selected structural malformations in Finland. Epidemiology 1995;6:23-30.

15 International Clearinghouse for Birth Defects Monitoring Systems. Congenital Malformations Worldwide. A report from the International Clearinghouse for Birth Defects Monitoring Systems. Amsterdam: Elsevier, 1991.

16 Källén B, Winberg J. Swedish register of congenital malformations. Experience with continuous registration during two years with special reference to multiple malformations. Pediatrics 1968;41:765.

17 World Health Organization. International Classification of Diseases, Ninth Revision. Geneva, Switzerland: World Health Organization, 1977.

18 Rothman KJ. Modern epidemiology. Boston: Little, Brown and Company, 1986.

19 Martínez-Frías ML. Clinical manifestation of prenatal exposure to valproic acid using case reports and epidemiologic information. Am J Med Genet 1990;37:277-282.

20 Martínez-Frías ML, Frías JL, Salvador J. Clinical/epidemiological analysis of malformations. Am J Med Genet 1990;35:121-125.

21 Czeizel A, Rácz J. Evaluation of drug intake during pregnancy in the Hungarian CaseControl Surveillance of Congenital Anomalies. Teratology 1990;42:505-512.

22 Czeizel A, Pazsy A, Pusztai J, Nagy M. Aetiological monitor of congenital 
abnormalities: A case-control surveillance system. Acta Paediatr Hungarica 1983;24:91-99.

23 Elwood $M$, Little J, Elwood JH. Maternal illness and drug use during pregnancy. In: Elwood JM, Little J, Elwood JH, eds. Epidemiology and control of neural tube defects. Monographs in Epidemiology and Biostatistics. Vol 20: Oxford: Oxford University Press, 1992;415-455. 


\section{CHAPTER 7}

\section{SPINA BIFIDA AND PARENTAL OCCUPATIONAL EXPOSURE}


CHAPTER 7.1

\title{
MATERNAL OCCUPATIONAL EXPOSURE DURING PREGNANCY AND THE RISK OF SPINA BIFIDA
}

\author{
BM Blatter, N Roeleveld, GA Zielhuis, FIM Cabreëls, ALM Verbeek \\ Occup Environ Med 1996;53:80-86 \\ with the permission of BMJ Publishing Group
}

\begin{abstract}
Objectives A case-control study was carried out to explore associations between spina bifida and occupational exposure of the mother.

Methods The cases were children with spina bifida aperta born between 1980 and 1992 from nine hospitals in the Netherlands. The controls were children born healthy in the same period as the cases, from hospitals and from the general population. Data collection was carried out in two steps. Firstly, postal questionnaires were sent to all the parents of cases and controls to gather information on occupations and potential confounders. In the second phase of the study, information on specific exposures was collected by means of job and task specific personal interviews. Interviews were performed with 55 case mothers and 66 control mothers who had occupations with a potential for chemical or physical exposure. Those exposures were assumed to be negligible for, for example, teachers and secretaries, so personal interviews were not indicated for these women. Information was collected on specific tasks in the period just after conception, and on the associated use of chemical or physical agents, frequency of exposure and use of protective equipment.
\end{abstract}

Results The analyses of occupation showed an increased risk for women working in agricultural occupations $(\mathrm{OR}=3.4,95 \% \mathrm{Cl}$ : 1.3-9.0), and, although less distinct, for cleaning women $(\mathrm{OR}=1.7,95 \% \mathrm{Cl}$ : $0.9-3.4)$. Only a few women seemed to be occupationally exposed to chemical or physical agents. No differences in occurrence of specific exposures could be detected between cases and controls. Besides, no differences were seen in pesticide or disinfectant exposure among case and control mothers in agricultural occupations.

Conclusions Occupational exposures of the mother during pregnancy were infrequent and did not seem to play an important part in the aetiology of spina bifida in this study. The association found between spina bifida and maternal agricultural occupations could not be explained by use of pesticides by the mother or by any other occupational exposure. 
Spina bifida is a congenital malformation that is caused by a failure in the process of neural tube closure. Although its aetiology is still largely unknown, both genetic and environmental factors seem to play an equally important part in the aetiology. One factor that seems to be associated with the prevalence of spina bifida is socioeconomic status of the parents. ${ }^{1-3}$ Since that fact was established, research into vitamin status during pregnancy, with emphasis on folic acid, has been expanded. It has been found that a deficiency of this B vitamin is one of the causes of neural tube defects; supplementation with folic acid seems to have a preventive effect. ${ }^{47}$ Another possible aetiological factor that is related to socioeconomic status, is maternal occupational exposure to chemicals or radiation during the first month of pregnancy.

Just a few studies have been performed to investigate the relation between maternal occupation and spina bifida. ${ }^{8}$ Some evidence was found for an increased risk among women working in industry, construction, transport and communication, ${ }^{9,10}$ dental surgeries, ${ }^{11}$ nursing, ${ }^{12}$ hairdressing, ${ }^{13}$ and farming. ${ }^{13,14}$ Occupational titles were used as a surrogate measure for exposure in these studies. This measure is too general for accurate exposure assessment: the same job title reported by different subjects may correspond to huge variations in exposure, whereas different job titles reported by different subjects may have the same or similar exposures. ${ }^{15}$ Therefore, it is important to evaluate individual job and time specific exposures. As obtaining this kind of information is costly and time consuming studies investigating the influence of occupational exposure are scarce.

A Finnish study from Holmberg and Nurminen ${ }^{16}$ showed an increased risk of central nervous system defects (including a large number of neural tube defects) for women working with organic solvents. The authors extended the data collection of this study and recently reported on the relation between birth defects and agricultural work. ${ }^{17}$ Unfortunately, the effect of pesticide exposure could not be studied as only one central nervous system case mother and one control mother had been moderately or heavily exposed to pesticides. In a study on parental occupation and anencephalic births in the United States ${ }^{18}$ the authors investigated in particular whether pesticide and solvent exposure were of importance. However, the number of exposed case and control mothers in this study again was too small to find any exposure effect.

The present paper describes a multicentre case-control study including a relatively large number of spina bifida cases, in which the relation between occupational exposures of the mother and the risk of spina bifida in offspring is investigated. To get detailed exposure information about the time period around conception, job, and task specific personal interviews were performed. 


\section{Subjects and methods}

Hospital records of six academic hospitals, one regional hospital and two rehabilitation centres in the Netherlands were searched to identify the cases and part of the controls. This resulted in $\mathbf{4 7 0}$ live born children with spina bifida aperta, born between 1 January 1980 and 31 December 1992, and 456 control children who were born healthy in the same period but who had experienced a cerebral trauma or meningitis during childhood. Most of the control group were 1894 children from the general population, born between 1 January 1980 and 31 December 1992, who were recruited from birth registries of $\mathbf{4 5}$ municipalities in the Netherlands. Stratified random sampling was performed to match the population based controls to the cases based on size of the municipality (in four categories) and geographical location.

Data collection was carried out in two steps (Figure 1). in the first step, a postal questionnaire was sent to the total study population to collect information on occupation of the mother and on potentially confounding factors. From 80 mothers ( 21 cases and 59 controls) current addresses could not be obtained. Three hundred and forty nine case mothers $(78 \%)$ and 1604 control mothers $(70 \%)$ returned the questionnaire. In the second step, detailed information on occupational exposures was collected from a subset of the mothers by means of personal interviews at home. Respondents who indicated in the questionnaire that they were willing to participate in a personal interview $(78 \%$ and $71 \%$, respectively) were eligible for this part of the study. All of the eligible case mothers were enrolled, together with a random sample of $27.5 \%$ of the control mothers. This resulted in a study population of 274 cases and 314 controls.

As detailed interviews would be redundant for mothers who did not have a job or who worked in jobs without hazardous exposure, only mothers who worked in occupations with a potential for exposure to chemicals or radiation were actually interviewed (55 cases and 66 controls). This group included health care workers, cleaners, hairdressers, workers in industry and transport, and agricultural workers. The chemical exposure of the remaining women (housewives, household personnel, shop attendants, teachers, artistes, social workers, and clerical and managerial staff) was assumed to be negligible.

Because of an increased risk found for agricultural women, ${ }^{19}$ additional interviews were performed at a later date, with two case mothers and six control mothers working in agriculture. Originally, these women were not available for study (cases) or were not included in the control sample. Their information was only used for agriculture specific descriptive analyses.

Ten different questionnaires were specifically designed for each of the following occupations: nurses, laboratory assistants, dental assistants, pharmaceutical assistants, physiotherapists, hairdressers, cleaners, printers, agricultural workers, and 


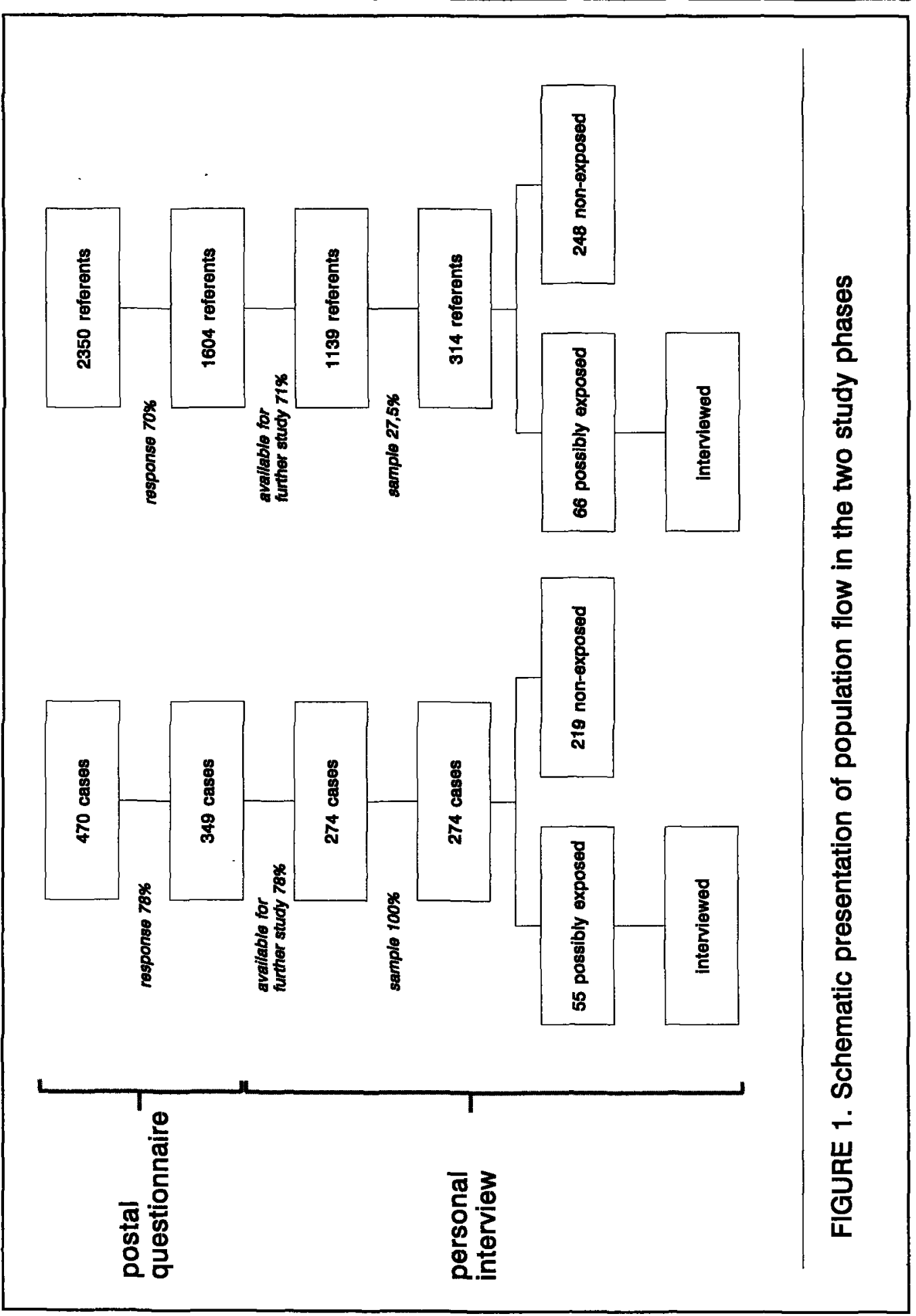


'occupations in industry or transport'. In each interview, traditional work history questions on job title, industry, company name, number of hours worked, and tasks performed, were asked first. Subsequently, questions that were developed by the investigators on the basis of occcupational hygiene information were used to inquire about every occupational task that had possibly been performed and on the associated use of chemicals and radiation, the frequency of the activity or exposure, the use of protective devices, and on exposure through the proximity of colleagues. For example, hairdressers were asked whether they applied hair sprays, what type of hair spray they used (with propellant gas or pump sprays), how often they applied hair dyes, and whether they had to prepare hair dyes themselves. Workers in the printing industry were asked, for example, what type of ink was used in the machines and whether they had to refill the ink supply and wash the ink rollers. At the end of each interview, a checklist with 17 categories of exposure was shown, to identify any agents that might have been missed. Detailed questions were asked again for the agents that were reported. The period of interest ranged from two weeks before conception until six weeks after conception, calculated from the duration of pregnancy that was reported in the questionnaire.

The exposures were classified into 23 categories (Table 7.1.3). Some related exposures were grouped into larger categories (disinfecting agents, organic solvents, and hydrocarbons). The self reported interview information was used for coding of exposure into three different variables for each category: exposure yes or no, frequency of exposure, and kind of protective equipment used. Based on these variables, the level of exposure was assessed by the professional investigators with a four point scale (no exposure, lightly, moderately, heavily exposed).

Descriptive analyses were performed within each of the selected occupational categories with potential exposure to identify differences between cases and controls in the number of exposed women and the frequency and level of exposure. Also, all mothers with and without potential for occupational exposure were combined to look at the possible effects of exposure to a particular agent, irrespective of occupation. Crude odds ratios (ORs) and adjusted ORs with $95 \%$ confidence intervals $(95 \% \mathrm{Cls})$ were calculated by means of logistic regression for those agents to which at least 10 women were exposed. In the final analyses, the variables for level of exposure were dichotomised into no exposure $v$ any level of exposure and used as the primary exposure variables.

\section{Results}

The first phase of the study was meant to identify occupations with increased risks of spina bifida (Table 7.1.1). After adjustment for confounders, an increased OR of 3.4 $(95 \% \mathrm{Cl}: 1.3-9.0)$ was found for women in agricultural occupations. An increased risk 
TABLE 7.1.1 Maternal occupation and risk of spina bifida aperta

\begin{tabular}{lccccc}
\hline & $\begin{array}{c}\text { Cases } \\
(\mathrm{N}=349)\end{array}$ & $\begin{array}{c}\text { Referents } \\
(\mathrm{N}=1604)\end{array}$ & $\mathrm{OR}_{\text {crude }}$ & OR $_{\text {adj }}{ }^{*}$ & $95 \% \mathrm{Cl}$ \\
\hline Nurses & 12 & 76 & 0.8 & 0.8 & $0.4-1.5$ \\
Nurse aids & 16 & 68 & 1.1 & 1.2 & $0.7-2.1$ \\
Other health care workers & 12 & 70 & 0.8 & 0.8 & $0.4-1.6$ \\
Cleaners & 13 & 32 & 1.9 & 1.7 & $0.9-3.4$ \\
Hairdressers & 3 & 17 & 0.8 & 0.6 & $0.2-2.8$ \\
Industry and transport & 15 & 56 & 1.3 & 1.4 & $0.8-2.6$ \\
Agricultural workers & 10 & 10 & 4.8 & 3.4 & $1.3-9.0$ \\
Non-exposed reference category & 268 & 1275 & & & \\
\hline
\end{tabular}

* Adjusted for a positive family history for NTD's of the father and use of ovulation stimulating agents by logic regression. Restriction for maternal use of vitamin A, antiepileptics, diabetes, diagnosis of homocysteinaemia and consanguinity.

of 1.7 was found for cleaning women. More details about this part of the study have been described elsewhere. ${ }^{19}$

In the second phase, detailed information was gathered on occupational exposures from 55 case mothers and 66 control mothers who had an occupation with potential for chemical exposure. This group included 71 mothers working in health care, eight hairdressers, 15 mothers working in industry or in transport, 16 cleaners, and 11 mothers in agricultural occupations. Time between exposure and interview was not equally distributed between case and control mothers: $31.4 \%$ of the women reported exposures for the period $10-14$ years ago $(27.3 \%$ of the cases and $34.8 \%$ of the controls), $35.5 \%$ for the period six to 10 years ago $(30.9 \%$ of the cases and $39.4 \%$ of the controls), and $33.1 \%$ for one to five years ago ( $41.8 \%$ of the cases and $25.8 \%$ of the controls).

No substantial differences were found in the distribution of background variables between case mothers $(N=274)$ and control mothers $(N=314)$ in the total interview population in the second phase, except for a positive family history of neural tube defects for both mother and father (Table 7.1.2).

Table 7.1.3 shows the number of exposed mothers within the different occupational groups, itemized for cases and controls, and the total number of case and control mothers with any level of exposure. It can be seen that, even within the occupational groups with a theoretically high potential for exposure, only a few women were exposed to hazardous agents such as antineoplastic drugs, ionising radiation, organic solvents, and pesticides. There was no frequent use of aggressive cleaning agents by the cleaning women and no differences could be detected between cases and controls. 
TABLE 7.1.2 Distribution of main background variables of cases and referents

\begin{tabular}{lrrrr}
\hline & \multicolumn{2}{c}{ Cases } & \multicolumn{2}{c}{ Referents } \\
& $\mathrm{N}=274)$ & $\mathrm{N}=314)$ & $\%$ \\
\hline Education & & & & \\
\multicolumn{1}{c}{ Low } & 91 & 33.7 & 85 & 27.2 \\
$\quad$ Moderate & 127 & 47.0 & 158 & 50.5 \\
$\quad$ High & 52 & 19.3 & 70 & 22.4 \\
Alcohol use (at least 1 glass/week) & 141 & 51.6 & 174 & 55.4 \\
Smoking (at least 1 cigarette/day) & 110 & 40.6 & 130 & 41.5 \\
Maternal family history of NTD* & 14 & 5.1 & 4 & 1.3 \\
Paternal family history of NTD* & 14 & 5.1 & 3 & 1.0 \\
Primiparity & 124 & 45.4 & 130 & 41.4 \\
Maternal age at birth child (average) & 28.2 yrs & & 28.4 yrs & \\
Oral contraceptive use & 99 & 36.5 & 104 & 33.1 \\
Use of ovulation stimulating agents & 12 & 4.4 & 9 & 2.9 \\
Fetal loss (ever) & 63 & 23.5 & 78 & 25.6 \\
\hline
\end{tabular}

* Defined as: neural tube defect in sibling or in family member in the first or second degree

As well as the 11 women in agricultural occupations, additional interviews were performed with two case mothers and six control mothers (Table 7.1.4). Four of the nine case mothers had been working in crop and stock farming, two mothers in poultry farming, one in market gardening, one in mushroom cultivation, and two in other agricultural occupations. Of the controls, six mothers had been working in crop and stock farming, one in fruit cultivation, two in plant and flower growing, and one in another agricultural occupation. Pesticide exposure does not seem to differ between case mothers (4/9) and control mothers (5/10). The number of women exposed to biologically active dust is also similar.

Table 7.1.5 shows the frequency distributions of exposure. The intensity of exposure (given in number of hours a week) was low for case mothers as well as for control mothers in all exposure categories. Disinfectants, cleaning agents, and alcohol are the most widely used agents in this population. However, most of the women used these agents for only 10 hours or less a week, and $50 \%$ of reported use was for a maximum of one hour only. When all categories were combined, as little as $11 \%$ of the total number of chemicals and radiation used were handled more than 10 hours a week.

Table 7.1.6 shows the ORs and the $95 \% \mathrm{Cls}$ that were calculated for the total group of potentially exposed and non-exposed occupations combined. The ORs were only calculated for chemical and physical agents to which at least 10 women were 


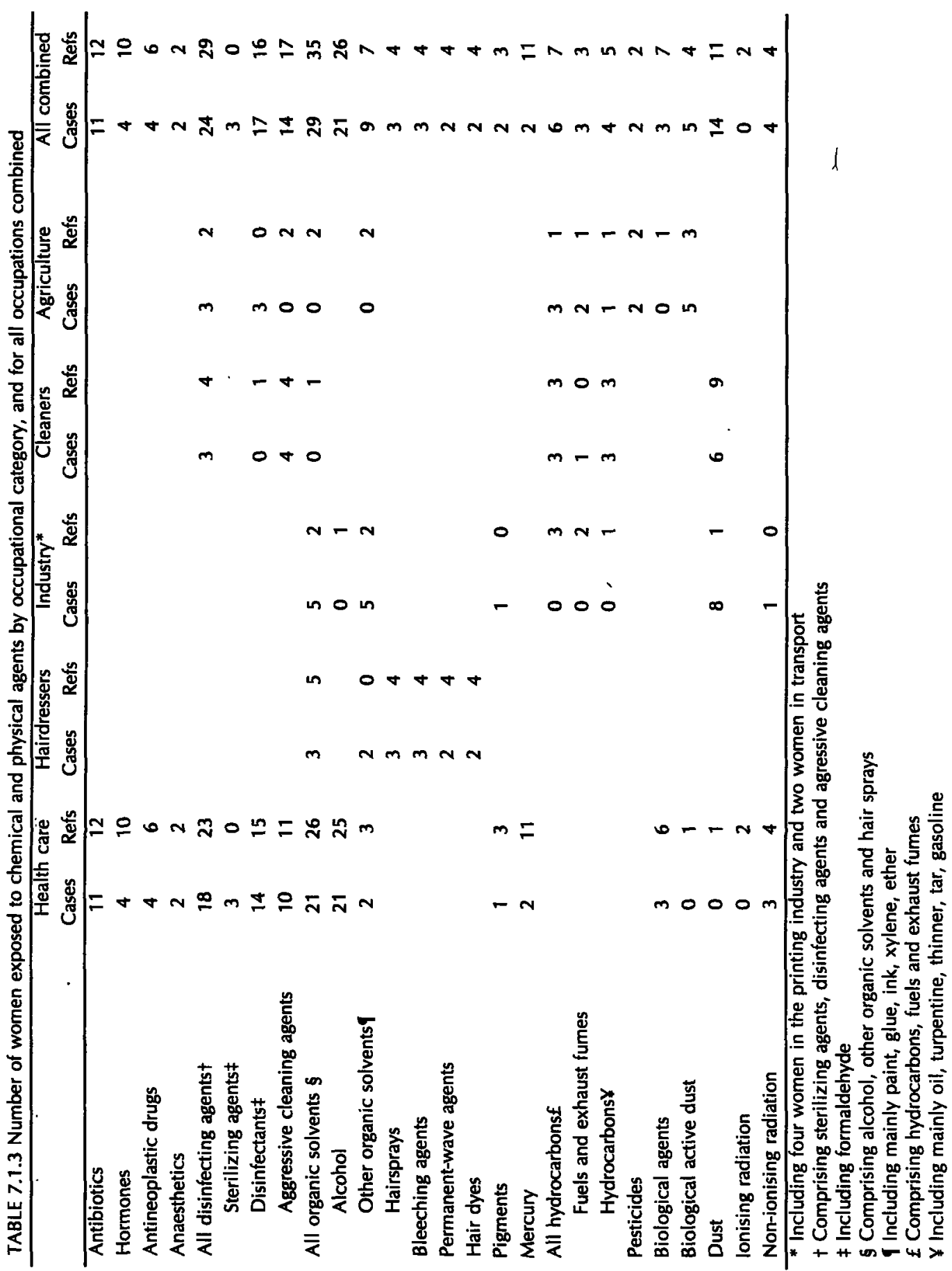


TABLE 7.1.4 Total number of agricultural women exposed to chemical agents*

\begin{tabular}{lcc}
\hline & $\begin{array}{c}\text { Cases } \\
(\mathbf{N}=9)\end{array}$ & $\begin{array}{c}\text { Referents } \\
(\mathbf{N}=10)\end{array}$ \\
\hline All disinfecting agentst & 4 & 3 \\
Disinfectants $\neq$ & 4 & 1 \\
Agressive cleaning agents & 0 & 3 \\
Other organic solvents\$ & 0 & 2 \\
All hydrocarbons & 3 & 2 \\
Hydrocarbonsf & 1 & 2 \\
Fuels and exchaust fumes & 3 & 2 \\
Pesticides & 4 & 5 \\
Biological agents & 0 & 3 \\
Biological active dust & 6 & 6 \\
\hline
\end{tabular}

* 11 agricultural women from table 3 plus 8 women with whom additional interviews were performed

t Comprising sterilizing agents, disinfectants and agressive cleaning agents

₹ Including formaldehyde

$\$$ Including mainly paint, glue, ink, xylene, ether

I Comprising hydrocarbons, fuels and exhaust fumes

$f$ Including mainly oil, turpentine, thinner, tar, gasoline

exposed. Controlling for potential confounders (use of vitamin A, antiepileptics, ovulation stimulating agents, oral contraceptives, alcohol, smoking, positive family history of neural tube defects, consanguinity, diabetes, diagnosis of homocysteinaemia, parity and fetall loss) did not change the results. Therefore, the crude ORs are presented. Although some slightly increased ORs were found for organic solvents and dust $(\mathrm{OR}=1.5), 95 \% \mathrm{Cls}$ were wide. Some decreased ORs were found, of which the $O R$ for exposure to mercury was significantly lower than one.

\section{Discussion}

It seemed that few women in this study were occupationnally exposed to chemicals or radiation during early pregnancy. Furthermore, no differences were found between case and control mothers. Although a more than threefold increased risk in spina bifida was found for agricultural occupations, few mothers working in agriculture were exposed to pesticides or disinfectants. Nor could any differences in pesticide exposure be detected between case mothers and control mothers with agricultural occupations. Before interpreting these findings, however, some methodological issues must be considered.

For reasons of validity and efficiency, data collection was carried out in two steps. Firstly, information on occupational titles was collected from the total study population by means of postal questionnaires, in which also information on potentially confounding factors was gathered. This probably minimised misclassification on the confounders as questionnaire information on lifestyle factors may be less influenced by the tendency to give socially desirable answers than information 
TABLE 7.1.5 Frequency of exposure*: number of hours per week exposed to chemical and physical agents, for cases and referents

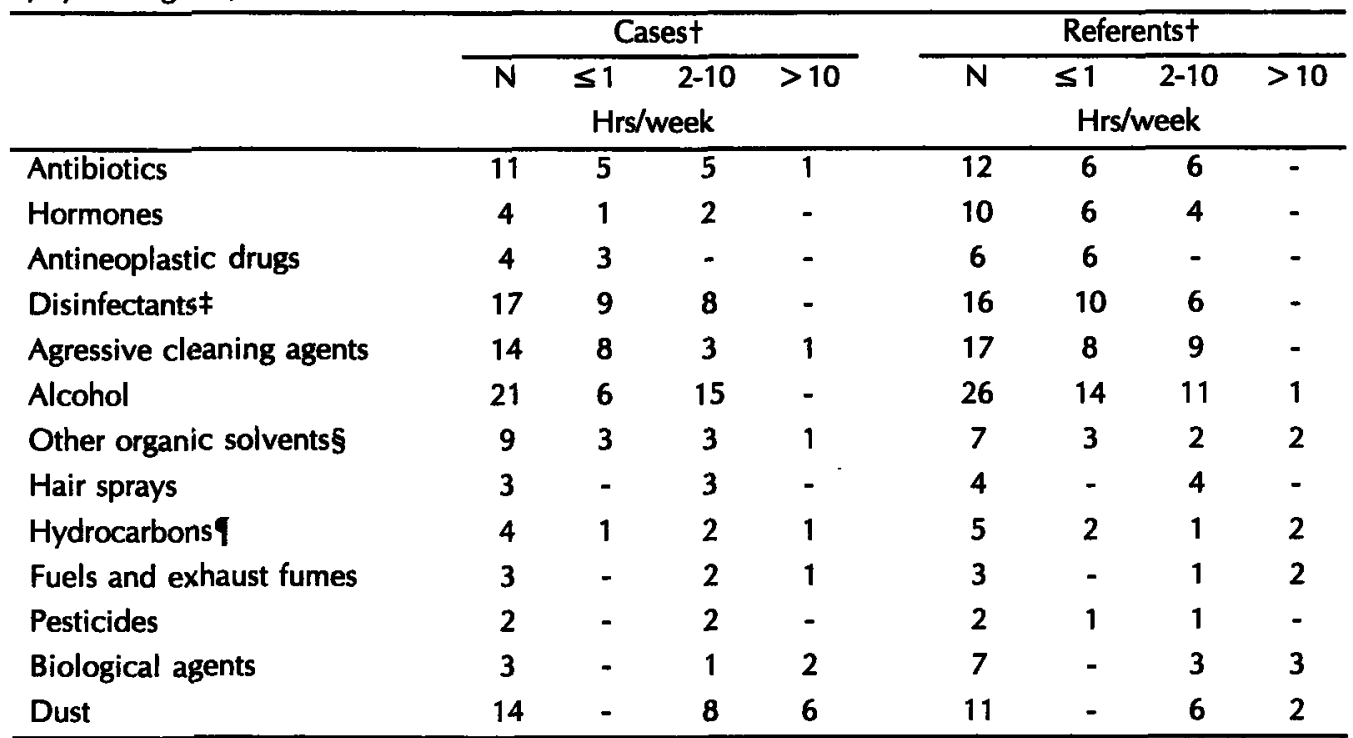

* Combined categories (see table 3), categories for which no detailed exposure information was available (e.g. mercury) and categories to which less than ten women were exposed (except hair sprays, hydrocarbons and pesticides) not included

t Some information on fequency of exposure is missing

₹ Including formaldehyde

5 Including mainly paint, glue, ink, xylene,ether

I Including mainly oil, turpentine, thinner, tar, gasoline

gathered in a face to face situation. Furthermore, as the birth of the index child minus one year was used as a proxy for the period around conception in the postal questionnaires, more valid estimates of, for example, smoking and drinking habits are expected. Life style factors before conception probably better resemble life style habits in the first month of pregnancy, in which most women do not know that they are pregnant.

In the second phase, information on exposures was gathered from a sample of the potentially exposed mothers by means of personal interviews at home. Potentially exposed was defined as working in health care, industry, transport or agriculture, or working as a cleaner or hairdresser. Exposure of mothers working in non-exposed occupations such as clerical and managerial staff, teachers, artistes and social workers, household personnel, shop attendants, and housewives was assumed to be negligible. Consequently, time consuming detailed exposure assessments were not performed for these mothers. This reduced the number of interviews and increased the efficiency of the study. Thus more attention could be paid to the quality of the remaining interviews and consequently to the validity of the exposure information. To achieve validity, occupation specific questionnaires were designed in 
which all the possible tasks performed were considered. For every specific task, questions were asked about frequency and duration of the task, the use of chemical or physical agents related to this task, use of protective devices, and exposure through use of chemicals by colleagues. By asking about exposure indirectly, by means of questions about specific tasks, and by asking direct questions on chemicals in the context of the occupation, recall is enhanced and validity of the study increased. ${ }^{15}$ As a consequence, information bias seemed less likely, although it can never be ruled out in a study with self reported data. Shaw and Gold described several studies specifically testing for information bias on exposures during pregnancy but have been unable to show its presence. ${ }^{20}$ Differential recall between cases and controls might have occurred as time between exposure and interview was unequally distributed in cases and controls. Forty two per cent of the cases reported exposures for the most recent period (one to five years ago) compared with $26 \%$ of the controls, thus recall might be slightly better for cases. Whether inaccurate recall of earlier periods causes a bias by under or overreporting, cannot be inferred.

TABLE 7.1.6 Maternal occupational exposure* and risk of spina bifida aperta

\begin{tabular}{lcccc}
\hline & $\begin{array}{c}\text { Cases } \\
(\mathrm{N}=274)\end{array}$ & $\begin{array}{c}\text { Referents } \\
(\mathrm{N}=314)\end{array}$ & OR & $95 \% \mathrm{Cl}$ \\
\hline Antibiotics & 11 & 12 & 1.1 & $0.5-2.4$ \\
Hormones & 4 & 10 & 0.5 & $0.1-1.4$ \\
Antineoplastic drugs & 4 & 6 & 0.8 & $0.2-2.7$ \\
All disinfecting agents† & 24 & 29 & 0.9 & $0.5-1.9$ \\
$\quad$ Disinfectants & 17 & 16 & 1.2 & $0.6-2.5$ \\
$\quad$ Agressive cleaning agents & 14 & 17 & 0.9 & $0.5-2.0$ \\
All organic solvents§ & 29 & 35 & 0.9 & $0.6-1.6$ \\
$\quad$ Alcohol & 21 & 26 & 0.9 & $0.5-1.7$ \\
$\quad$ Other organic solvents & 9 & 7 & 1.5 & $0.6-4.0$ \\
Mercury & 2 & 11 & 0.2 & $0.1-0.8$ \\
All hydrocarbonsf & 6 & 7 & 1.0 & $0.3-3.0$ \\
Biological agents & 3 & 7 & 0.5 & $0.1-1.9$ \\
Dust & 14 & 11 & 1.5 & $0.7-3.3$ \\
\hline
\end{tabular}

* Only categories included to which at least ten women were exposed

+ Comprising sterilizing agents, disinfectants and agressive cleaning agents

\# Including formaldehyde

$\$$ Comprising alcohol, other organic solvents and hair sprays

I Including mainly paint, glue, ink, xylene, erther

$f$ Comprising hydrocarbons (including mainly oil, turpentine, thinner, tar, gasoline), fuels and exhaust fumes

A disadvantage of this two step data collection is that non-response accumulates. The response rates for the postal questionnaires were $78 \%$ for case mothers and $70 \%$ for control mothers. In the postal questionnaire the mothers were asked 
whether they were willing to participate in a personal interview later. Seventy eight per cent of the case mothers and $71 \%$ of the control mothers answered positively to this question. Differences in non-response between occupations could have resulted in selection bias. Also, the occupational distribution in the sampled control population may differ from the distribution in the total control population due to random sampling error. Comparison of the total postal questionnaire population (cases $=349$, controls $=1604$ ) with the interview study population (cases $=274$, controls =314), yielded similar occupational distributions in general, with the exception of cleaners and agricultural occupations. As a result of both mechanisms, the proportion of cleaners decreased by $37 \%$ among the cases and increased by $45 \%$ among the controls. For the agricultural occupations, the proportion among the cases did not change whereas the proportion among the controls increased by $116 \%$.

This might partly be caused by an over representation of hospital based controls who seemed to contain a higher proportion of agricultural workers (manuscript in preparation). As a consequence, an excess of agricultural controls and cleaners was found in the interviewed study population, which may have resulted in underestimation of the ORs for substances that were frequently being used by farmers and cleaners. Therefore, the frequencies of exposure have been considered within the specific occupational groups as well as in the combined population (Table 7.1.3).

As a selection (only live born cases) of spina bifida cases were studied, the low exposure levels in this study might be a result of the so called 'inverse doseresponse relationship': a very high exposure could result in early fetal loss, whereas a lower one might result in a congenital malformation recognised at birth. ${ }^{21}$ Furthermore, misclassification on the outcome variable may have occurred. As open neural tube defects probably differ from closed neural tube defects in pathogenesis and aetiology, ${ }^{22}$ and these different forms cannot always be clinically distinguished, the case group may have-been diluted with a few of closed lesions. This may have led to a bias towards the null value.

Although the original size of the study was rather large, only a small proportion of women were exposed to chemicals during work and consequently, small numbers are involved in the analyses. Studies with small sample size or a low prevalence of exposure usually have a low statistical power. In this study, ORs were only calculated for chemical exposure categories that were reported at least 10 times among cases and controls. This constituted half of the categories. Power calculations for these categories yielded a power to detect an OR of 2 ranging from only $20 \%$ for antineoplastic drugs to $\mathbf{8 2} \%$ for all disinfecting agents. For the other exposure categories, including pesticides, sterilising agents and ionising radiation, the power was even lower and the data did not allow a proper study of these exposures. Instead, we had to resort predominantly to descriptive analyses. The low prevalence of exposure suggests that in The Netherlands, working conditions with exposure to chemicals during pregnancy are not unfavourable for most women. Also, the kind of exposures and their dose and intensity may not be so hazardous as to induce spina bifida in the fetus. As working conditions in other countries may be less favourable, the results 
from this study cannot be generalised to any given country.

In the scientific literature, some studies on neural tube defects and parental occupation have found a positive association between maternal agricultural occupations and spina bifida. ${ }^{13,14}$ Studies on maternal occupational exposure, however, are scarce and inconclusive and do not show any evidence of a relation between maternal pesticide exposure and spina bifida. White et al found that environmental exposure to agricultural chemicals was associated with an increased number of children with spina bifida. ${ }^{23}$ However, exposure assessment was very crude. Brender and Suarez looked at occupational solvent and pesticide exposure, but did not find any exposure effect for the mothers because of low numbers of exposed cases and controls. ${ }^{19}$ Moreover, information on exposures was inferred from information on birth certificates and was not gathered by means of personal interviews. Recently, Nurminen et al. ${ }^{17}$ reported the results of a study on agricultural work and structural malformations. Tree hundred and sixty five central nervous system defects were included, of which most were neural tube defects. The study was case-control by design and made use of interview data. A slightly increased risk was found when agricultural work was compared with non-agricultural work. Also, the authors especially focused on use of pesticides, but a potential effect could not be studied because of small numbers.

In conclusion, our results from the first phase of the study, in which job titles were considered, yielded an increased risk for women working in agricultural occupations. Without further study, this risk would easily be ascribed to pesticide use. However, in depth analyses of tasks and chemical exposure did not confirm this hypothesis, nor could any other occupational explanation be found for the increased risk of women working in agriculture. Remaining explanatory hypotheses besides chance are environmental pollution with pesticides on and around the farm, irrespective of a woman's own activities, and exposure to other factors that might not be work related, such as genetic, behavioural, or nutritional factors. Specific research among larger numbers of women in agricultural occupations, including both occupational and environmental factors might resolve the discrepancy found.

\section{Acknowledgements}

This study was supported by a grant from the Prinses Beatrix Fonds. We are most obliged to the Spina Bifida Teams of the University Hospital Groningen ( $\mathrm{Dr} J \mathrm{H}$ Begeer), the University Hospital of the Free University Amsterdam (Dr CA Kurk), the University Hospital Rotterdam (Dr PCJ de Laat), the rehabilitation centre the Maartensclinic (Dr MJ Poelma), the Elisabeth Hospital Tilburg (Dr JA Rammeloo), the rehabilitation centre Het Roessingh ( $\mathrm{Dr} M$ Stroo), the Academic Medical Centre Amsterdam (Dr JW Weber), the University Hospital Utrecht ( $\mathrm{Dr} \mathrm{H}$ van Wieringen), and the University Hospital of Nijmegen (Dr RA Mullaart). We want to thank Ellen Arends, Miep Opsteeg en Annelies Pellegrino for performing the interviews. Furthermore, we specially thank all the parents for their participation in the study. 


\section{References}

1 Nevin NC, Johnston WP, Merrit JD. Influence of social class on the risk of recurrence of anencephalus and spina bifida. Dev Med Child Neurol 1981;23:155-159.

2 Elwood JM, Elwood JH. Epidemiology of anencephalus and spina bifida. Oxford: Oxford University Press, 1980.

3 Little J, Elwood JH. Socio-economic status and occupation. In: Elwood JM, Little J, Elwood $\mathrm{JH}$, eds. Epidemiology and control of neural tube defects. Monographs in epidemiology and biostatistics. Vol 20. Oxford: Oxford University Press, 1992;456520.

4 Slattery $M L$, Janerich DT. The epidemiology of neural tube defects: a review of dietary intake and related factors as etiologic agents. Am J Epidemiol 1991;133:526540.

5 Smithells RW, Seller MJ, Harris R, Fielding DW, Schorah CJ, Nevin NC, Sheppard S, Read AP, Walker S, Wild J. Further experience of vitamin supplementation for prevention of neural tube defect recurrences. Lancet 1983;1:1027-1031.

Wald N, Sneddon J, Frost C, Stone R. Prevention of neural tube defects: results of the Medical Research Council vitamin study. Lancet 1991;338:131-137.

7 Czeizel AE, Dudas I. Prevention of the first occurrence of neural tube defects by periconceptional vitamin supplementation. N Engl J Med 1992;327:1832-1835.

8 Blatter BM, van der Star M, Roeleveld N. Review of neural tube defects. Risk factors in parental occupation and the environment. Environ Health Perspect 1994;102:140145.

9 Hemminki K, Mutanen P, Luoma K, Saloniemi I. Congenital malformations by the parental occupation in Finland. Int Arch Occup Environ Health 1980;46:93-98.

10 Hemminki K, Mutanen P, Saloniemi I, Luoma K. Congenital malformations and maternal occupation in Finland: multivariate analysis. J Epidemiol Community Health 1981;35:5-10.

11 Sikorski R, Juszkiewicz T, Paszkowski T, Szprengier-Juszkiewicz T. Women in dental surgeries: reproductive hazards in occupational exposure to metallic mercury. Int Arch Occup Environ Health 1987;59:551-557.

12 Matte TD, Mulinare J, Erickson JD. Case-control study of congenital defects and parental employment in health care. Am J Ind Med 1993;24:11-23.

13 Hammond FG, Canache MF. Some epidemiological aspects of neural tube defects in Barquisimeto, Venezuela (Abstract). Am J Hum Genet 1991;49 (suppl.):470.

14 Ericson A, Källén B, Löfkvist E. Environmental factors in the etiology of neural tube defects: a negative study. Environ Res 1988;45:38-47.

15 Stewart WF, Stewart PA. Occupational case-control studies: I. Collecting information on work histories and work-related exposures. Am J Ind Med 1994;26:297-312.

16 Holmberg PC, Nurminen $M$. Congenital defects of the central nervous system and occupational factors during pregnancy. A case-referent study. Am J Ind Med 1980;1: 167-176.

17 Nurminen T, Rantala K, Kurppa K, Holmberg PC. Agricultural work during pregnancy and selected structural malformations in Finland. Epidemiology 1995;6:23-30.

18 Brender CJ, Suarez L. Paternal occupation and anencephaly. Am J Epidemiol 1990;131:517-521.

19 Blatter BM, Roeleveld N, Zielhuis GA, Mullaart RA, Gabreëls FJM. Spina bifida and parental occupation. Epidemiology 1996;7:188-193. 
20 Shaw GM, Gold EB. Methodological considerations in the study of parental occupational exposures and congenital malformations in offspring. Scand J Work Environ Health 1988;14:344-355.

21 Selevan SG, Lemasters GK. The dose-response fallacy in human reproductive studies of toxic exposures. J Occup Med 1987;29:451-454.

22 Lemire RJ. Neural tube defects. JAMA 1988;259:558-562.

23 White FMM, Cohen FG, Sherman G, McCurdy R. Chemicals, birth defects and stillbirths in New Brunswick: associations with agricultural activity. Can Med Assoc J $1988 ; 138: 117-124$. 


\title{
CHAPTER 7.2
}

\section{PATERNAL OCCUPATIONAL EXPOSURE AROUND CONCEPTION AND SPINA BIFIDA IN OFFSPRING}

\author{
BM Blatter, R Hermens, M Bakker, N Roeleveld, ALM Verbeek, GA Zielhuis \\ Am J Ind Med (accepted)
}

\begin{abstract}
A multicenter case-referent study was conducted on the relation between paternal occupational exposure and spina bifida in offspring. Cases were born between 1980 and 1992 in the Netherlands. Referents were recruited from hospitals and from the general population. Postal questionnaires were used to gather information on occupation and potential confounders. Through job-specific telephone interviews with 122 case fathers and 411 referent fathers, detailed exposure information was collected on specific tasks, the use of chemical or physical agents, frequency of exposure, and use of protective equipment. The study yielded statistically significant associations between spina bifida and low exposure to welding fumes (OR=1.6, 95\% Cl: 1.0-2.6) and low exposure to UV-radiation during welding $(O R=2.6,95 \% \mathrm{Cl}: 1.2-5.6)$, and suggestive findings of an association between spina bifida and moderate or high exposure to cleaning agents, moderate or high pesticide exposure $(\mathrm{OR}=1.7,95 \% \mathrm{Cl}: 0.7-4.0)$, and stainless steel dust $(O R=2.0$, 95\% Cl: 0.8-5.2). No associations were identified for other paternal occupational exposures, such as organic solvents.
\end{abstract}

\section{Introduction}

Most teratogenic substances are considered to be affecting the child through the mother. Therefore, the majority of studies assessing the role of occupational exposure as a cause of congenital malformations have focused on maternal exposures. ${ }^{1}$ However, a potential for reproductive toxicity in men as a result of occupational exposure was also established, leading to increased concern about the role of male reproductive toxicants in adverse pregnancy outcomes. ${ }^{2}$ Some mechanisms concerning male-mediated teratogenesis have been proposed. ${ }^{3,4}$ Paternal occupational exposure to chemicals or radiation could theoretically result in genetic damage to germ cells or in concentrations of teratogenic substances in the seminal fluid. These substances might affect the child at conception or later during embryonic development. ${ }^{5}$ Also, indirect exposure of the mother could be caused by carry-home 
exposure of the father.

As a number of studies have reported a relation between neural tube defects and socioeconomic status, ${ }^{6-9}$ studies on the association between these defects and parental occupation were indicated and were indeed suggested in several epidemiologic studies. Some case-referent studies evaluated associations between a large set of paternal occupations and spina bifida. Schnitzer et al. recently conducted a casereferent study with 176 cases of spina bifida and 2,279 referents using self-reported information on paternal occupation from telephone interviews. ${ }^{10}$ They found moderately increased risks for vehicle manufacturers, electronic equipment operators, welders, and carpenters and woodworkers, although the latter three effect estimates were imprecise. Olshan et al. compared paternal occupations of 534 cases of spina bifida with 1,033 referents. ${ }^{11}$ Information on occupation of the father was collected from birth certificates. Increased risks were observed for forestry and logging workers, paper workers, painters, service station attendants, and personal service workers. In an earlier phase of our case-referent study we did an analysis on occupational titles, in which we compared 347 spina bifida cases with 1566 referents. ${ }^{12}$ Postal questionnaires were used to assess the occupation of the father. We saw increased risks for welders and transport workers, although these were not statistically significant.

Several studies investigated only some specific occupations or were small scale studies. Occupations that were identified as a risk factor in two or more of these studies are painters, ${ }^{13-15}$ transport and communication workers, ${ }^{15,16}$ and farmers. ${ }^{16-18}$

Although few of the above findings are consistent, these studies provide some evidence for associations between spina bifida and paternal occupation. However, an important limitation of the studies mentioned is that occupational titles are used as a surrogate for occupational exposure. As Sever and Olshan point out, ${ }^{2,11}$ there is a need for large-scale case-referent studies that include improved assessment of paternal exposure and allow for potentially confounding factors. To our knowledge, no studies have been performed that investigate the effect of occupational exposure of the father on the risk of spina bifida in offspring. We evaluated this relation in a multicenter case-referent study including a relatively large number of spina bifida cases. To get detailed exposure information about the period around conception, joband task-specific telephone interviews were performed.

\section{Population and methods}

Population

In this case-referent study, cases were live-born children with spina bifida aperta (International Classification of Diseases (ICD-9) ${ }^{19}$ codes 741.0 and 741.9) who were born between January 1, 1980 and December 31, 1992. Cases $(N=470)$ were identified by review of medical records in six university hospitals, one regional 
hospital and two rehabilitation centers in the Netherlands. The referent group consisted of 456 children who were born healthy but who experienced a trauma capitis or meningitis during early childhood and were diagnosed in three of the above-mentioned hospitals, and 1894 children from the general population. The latter were recruited from birth registries of $\mathbf{4 5}$ municipalities in the Netherlands. Stratified random sampling was performed to match the population-based referents to the cases, based on size of the municipality (in four categories) and geographic location.

\section{Data collection}

Data collection was carried out in two steps (Figure 1). Firstly, postal questionnaires were sent to the parents of the total study population to collect information on occupation of the father and potentially confounding factors around conception. This part of the study has previously been described in more detail elsewhere. ${ }^{18}$ Secondly, detailed information on paternal occupational exposure was collected from a subset of the fathers by means of telephone interviews. Only fathers who gave consent for participation and who had an occupation with potential for chemical or physical exposure according to the postal questionnaire were interviewed. Detailed interviews with fathers who did not have a job or who worked in jobs without hazardous exposure were deemed irrelevant. The interviewed group included mainly painters, printers, and paper workers, metal workers and mechanics, construction workers, transport workers, agricultural workers, health care workers, and laboratory workers. Because exposure in certain occupations, such as general practitioners, physiotherapists, and higher-level technical occupations, was uncertain, fathers with these occupations were not interviewed and not included in the analyses. Exposure of the remaining fathers (teachers, social workers, clerical and managerial staff) was assumed to be negligible. These men were included in the analyses as non-exposed.

The period of interest ranged from three months before conception until one month after conception, calculated from the duration of pregnancy that was reported in the questionnaire by the mother. In order to pose job-specific questions to the participants, seventeen different questionnaires were specifically designed for printers, painters, plastic or rubber workers, paper workers, metal workers, mechanics, welders, plumbers, bricklayers or jointers, tilers, roadworkers, roofers, carpenters, agricultural workers, transport workers, health care workers, and laboratory workers. Men who could not be classified into one of these groups were interviewed using a general open-ended questionnaire or parts or combinations of the existing questionnaires.

In each interview, traditional work history questions on job title, type of industry, company name, and number of hours worked, were asked first. Subsequently, questions were posed to inquire about every occupational task that had 


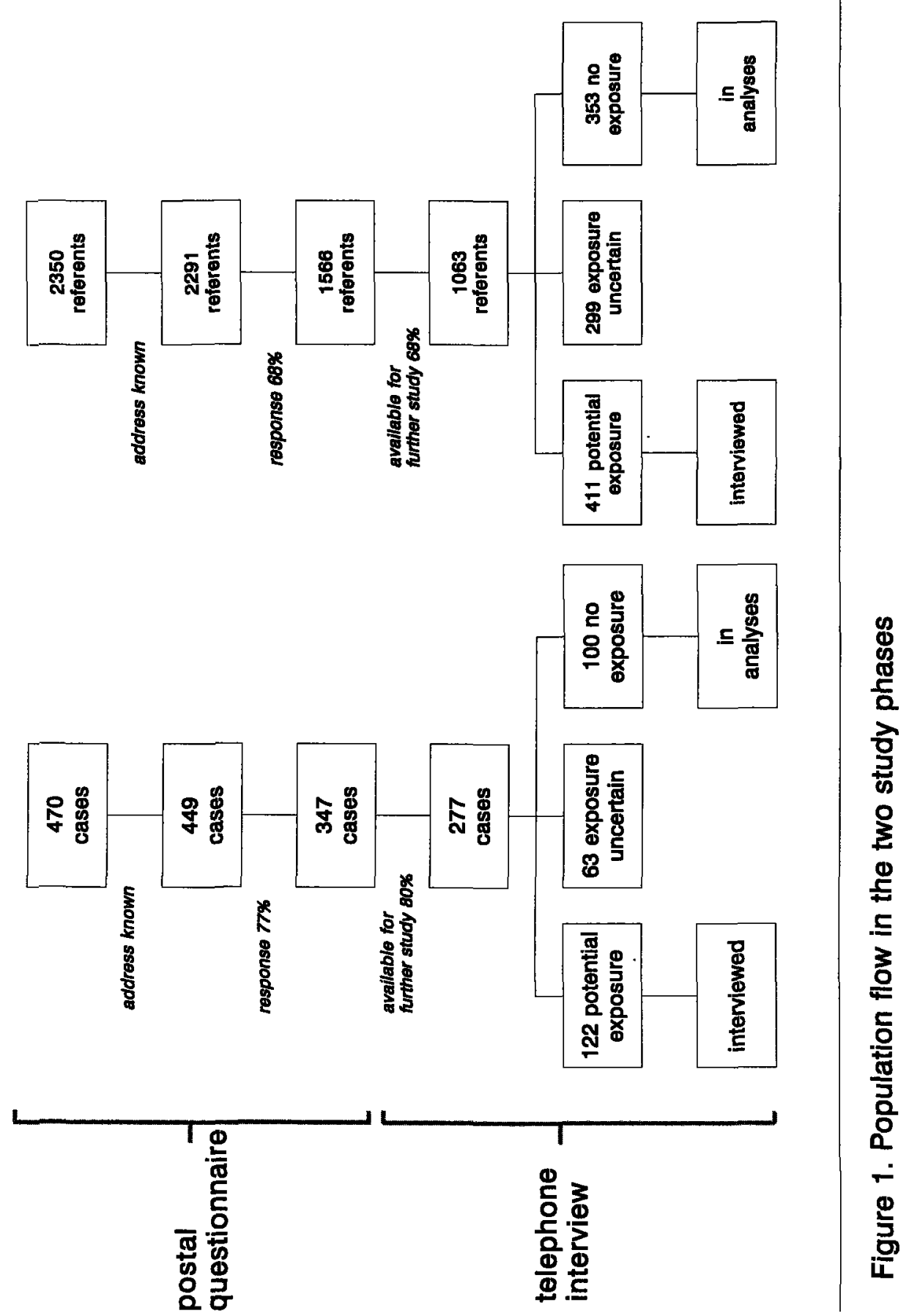


possibly been performed and the associated use of chemicals and radiation, the frequency of the activity or exposure, the use of protective devices, and exposure through proximity of colleagues. Tilers, for instance, were asked whether they used mortar or glue, agricultural workers were asked whether they sprayed pesticides using a tractor or backpack sprayer, and printers were asked whether they had to refill the ink supply and wash the ink rollers. The questionnaires were designed by the investigators on the basis of occupational hygiene information, comparable to the job-specific modules used by Stewart and Stewart in the USA. ${ }^{20}$ At the end of each interview, a checklist with 17 categories of exposure was used to get information on any agents that might have been missed. Again, detailed questions were asked for the agents that were reported using the checklist.

Estimation of the level of exposure for each exposure category was based on the self-reported interview information (exposure yes or no, frequency of exposure in hours per week, and kind of protective equipment used) and on the the professional judgement of the investigators. A 4-point scale was used to indicate the level of exposure (not exposed, lightly exposed, moderately exposed, or heavily exposed).

\section{Analysis}

The prevalence of exposure was evaluated among fathers in certain occupational groups and in the total group of possibly exposed (interviewed) and nonexposed workers. Within each of the well-defined occupational groups with potential for exposure (see Tables 7.2.2 through 7.2.4), descriptive analyses were performed in order to identify differences between cases and referents. For each occupational group only agents specific for that group were included in these analyses. The chisquare test was used to calculate p-values for the categories for which prevalences differed between cases and referents.

After combining all occupational groups, frequency distributions and odds ratios (ORs) with $95 \%$ confidence intervals $(95 \% \mathrm{Cls})$ were calculated. To be parsimonious, 39 of the 72 exposure categories that we coded are not presented. Criteria for exclusion of exposure categories from Table 7.2.5 were: less than 10 exposed subjects (cases and referents) and a probable local working mechanism, in which case the exposure categories were considered irrelevant with respect to a possible teratogenic effect. For instance, various types of dust and asbestos were not presented. For exposure categories with 10 or less exposed cases, the level of exposure was dichotomized into no exposure versus any level of exposure. ORs were separated for light and moderate or heavy exposure for exposure categories with more than 10 cases exposed. Fathers in one exposure category were compared with all fathers who were not exposed to that specific agent.

The odds ratios were adjusted by means of restriction for maternal use of antiepileptics, maternal diagnosis of homocysteinaemia or diabetes, and consanguin- 
ity, and by means of logistic regression analysis for ovulation stimulating agents, oral contraceptives, parity, maternal and paternal family history of neural tube defects (NTD), and maternal and paternal alcohol use and smoking.

\section{Results}

Three hundred forty-seven case fathers $(77 \%)$ and 1566 referent fathers $(68 \%)$ returned the questionnaire in the first phase of the study (Figure 1). From these fathers, $277(80 \%)$ and $1063(68 \%)$, respectively, were available for participation in a personal interview. Of the 277 case fathers, 122 had an occupation with potential for chemical or physical exposure and were interviewed; 100 had a nonexposed occupation. Of the 1063 referents, 411 were potentially exposed and interviewed; 353 had a nonexposed occupation. The remaining fathers had occupations in which exposure was uncertain and were excluded from this phase of the study.

TABLE 7.2.1 Distribution of potentially confounding factors for cases of spina bifida and referents, in a study on paternal occupational exposure, The Netherlands, 1980-1992

\begin{tabular}{|c|c|c|c|c|}
\hline \multirow[b]{2}{*}{ Potential confounders } & \multicolumn{2}{|c|}{ Cases $(N=222)$} & \multicolumn{2}{|c|}{ Referents $(\mathrm{N}=764)$} \\
\hline & $\mathbf{N}$ & $\%$ & $N$ & $\%$ \\
\hline \multicolumn{5}{|l|}{ Paternal education* } \\
\hline Low & 69 & 31.7 & 202 & 26.5 \\
\hline Middle & 90 & 41.3 & 277 & 36.4 \\
\hline High & 59 & 27.1 & 283 & 37.1 \\
\hline \multicolumn{5}{|l|}{ Maternal education* } \\
\hline Low & 70 & 32.3 & 199 & 26.2 \\
\hline Middle & 103 & 47.5 & 362 & 47.7 \\
\hline High & 44 & 20.3 & 198 & 26.1 \\
\hline Paternal alcohol use & 185 & 83.3 & 659 & 86.5 \\
\hline Maternal alcohol use & 114 & 52.1 & 446 & 58.5 \\
\hline Paternal smoking & 107 & 48.4 & 354 & 46.4 \\
\hline Maternal smoking & 88 & 40.5 & 303 & 39.8 \\
\hline Primiparity & 99 & 45.2 & 311 & 40.8 \\
\hline Oral contraceptive use & 84 & 38.5 & 242 & 32.0 \\
\hline Diabetes mellitus & 1 & 0.5 & 5 & 0.7 \\
\hline Maternal use of antiepileptics & 0 & 0.0 & 2 & 0.3 \\
\hline Homocysteinaemia & 2 & 0.9 & 0 & 0.0 \\
\hline Ovulation stimulating agents & 9 & 4.1 & 26 & 3.4 \\
\hline Consanguinity & 1 & 0.5 & 2 & 0.3 \\
\hline Paternal family history of NTDs & 16 & 7.2 & 11 & 1.4 \\
\hline Maternal family history of NTDs & 10 & 4.5 & 8 & 1.1 \\
\hline
\end{tabular}


TABLE 7.2.2 Occupational exposure of fathers of spina bifida cases and referents, among industrial workers and by occupational group, The Netherlands, 1980-1992

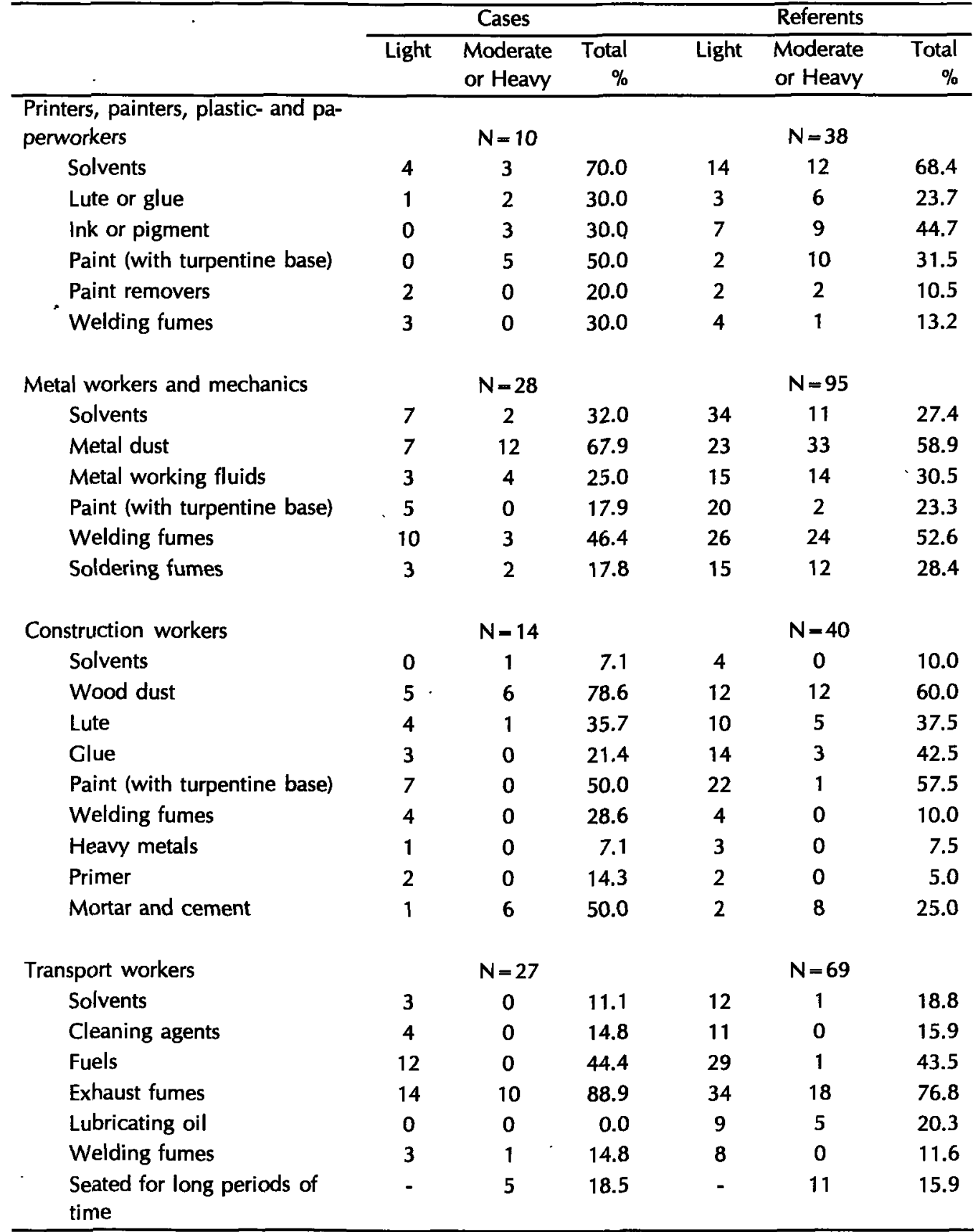


Table 7.2.1 presents the distribution of potentially confounding factors for cases and referents. Both paternal and maternal education of the cases was slightly lower than that of the referents. Furthermore, small differences were seen in alcohol use. The largest differences were found in the prevalence of paternal and maternal positive family histories of NTDs: $7.2 \%$ and $4.5 \%$, respectively, among the cases, and $1.4 \%$ and $1.1 \%$ among the referents.

In Table 7.2.2, the number and the total proportion of exposed industrial workers is presented, itemized by four rather homogeneous occupational groups: painters, printers, plastic, and paper workers; metal workers and mechanics; construction workers; and transport workers. Only those agents that were specifically used in these occupations are shown. Moderately and heavily exposed workers were combined in one category, because of small numbers. In general, differences between exposure prevalences were small and based on very small numbers. Exposure to welding fumes seemed to be more frequent among case fathers in printers, painters, plastic and paper workers $(30 \%$ vs $13 \%, p=0.20)$, just as for construction workers $(29 \%$ vs $10 \%, p=0.11)$. In addition, exposure to primers $(14 \%$ vs $5 \%$,

TABLE 7.2.3 Occupational exposure of fathers of spina bifida cases and referents, in agricultural occupations, The Netherlands, 1980-1992

\begin{tabular}{lcccccc}
\hline & \multicolumn{3}{c}{ Cases $(\mathrm{N}=11)$} & \multicolumn{3}{c}{ Referents (N-48) } \\
\cline { 2 - 7 } Chemical or & Light & $\begin{array}{r}\text { Moderate } \\
\text { physical agents }\end{array}$ & Total & Light & $\begin{array}{c}\text { Moderate } \\
\text { or Heavy }\end{array}$ & $\begin{array}{c}\text { Total } \\
\%\end{array}$ \\
\hline Cleaning agents & 1 & 2 & 27.3 & 15 & 3 & 37.5 \\
Disinfectants & 2 & 0 & 18.2 & 8 & 4 & 25.0 \\
$\quad$ Formaldehyde & 2 & 0 & 18.2 & 4 & 1 & 10.4 \\
Biological material & 3 & 1 & 36.4 & 18 & 1 & 39.6 \\
Hay dust & 1 & 5 & 54.5 & 3 & 20 & 47.9 \\
Bioactive agents (cattle fodder) & 1 & 6 & 63.6 & 5 & 22 & 56.3 \\
Artificial fertilizers & 3 & 0 & 27.3 & 17 & 3 & 41.7 \\
Pesticides & 1 & 8 & 81.8 & 17 & 17 & 71.0 \\
$\quad$ Herbicides & 0 & 7 & 63.6 & 11 & 15 & 54.2 \\
$\quad$ Fungicides & 0 & 1 & 9.1 & 3 & 2 & 10.4 \\
$\quad$ Insecticides & 0 & 3 & 27.3 & 6 & 8 & 29.2 \\
$\quad$ 'Tree disease' agents & 0 & 1 & 9.1 & 0 & 4 & 8.3 \\
Working with backpacksprayer & & 5 & 45.5 & & 14 & 29.2 \\
Fuel & 7 & 0 & 63.6 & 36 & 0 & 75.0 \\
Exhaust fumes & 7 & 1 & 72.7 & 28 & 9 & 77.1 \\
Lubricating oil & 3 & 1 & 36.4 & 9 & 4 & 27.1 \\
Welding fumes & 4 & 1 & 45.5 & 10 & 0 & 20.8 \\
Wood conserving agents & 4 & 0 & 36.4 & 15 & 0 & 31.3 \\
\hline
\end{tabular}


$\mathrm{p}=0.27)$ and mortar and cement $(50 \%$ vs $25 \%, \mathrm{p}=0.08)$ was more frequent among case fathers with construction work; exposure to glue occurred less often in fathers of cases $(21 \%$ vs $43 \%, p=0.16)$. Except for wood dust and mortar and cement, moderate or high exposure occurred infrequently in construction workers. For the groups of metal workers and transport workers, no differences in exposure frequencies were observed. Except for exhaust fumes, moderate or high exposure rarely occurred in transport workers. 'Being seated for long periods of time' was included because of the hypothesis of an adverse effect of increased sperm temperature. No difference was found between cases and referents.

Table 7.2.3 presents the distribution of occupational exposure in agricultural workers. No differences were seen in the total number of pesticides users between fathers of cases and referents. However, moderate or high exposure to pesticides was more frequent in cases than in referents $(73 \%$ vs $35 \%, p=0.05)$. Moreover, $45 \%$ of the case fathers worked with a backpack sprayer, compared to $29 \%$ of the referent fathers $(p=0.24)$. Exposure to welding fumes was also more frequent in case fathers than referent fathers $(45 \%$ vs $21 \%, p=0.10)$, but all but one of the men were lightly exposed.

TABLE 7.2.4 Occupational exposure of fathers of spina bifida cases and referents, in health care and laboratory work, The Netherlands, 1980-1992

\begin{tabular}{llrcr}
\hline Chemical or & \multicolumn{2}{c}{ Cases $(\mathrm{N}=7)$} & \multicolumn{2}{c}{ Referents $(\mathrm{N}=\mathbf{2 8})$} \\
physical agents & $\mathrm{N}$ & $\%$ & $\mathrm{~N}$ & $\%$ \\
\hline Solvents & 3 & 42.9 & 16 & 57.1 \\
$\quad$ Chloride containing solvents & 1 & 14.3 & 5 & 17.9 \\
$\quad$ Alcohol & 3 & 42.9 & 16 & 57.1 \\
Cleaning agents & 2 & 14.3 & 7 & 25.0 \\
Disinfectants & 2 & 28.6 & 9 & 32.1 \\
$\quad$ Formaldehyde & 0 & 0.0 & 4 & 14.3 \\
Biological material & 0 & 0.0 & 8 & 28.6 \\
Antibiotics & 2 & 28.6 & 8 & 28.6 \\
Antineoplastic drugs & 1 & 14.3 & 2 & 7.1 \\
Anesthetics & 0 & 0.0 & 4 & 14.3 \\
lonising radiation & 1 & 14.3 & 9 & 32.1 \\
\hline
\end{tabular}

In Table 7.2.4, exposure of health care workers and laboratory workers is shown. The exposure levels were combined because of small numbers of exposed. No differences were observed between exposure of cases and referents.

Table 7.2.5 presents the results of the adjusted ORs with $95 \% \mathrm{Cls}$ for all fathers in the possibly-exposed occupations $(N=533)$ and nonexposed occupations $(N=453)$ 


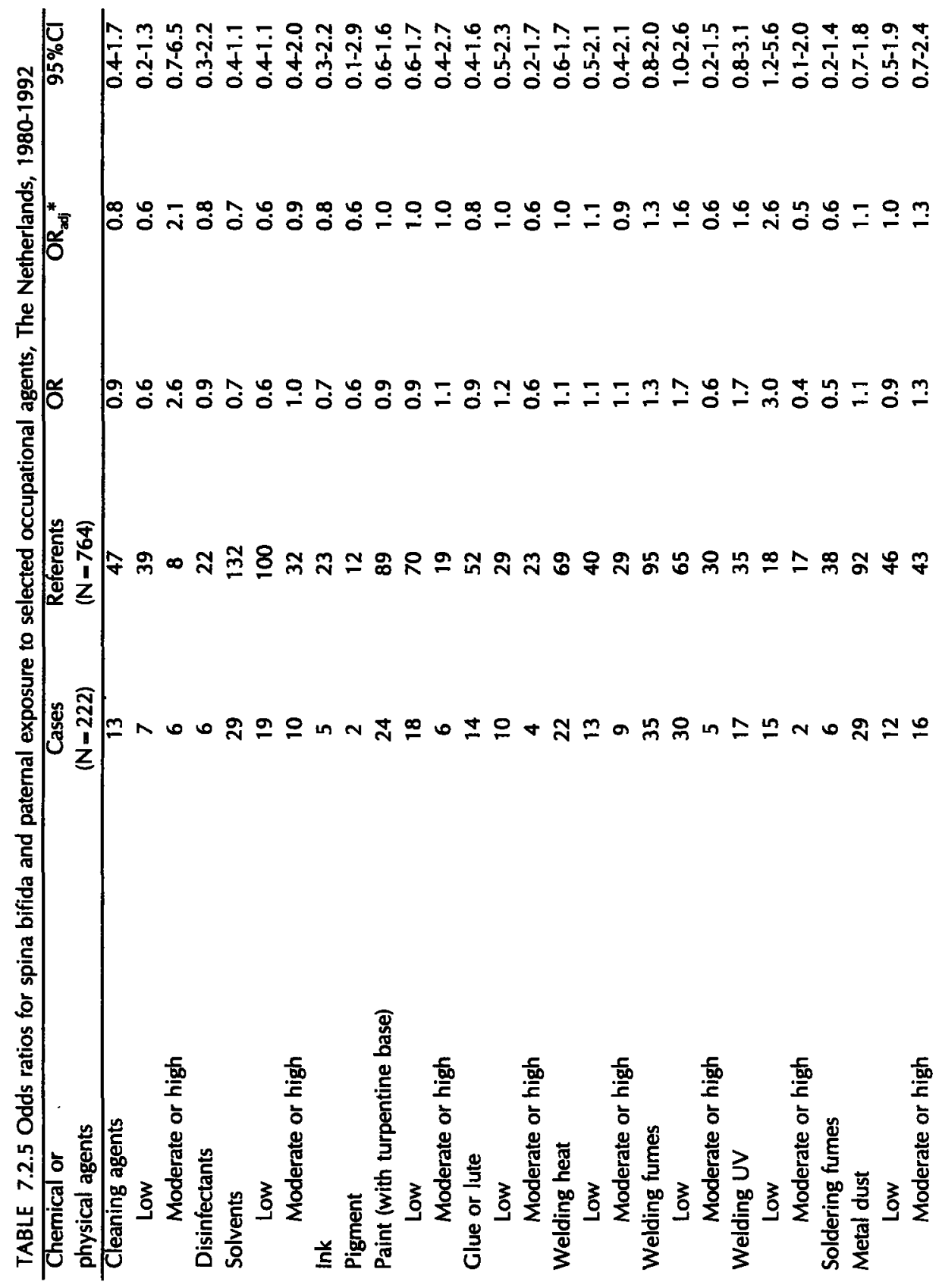




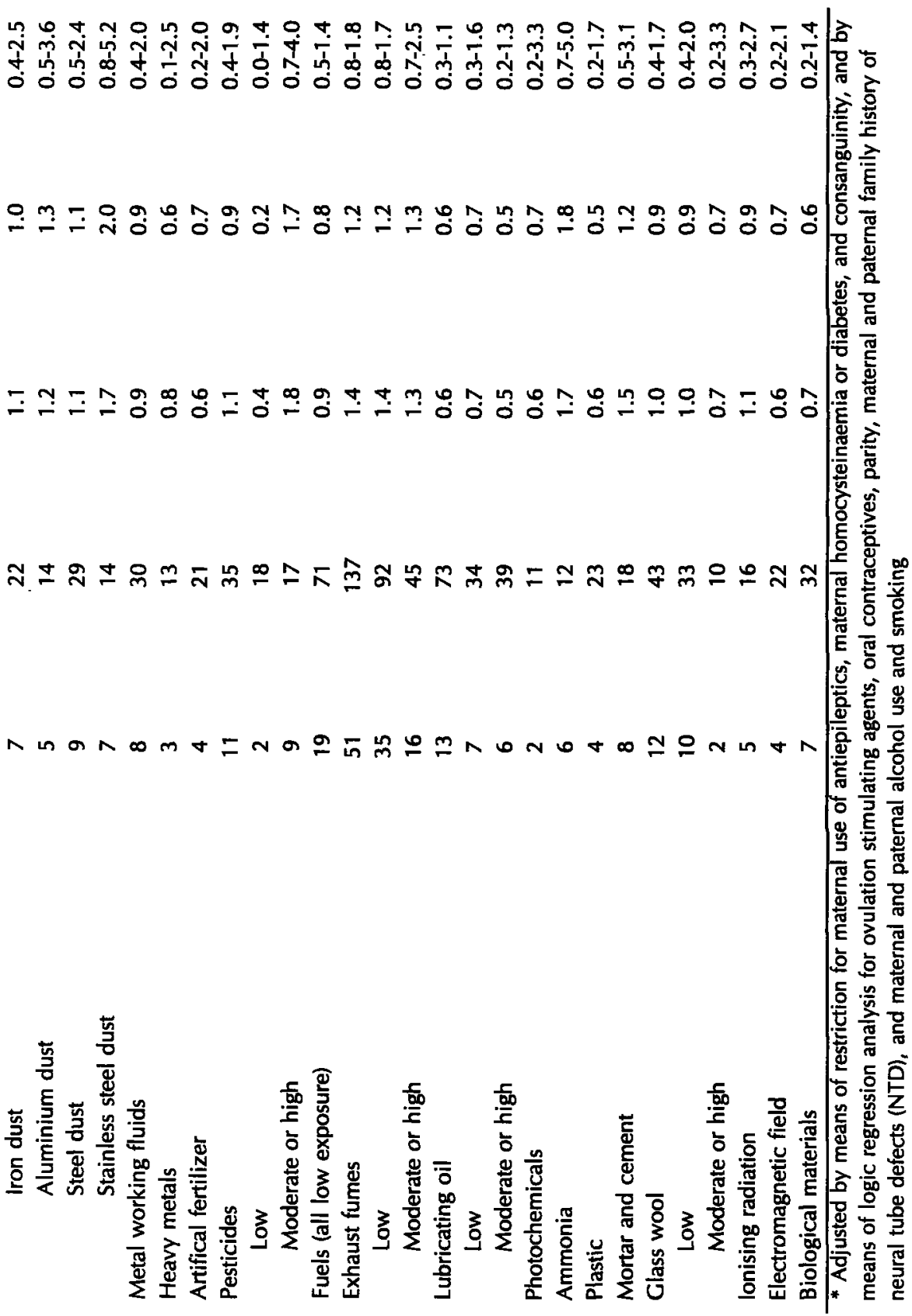


combined. Most adjusted ORs did not differ from the crude ORs, except for moderate or high exposure to cleaning agents, low exposure to UV radiation during welding and exposure to stainless steel dust. Besides for low exposure to welding fumes and low exposure to UV radiation during welding, all of the $95 \% \mathrm{Cls}$ included unity. An increased risk was found for moderate or high exposure to cleaning agents $(\mathrm{OR}=2.1,95 \% \mathrm{Cl}: 0.7-6.6)$, which was not statistically significant, and for low exposure to welding fumes $(O R=1.6,95 \% \mathrm{Cl}$ : 1.0-2.6). A statistically significantly increased ORs was also found for low exposure to UV radiation during welding $(O R=2.6,95 \% \mathrm{Cl}: 1.2-5.6)$. Stainless steel dust $(\mathrm{OR}=2.0,95 \% \mathrm{Cl}: 0.8-5.2)$, ammonia $(\mathrm{OR}=1.8,95 \% \mathrm{Cl}: 0.8-5.0)$, and moderate or high exposure to pesticides were associated with spina bifida $(O R=1.7,95 \% \mathrm{Cl}$ : $0.7-4.0)$. As exposure to the latter agents might be associated with an agricultural occupation of the mother, which appeared to be a risk factor for spina bifida, ${ }^{12}$ we performed an analysis in which we adjusted for agricultural occupation of the mother. The ORs did not change substantially after correction $\left(O R_{\text {total welding fumes }}=1.2, O R_{u v}=1.5, O R_{\text {high or moderate pesticides }}=1.6\right)$. Finally, it has to be noticed that among the multitude of comparisons a number of decreased risks of spina bifida were found as well.

\section{Discussion}

This study did not identify any strong associations between paternal occupational exposure to chemicals or radiation shortly before pregnancy and the risk of spina bifida in offspring. Associations that were not always statistically significant were found between low exposure to welding fumes and UV-radiation during welding, high or moderate exposure to pesticides, stainless steel dust, and high or moderate exposure to cleaning agents and spina bifida. The slightly increased risk for exposure to welding fumes was primarily caused by an increase among painters, printers, plastic and paper workers, construction workers, and agricultural workers, but not by an increase among the professional welders or metal workers. The level of exposure to welding fumes in these workers was low, but less protective equipment was used by these workers than by professional welders ( $46 \%$ compared with $86 \%$ ). The increased risk for UV-radiation during welding might be a proxy for the risk for exposure to welding fumes. Because UV-radiation is visible to the worker, it might be less prone to subjective interpretation of the participant.

An increased risk of spina bifida for welders has been found before in a study in Atlanta. ${ }^{10}$ We also found an association with welders in an analysis on occupational titles in the Dutch case-referent study, ${ }^{12}$ of which a large part of the population was used in the present study to thoroughly investigate the influence of occupational exposure. In both studies, however, confidence intervals were wide. Scandinavian investigators reported that sperm quality and fertility seem to be reduced among welders. ${ }^{21,22}$ 
In accordance with the increased risk that we found for moderate or high pesticide exposure, Brender and Suarez also found a slightly increased risk for pesticide exposure $(\mathrm{OR}=1.3,95 \% \mathrm{Cl}: 0.8-2.1){ }^{14}$ However, exposure was inferred from occupational title and not assessed by means of detailed exposure information. We are unaware of any studies that have investigated paternal occupational exposures to pesticides and the risk of spina bifida, but farmers have been associated with spina bifida by Polednak and Janerich, ${ }^{16}$ Balarajan and McDowall, ${ }^{17}$ and Hammond and Canache. ${ }^{18}$

We found an increased risk for moderate or high exposure to cleaning agents, which often include solvent, but no differences in (other) solvent exposure were observed in this study. Taskinen et al. performed a small scale nested case-referent study on solvents and congenital malformations in general, using questionnaires and biological monitoring to assess the exposure to six organic solvents. ${ }^{23}$ Slightly increased risks were found for toluene, xylene, and miscellaneous organic solvents, but numbers were small and no firm conclusions could be drawn. Brender and Suarez found an increased risk of anencephaly for fathers with occupations associated with solvent exposure $(\mathrm{OR}=2.5,95 \% \mathrm{Cl}: 1.6-4.1){ }^{14}$ We found no difference in exposure between case and referent fathers who worked in health care. This is consistent with findings of Matte et al., ${ }^{24}$ who conducted a case-referent study with 211 cases of spina bifida focusing on the potential associations with employment in health care. They did not find an association between spina bifida and paternal health care employment or any specific exposure.

The present study has some potential limitations that deserve consideration. Exposures occurred between two and 15 years before the interview. Therefore, recall of early exposures might be limited, probably causing bias towards the null value. Differential recall between case and referent fathers may also have occurred, as the time lag between exposure and interview was unequally distributed in cases and referents. Thirty-six percent of the case fathers reported exposures for the most recent period (one to five years ago) compared to $22 \%$ of the referent fathers. Therefore, recall might have been better for cases. Whether inaccurate recall of earlier periods causes a bias by under- or overreporting cannot be inferred. Also, another form of information bias may have occurred. Although generally there is concern that parents of cases recall exposures better, and overreport exposures compared to referent parents, our experience is that case fathers sometimes tend to ascribe their child's birth defect to other factors, such as the nuclear accident in Chernobyl, genetic factors, recreational drug use, or poor living conditions. We tried to enhance recall and reduce information bias by asking about exposure indirectly with questions about concrete tasks and by asking direct questions about chemicals used in these tasks. In addition, the self-reported information was reviewed and adjusted by the professional judgement of the investigators with respect to frequency and other 
details of exposure. Shaw and Gold mention a number of studies specifically evaluating information bias on exposures during pregnancy; the presence of information bias was not demonstrated. ${ }^{25}$ However, information bias can never be ruled out in a study using self-reported data.

A limitation of two-step data collection is that nonresponse accumulates. The response rates for the postal questionnaires were $77 \%$ for case fathers and $68 \%$ for referent fathers. In the postal questionnaire the fathers were asked whether they were willing to participate in a personal interview at a later time. Eighty-one percent of the case fathers and $69 \%$ of the referent fathers answered positively. Differences in nonresponse between fathers with different occupations could have resulted in selection bias. Comparison of the initial total population $\left(N_{\text {cases }}=347, N_{\text {refs }}=1566\right)$ with the population used in this study $\left(N_{\text {cases }}=222, N_{\text {refs }}=764\right.$ ) yielded only small differences between the occupational distributions.

As a selection of only live-born spina bifida cases was studied, the small effects that were found in this study might be a result of the so-called 'inverse dose-response relationship': a very high exposure could result in infertility or early fetal loss, whereas a lower exposure might result in a congenital malformation recognized at birth. ${ }^{26}$ Furthermore, misclassification on the outcome variable may have occurred. As open spina bifida probably differs from closed spina bifida with respect to pathogenesis and etiology, ${ }^{27}$ and these different forms cannot always be clinically distinguished, the case group may have been diluted with a few closed lesions. This may have led to a bias towards the null value.

The present study has several strengths which probably reduce misclassification relative to other studies on paternal occupation and spina bifida. ${ }^{25}$ We did not use job titles in this study as a surrogate for occupational exposure, nor did we infer exposure by means of job exposure matrices which are often unspecific. Postal questionnaires were first used to collect information on the fathers' occupation shortly before pregnancy. We then interviewed the potentially exposed participants with job-specific questionnaires, in which questions were asked about all the tasks that possibly were performed, the frequency and duration of the tasks and the associated chemical or physical exposure, use of protective devices, and use of chemicals by colleagues. In this way, we were able to form relatively homogeneous exposure groups.

Information on potentially confounding factors was gathered by means of postal questionnaires. This might have minimized misclassification on the confounders as questionnaire information on life style factors may be less influenced by the tendency to give socially desirable answers than information gathered in a face-to-face situation or during telephone interviews. ${ }^{28}$ In addition, data on potentially confounding factors related to the father were available from the paternal questionnaire, but data on factors related to the mother were reported by the mother herself in the maternal questionnaire. Therefore, the ORs could be adjusted for all potential 
confounders. Periconceptional folic acid use was not taken into account as a confounder, as this vitamin was not added to multivitamin supplements nor separately available in the Netherlands during the study period. Education was not adjusted for, because of the risk of overadjustment. We were not able to adjust for maternal occupational exposure as we only had information on maternal exposures for a part of the fathers. We did perform an additional analysis adjusting for maternal agricultural occupation, which appeared to be a risk factor for spina bifida. ${ }^{12}$ No differences were observed.

Finally, we may notice that a relatively large number of spina bifida cases was included in this study. The study had a power of $96 \%$ to detect a twofold statistically significantly increased risk of solvent exposure, a power of $90 \%$ to detect a twofold increased risk of welding fumes and paint, and a power of $75 \%$ to detect a twofold increased risk of glue and lute. However, for exposure to stainless steel dust the power was only $29 \%$ to detect an OR of 2 , and for moderate or high pesticide exposure the power was $42 \%$.

Our research findings may also be viewed in terms of the population attributable proportion, which is the proportion of cases in the target population that is attributable to the exposure under study. As the risks of spina bifida from welding fumes or high or moderate pesticide exposure are only slightly elevated and the exposure prevalences in the population are low, the population attributable proportions are small also. For exposure to welding fumes it is $3 \%$; for high or moderate pesticide exposure it is $1.5 \%$. Attributable proportions computed with ORs of exposure to high or moderate pesticide exposure equal to 2,4 or 6 , are $2 \%, 6 \%$ and $10 \%$, respectively. This enables us to draw the conclusion that paternal occupational exposure does not seem to play a major role in the causation of spina bifida. Still, the associations between spina bifida and welding UV, welding fumes, stainless steel dust, and pesticides deserve further in-depth study, which may elucidate more of the multifactorial etiologic mechanisms of spina bifida.

\section{Acknowledgements}

This study is financially supported by the Prinses Beatrix Fonds. We would like to thank the Spina Bifida Teams of the University Hospital Groningen (JH Begeer), the University Hospital of the Free University Amsterdam (CA Kurk), the University Hospital Rotterdam (PCJ de Laat), the University Hospital of Nijmegen (RA Mullaart), the rehabilitation centre the Maartensclinic (MJ Poelma), the Elisabeth Hospital Tilburg (JA Rammeloo), the rehabilitation centre Het Roessingh (M Stroo), the Academic Medical Centre Amsterdam (WW Weber), the University Hospital Utrecht $(\mathrm{H}$ van Wieringen), and all the participating parents in the study. Furthermore, we thank Annelies Pellegrino for performing part of the telephone interviews and Patricia Stewart of USA National Cancer Institute for sharing some of their job modules with us. 


\section{References}

1 Sever LE. Congenital malformations related to occupational reproductive hazards. Occ̈up Med 1994;9:471-494.

2 Sever LE. Male-mediated developmental toxicity (editorial). Epidemiology 1995;6:573574.

3 Colie CF. Male mediated teratogenesis. Reprod Toxicol 1993;7:3-9.

4 Olshan AF, Faustman EM. Male-mediated developmental toxicity. Reprod Toxicol 1993;7:191-202.

5 Hales BF, Smith S, Robaire B. Cyclophosphamide in the seminal fluid of treated males: transmisison to females by mating and effect on pregnancy outcome. Toxicol Appl Pharm 1986;84:423-430.

6 Leck I. Causation of neural tube defects: clues from epidemiology. Brit Med I 1974;30:158-163.

7 Nevin NC, Johnston WP, Merrit JD. Influence of social class on the risk of recurrence of anencephalus and spina bifida. Dev Med Child Neurol 1981;23:155-159.

8 Elwood JM, Elwood JH. Epidemiology of anencephalus and spina bifida. Oxford: Oxford University Press, 1980.

9 Little J, Elwood JH. Socio-economic status and occupation. In: Elwood JM, Little J, Elwood $\mathrm{JH}$, eds. Epidemiology and control of neural tube defects. Monographs in Epidemiology and Biostatistics. Vol 20. Oxford: Oxford University Press, 1992;456520.

10 Schnitzer PG, Olshan AF, Erickson JD. Paternal occupation and risk of birth defects in offspring. Epidemiology 1995;6:577-583.

11 Olshan AF, Teschke K, Baird PA. Paternal occupation and congenital anomalies in offspring. Am J Ind Med, 1991;20:447-475.

12 Blatter BM, Roeleveld N, Zielhuis GA, Mullaart RA, Gabreëls FJM. Spina bifida and parental occupation. Epidemiology 1996;7:188-193.

13 Olsen J. Risk of exposure to teratogens amongst laboratory staff and painters. Dan Med Bull 1983;30:24-28.

14 Brender CJ, Suarez L. Paternal occupation and anencephaly. Am J Epidemiol 1990;131:517-521.

15 Fedrick J. Anencephalus in the Oxford Record Linkage Study area. Dev Med Child Neurol 1976;18:643-656.

16 Polednak AP, Janerich DT. Use of available record systems in epidemiologic studies of reproductive toxicology. Am J Ind Med 1983;4:329-348.

17 Balarajan R, McDowall M. Congenital malformations and agricultural workers. Letter. Lancet 1983; I:1112-1113.

18 Hammond FG, Canache MF. Some epidemiological aspects of neural tube defects in Barquisimeto, Venezuela. Abstract. Am J Hum Genet 1991;49, suppl., 470.

19 World Health Organization. International Classification of Diseases, Ninth Revision. Geneva, Switzerland: World Health Organization, 1977.

20 Stewart WF, Stewart PA. Occupational case-control studies: I. Collecting information 
on work histories and work-related exposures. Am J Ind Med 1994;26:297-312.

21 Mortensen JT. Risk for reduced sperm quality among metal workers, with special reference to welders. Scand J Work Environ Health 1988;14:27-30.

22 Bonde JP, Hansen KS, Levine RJ. Fertility among Danish male welders. Scand J Work Environ Health 1990;16:315-322.

23 Taskinen H, Antilla A, Lindbohm ML, Sallmen M, Hemminki K. Spontaneous abortions and congenital malformations among the wives of men occupationally exposed to organic solvents. Scand J Work Environ Health 1989;15:345-352.

24 Matte TD, Mulinare J, Erickson JD. Case-control study of congenital defects and parental employment in health care. Am J Ind Med 1993;24:11-23.

25 Shaw GM, Gold EB. Methodological considerations in the study of parental occupational exposures and congenital malformations in offspring. Scand J Work Environ Health 1988; 14:344-355.

26 Selevan SG, Lemasters GK. The dose-response fallacy in human reproductive studies of toxic exposures. J Occup Med 1987;29:451-454.

27 Lemire RJ. Neural tube defects. JAMA 1988;259:558-562.

28 Armstrong BK, White E, Saracci R. Principles of exposure measurement in epidemiology. Monographs in Epidemiology and Biostatistics. Vol 21. Oxford: Oxford University Press, 1992;22-48. 


\section{CHAPTER 8}

\section{GENERAL DISCUSSION}

The main objectives of this thesis were to identify whether parents with specific occupations have an increased risk of spina bifida in offspring and to study whether parental occupational exposure to specific chemicals or radiation during or shortly before pregnancy is a risk factor for the occurrence of spina bifida. These issues may be of concern to physicians dealing with spina bifida and prenatal care and policy makers dealing with occupational health, but also to many parents who have a child with spina bifida and who are searching for causes of their child's handicap. At the time this study was started in 1991, there were some indications for associations between central nervous system defects or neural tube defects and parental occupations. Recently, one study besides our study, conducted by Shaw and co-workers, has focussed on occupational exposures as risk factors of spina bifida.

In this chapter, the results that we observed will be evaluated and set in a wider context of the epidemiologic literature on this topic, preceded by an evaluation of the study methodology that was used. The conclusions, practical implications, and leads for future research will be addressed in the last part of this chapter.

\section{Evaluation of study methodology}

Several aspects of methodological issues were learned from this study, some of which are inherent to epidemiologic studies in the field of reproductive disorders. Case definition in case-referent studies deserves some attention, which means that investigators should aim to form homogeneous case groups of people with diseases or defects. With regard to spina bifida, some findings suggest that this defect actually encompasses an aetiologically heterogeneous group of defects. ${ }^{1-4}$ We evaluated this in a sample of our population using subcategories of high and low, and open and closed spina bifida based on information from medical records (Chapter 5). Although the risk estimates were imprecise due to small numbers in the subcategories and misclassification could have occurred, we found indications that some parental occupations and genetic susceptibility factors in particular were differentially associated with subclasses of spina bifida. Therefore, the suggestion holds for future studies to evaluate different types of spina bifida separately in addition to the overall analyses.

The choice of an appropriate referent group is another major difficulty in casereferent studies on reproductive disorders. In the literature it is stressed that the use 
of hospital referents increases the response to the questionnaire, is more convenient, and in particular reduces recall bias. A disadvantage of the use of a hospital-based referent group might be selection bias due to a possible association of exposure with the referent disorder. ${ }^{5}$ We compared questionnaire information from a hospital-based referent group of children with cerebral trauma or meningitis with a populationbased referent group derived from municipal birth registers, with regard to indications for selection bias and recall bias, response rates, and feasibility aspects (Chapter 3.2). The selection process of population referents via municipal birth registers was more convenient than via hospital records or patient lists, and higher response rates were observed among the population referents (Chapter 3.2). In addition, fathers in agricultural occupations and parents with a lower education appeared to be overrepresented among the hospital referents. This might have been due to selective non-response or to an association between the specific referent disorder that we selected and the risk factors under study, thereby rendering the referent group a nonrepresentative sample of the base population. As similar answers were obtained in hospital and population referents to questions on alcohol use and smoking, no indications for recall bias with regard to lifestyle factors came up in this study. However, recall bias was found for some occupational exposures. A more accurate method of exposure assessment, as we applied in the second phases of our core study, would minimize this. Another important issue in weighing the use of hospital referents against the use of population referents is that parents of healthy children who are approached for a questionnaire study may face fewer emotional problems than parents of sick or disabled children who do not have the condition being studied. Combining all of these factors, we conclude that population referents may be a valid and feasible alternative to hospital referents in this type of reproductive study.

The two-step method of data collection used seems suitable for the study purpose. Postal questionnaires were designed to gather information on parental occupations and other risk factors of spina bifida in the first phase of the study. Assessment of occupations in this way is preferred to using birth registers or hospital records because it is possible to fine-tune the coding of occupations with the information provided on daily activities. The time period that was taken as a proxy for the date of conception was one year before birth of the child. This date is easy to calculate and may result in more valid estimates of lifestyle habits in the first month of pregnancy than questions about the pregnancy period itself.

Usually, data on occupational exposures collected in interviews are limited to responses to general questions asked of all participants. To specify occupational exposures in the second phase of our study, job-specific 'tailor-made' interviews were designed. Standardized questionnaires were used with indirect questions on tasks performed, to ease the recall of occupational exposures. Self-reported informa- 
tion and expert evaluation were combined to assess the level of exposure. Later, a comparative study confirmed our hypothesis that data collection on occupational exposure using job-specific interviews yielded results of better quality than data collection by a postal questionnaire (Chapter 2.1). An additional advantage of the two-step procedure was that knowledge of the occupations of the participants enhanced the efficiency of the data collection in the second phase of the study. Only questionnaires considering occupations that occurred in our study population had to be designed and costly interviews with clerks, administrators, teachers, directors, and managers, who have negligible chemical and physical exposure, could be avoided. Our approach is partly comparable to a method used by $\mathrm{NCl}$, which was recently presented in the epidemiologic literature. ${ }^{6}$ The two-step method of data collection might also be useful in research on other topics.

The explorative character of the present study requires knowledge of a broad range of occupations and exposures, which in turn would require several industrial hygienists with specific expertise to design and evaluate the questionnaires. Our method of data collection would improve in future studies by limiting the research question to a few occupational or exposure categories or using a larger number of industrial hygienists with specific knowledge.

Many studies on the relation between birth defects and parental occupation are register-based, with the possibility of only limited control of confounding. We included in the questionnaire most of the potentially confounding factors, such as use of antiepileptic drugs, diabetes mellitus, use of vitamin supplements, consanguinity, and family history of neural tube defects, so that these factors could be accounted for in the analyses. However, we considered it not feasible to measure folic acid intake in maternal diet in the distant past. Moreover, it seemed not necessary as nutrient intake and vitamin intake in The Netherlands differ only slightly between the highest and lowest socioeconomic classes. ${ }^{7}$ Theoretically, residual confounding might have occurred by inadequate measurement of folate intake. ${ }^{10}$ However, as the association between these factors and parental occupation is not expected to be very strong, the influence of residual confounding will probably be small. Residual confounding due to genetic factors is even less likely. Although genetic predisposition is measured by proxies such as a positive family history of neural tube defects and consanguinity of the parents, while homozygosity or heterozygosity for the $677 \mathrm{~T}->\mathrm{C}$ mutation might be one of the specific genetic factors of interest, ${ }^{8,9}$ the association between this specific factor and parental occupation is unlikely. Nevertheless, adequate measurement of relevant risk factors should be strived for in future studies.

In order to find support for our findings in The Netherlands we performed three register-based case-referent studies in Sweden, Spain, and Hungary. These studies, using routinely collected data, faced some specific limitations. Analyses were 
confined to job titles as no valid occupational exposure information had been collected by the registers. In addition, coding of occupations is just part of coding a larger set of risk factors and therefore is less adequate than in specifically designed case-referent studies, which may have led to more random misclassification. One of the strengths of the register-based studies, however, was that the time lag between data collection and the period in which exposure occurred was short. Moreover, in the Swedish study, data were collected before the pregnancy outcome was known, thus preventing potential information bias. The most obvious advantage of the use of registers is that the data are readily available as data collection has been performed in the past. Their usefulness thus lies in the possibility of conducting studies quickly. In the future, when numbers of cases have increased, the registers provide opportunities for joint studies on occupations with low prevalences. However, this will only be possible if the collection and coding of occupational data is performed in a comparable manner.

\section{Evaluation of study results}

The most important finding of our core study was an increased risk of spina bifida for women who had an agricultural occupation around conception. Also, working as a cleaning woman was found to be associated with spina bifida, although this association was less pronounced (Chapter 4). A more detailed search for associations between spina bifida and occupational exposures did not yield any conclusive results as the prevalence of most of the exposure categories for women was too low (Chapter 7.1). The results with regard to paternal occupations suggest associations with welders and transport workers (Chapter 4). The study of detailed exposure categories among the fathers showed a moderately increased risk for exposure to stainless steel dust, welding UV and low levels of welding fumes, and associations with a high level of pesticide exposure and a high level of exposure to cleaning agents (Chapter 7.2).

These results need careful consideration. Despite the relatively large number of cases and referents that were included in the study, risk estimates were often calculated with small numbers because of the low prevalence of certain occupations and occupational exposures. Therefore, confidence intervals were generally wide, which means that the results are compatible with a range of possibilities. No firm conclusions on actual risks can be drawn based solely on this single epidemiologic study with limited power. Therefore, the results should be set in a wider context including the register-based studies that we performed and the literature on spina bifida and neural tube defects in general.

The moderate association observed between spina bifida and working as a cleaning woman could not be confirmed in the register-based studies nor in studies 
in the literature. ${ }^{11,12} \mathrm{~A}$ study on the composition of cleaning agents performed in The Netherlands showed that the concentrations of hazardous components in cleaning agents in The Netherlands are low. ${ }^{13}$

Although the strong association that was found between spina bifida and maternal agricultural occupations in The Netherlands could not be equalled in the register-based studies, increased risks were observed for mothers working in agriculture in Sweden and in Spain, but not in Hungary (Chapter 6). The differences in effect might be caused by differences in the quality of the studies, but it is likely that there are also large inter-country differences in the characteristics of agricultural work (i.e. specific tasks, involvement of farmers' wives, and the amount and types of pesticides used). Differences in the magnitude of the relative risk estimates might also be due to variations between the countries in the prevalences of other risk factors for spina bifida, and thus the differences in background prevalence rates of spina bifida. ${ }^{14}$ Unfortunately, the limited amount of data did not allow a subdivision of the rather heterogeneous occupational category of agricultural workers into more homogeneously exposed groups. A stratified pooled analysis of the crude results of all four studies, including the study in The Netherlands, resulted in an OR of 1.7 (95\% Cl: 1.2-2.3).

Indications for an increased risk for maternal agricultural occupations was also found in case-referent studies of neural tube defects in Sweden ${ }^{11}$ and in a small-scale study in Venezuela, ${ }^{12}$ which increases the credibility of a true association. However, specific teratogenic exposures accounting for the increased risk for women working in agriculture have not yet been found. Although pesticides are suspect for reproductive effects, in our study on exposures based on detailed interviews, no indication was found for an adverse effect of exposure to pesticides or any specific types of agricultural work. This might have been due to small numbers of exposed or misclassification of exposure. Preliminary findings of a case-referent study on maternal occupational exposures as risk factors for all neural tube defects in California, with 538 cases and 539 referents, yielded moderately increased risks for insecticides $(\mathrm{OR}=1.6,95 \% \mathrm{Cl}: 0.8-3.1)$, among others. ${ }^{15}$ In addition to a possible adverse effect of pesticides, alternative but less likely hypotheses may be formulated with respect to agriculture-related factors, such as the risk of infections, physical workload, and emotional stress. As we did not collect any of these data, it is not possible to draw conclusions about the influence of these factors during early pregnancy.

For the fathers, less consistent results were found. We observed an increased risk of offspring with spina bifida for welders, but the risk estimate was not precise. Comparably increased but imprecise results were found in the Spanish register-based study and in a study in Atlanta, USA, ${ }^{16}$ but not in Hungary and British Columbia. ${ }^{17}$ In our study on exposures based on detailed interviews, we found an association with paternal exposure to welding fumes and UV radiation during welding, that seems to 
be consistent with the association we found for welders. However, the increased risk of exposure to welding fumes was primarily attributable to men who were not professional welders but who performed welding tasks in other occupations with a low frequency of exposure but with limited or less frequent use of protective equipment. Until more is known about possible mechanisms, that is whether chronic exposure at low levels or peak exposure at a relatively high level at the 'right' moment is more harmful to developing sperm cells, no conclusions can be drawn on the implications of this finding.

As mentioned above, a potential role in the aetiology of spina bifida is suggested for some occupational factors. Subsequently we may ask ourselves what impact these factors have on the prevalence of spina bifida. It should be noted that the occupational factors we have identified do not play a major role in the aetiology of spina bifida, especially in The Netherlands. Even if the risk of offspring with spina bifida in women working in agriculture were elevated five-fold, only seven per cent of the total number of children with spina bifida would be attributable to maternal agricultural work, as the frequency of women with agricultural occupations is very low (that is, approximately 1.7 per cent among women of childbearing age). The same holds true for paternal exposure to welding fumes.

\section{Conclusions}

We conclude from our study that:

- $\quad$ in future studies on risk factors of spina bifida, spina bifida subgroups with relative homogeneity should also be evaluated

- the use of population referents in case-referent studies on congenital defects is feasible and preferable if adequate methods of exposure assessment are used to prevent recall bias

- retrospective assessment of occupational exposures can be improved by using occupation-specific questionnaires with questions on performed tasks

- there is an increased risk of offspring with spina bifida for women in agricultural occupations which is confirmed by other studies, but no conclusions can be drawn about specific pesticides responsible for the effect or about possible underlying mechanisms

- there may be an increased risk of a child with spina bifida for male welders and men with welding tasks, but these results need corroboration

- occupational risk factors do not account for a large part of the prevalence of spina bifida in the total population 


\section{Epilogue}

This study does not provide arguments for improving the occupational environment as a way to substantially reduce the birth prevalence of spina bifida. As the frequency of men and women with occupations with moderate or high exposure to chemicals or radiation in The Netherlands is low, attributable risks of specific exposures are very small. Although reducing the exposure to specific occupational factors might be justified for several other reasons, the effect on the occurrence of spina bifida is limited.

Still, associations that are observed in this study might be of interest to specific occupational categories, for instance agricultural workers and welders, as their personal risk of having a child with spina bifida is likely to be elevated. Unfortunately, no specific recommendations about preventive measures can be put forward to be applied by specific occupational branches suspected for an increased risk of spina bifida. More research should be conducted to identify specific teratogens. Therefore, further studies focussing on welding and farming in particular, and elaborating on specific exposures, are warranted.

The most valid and efficient design for this kind of research seems to be an historical cohort study. However, because of the relatively low birth prevalence of spina bifida, a cohort study would require a very large cohort of agricultural workers, which is not available in The Netherlands. The problem of small numbers might be solved by international collaboration. Agriculture has been associated with other reproductive disorders, such as time to pregnancy, ${ }^{18}$ spontaneous abortion, stillbirths, ${ }^{19}$ and birth defects. ${ }^{20}$ Therefore, and because reproductive end points may be viewed as a continuum, ${ }^{21}$ the reproductive experiences of various types of male and female agricultural workers could be evaluated, including time-to-pregnancy, spontaneous abortion, birth defects, length of pregnancy, birth weight, and functional developmental disorders. In separate case-cohort studies focussing on different outcomes, specific questionnaires for different types of agricultural workers should be designed to collect detailed information on pesticides, disinfectants, and other exposures of the study population. Exposure measurements performed in a sample of the population should be related to tasks and activities to identify determinants of exposure that can be used in the questionnaires. In addition to occupational factors, information on environmental pesticide exposure, specific nutritional factors, and emotional and physical stress might be collected. In this way, the question of whether people with specific types of agricultural work have higher risks of reproductive disorders might be answered, whereas existing uncertainties about the underlying chemical or physical factors might be clarified. 


\section{References}

1 Khoury MJ, Erickson JD, James LM. Etiologic heterogeneity of neural tube defects: Clues from epidemiology. Am J Epidemiol 1982;115:538-548.

2 Martin RA, Fineman RM, Lorde LB. Phenotypic heterogeneity in neural tube defects: A clue to causal heterogeneity. Am J Med Genet 1983;16:519-525.

3 Park $\mathrm{CH}$, Stewart W, Khoury MJ, Mulinare J. Is there etiologic heterogeneity between upper and lower neural tube defects? Am J Epidemiol 1992;136:1493-1501.

Shaw GM, Jensvold NG, Wasserman CR, Lammer EJ. Epidemiologic characteristics of phenotypically distinct neural tube defects among 0.7 million California births, 19831987. Teratology 1994;49:143-149.

5 Swan SH, Shaw GM, Schulman J. Reporting and selection bias in case-control studies of congenital malformations. Epidemiology 1992;3:356-363.

6 Stewart PA, Stewart WF, Heineman EF, Dosemeci MA, Linet M, Inskip PD. A novel approach to data collection in a case-control study of cancer and occupational exposures. Int J Epidemiol 1996;25:744-752.

7 Hulshof KFAM, Löwik MRH, Kok FJ, Wedel M, Brants HAM, Hermus RJJ, Hoor ten F. Diet and other life-style factors in high and low socio-economic groups (Dutch Nutrition Surveillance System). Eur J Clin Nutr 1991;45:441-450.

8 Put van der NMJ, Steegers-Theunissen RPM, Frosst P, Trijbels FJM, Eskes TKAB, Heyer den $M$, Rozen $R$, Blom $H$ J. Mutated methylenetetrahydrofolate reductase as a risk factor for spina bifida (Short report). Lancet 1995;346:1070-1071.

9 Posey DL, Khoury MJ, Mulinare J, Adams Jr MJ, Ou CY. Is mutated MTHFR a risk factor for neural tube defects? Lancet 1996;347:686-687.

10 Marshal JR, Hastrup JL. Mismeasurement and the resonance of strong confounders: uncorrelated errors. Am J Epidemiol 1996;143:1069-1078.

11 Ericson A, Källén B, Löfkvist E. Environmental factors in the etiology of neural tube defects: a negative study. Environ Res 1988;45:38-47.

12 Hammond FG, Canache MF. Some epidemiological aspects of neural tube defects in Barquisimeto, Venezuela (Abstract). Am J Hum Genet 1991;49 (suppl.):470.

13 Vollebregt L, Mooy $R$ de, Broekhuizen $P$ van. De grote schoonmaak: totaal vernieuwd. Amsterdam: Chemiewinkel UvA. 1994.

14 Rothman KJ. Modern epidemiology. Boston: Little, Brown and Company. 1986.

15 Shaw GM, Velie EM, Katz EA, Morland KB, Harris JA. Maternal occupational exposures as risk factors for neural tube defects (Abstract). Am J Epidemiol 1996;142:S1.

16 Schnitzer PG, Olshan AF, Erickson JD. Paternal occupation and risk of birth defects in offspring. Epidemiology 1995;6:577-583.

17 Olshan AF, Teschke K, Baird PA. Paternal occupation and anomalies in offspring. Am J Ind Med 1991;20:447-475.

18 Cock de J, Westveer K, Heederik D, Velde te E, Kooij van R. Time to pregnancy and occupational exposure to pesticides in fruit growers in The Netherlands. Occup Environ Med 1994;51:693-699.

19 Rupa DS, Reddy PP, Reddi OS. Reproductive performance in population exposed to 
pesticides in cotton fields in India. Environ Res 1991;55:123-128.

20 Garry VF et al. Pesticide appliers, biocides, and birth defects in rural Minnesota. Environ Health Perspect 1996;104:394-399.

21 Selevan SG, Lemasters GK. The dose-response fallacy in human reproductive studies of toxic exposures. J Occup Med 1987;29:451-454. 


\section{SUMMARY}

Spina bifida is a major birth defect with a prevalence at birth of about 7 per 10,000 , varying with secular, racial, geographical, and socioeconomic factors. The defect is caused by a disturbance in the fusion of the neural folds, occurring before the fourth week of pregnancy. Genetics and preconceptional folic acid supplementation are important factors in the occurrence and recurrence of spina bifida. It is hypothesised that the presence of teratogens in the workplace may be an additional explanation for the differential prevalence rates by socioeconomic class.

To explore this hypothesis, an extensive review of the literature on risk factors of neural tube defects was performed, with an emphasis on occupational and environmental factors. As studies on the topic of parental occupation and neural tube defects were scarce, the broader malformation category of central nervous system defects was also considered. From these studies, associations were suggested between neural tube defects and mothers working in industry and construction, health care, agriculture, and hairdressing. Paternal occupations suspected for an increased risk were solventexposed occupations such as painting and printing, and occupations in agriculture, transport, and industry. It must be noted, however, that information on parental occupation was often derived from municipal birth registries, introducing misclassification, and that few findings have been repeated in two or more studies.

A case-referent study was conducted to identify parental occupations with an increased risk of spina bifida in offspring in The Netherlands, and to examine whether parental occupational exposure during or shortly before pregnancy is a risk factor for the occurrence of spina bifida. The study population consisted of the parents of 533 children with spina bifida, diagnosed in nine hospitals in The Netherlands, and the parents of $\mathbf{2 3 5 0}$ referent children. All the children were born between 1980 and 1992. The referent group consisted mainly of population referents $(\mathrm{N}=1894)$ derived from municipal birth registries, and partly of hospital referents $(\mathrm{N}=456)$, who had been born healthy but who had experienced a cerebral trauma or meningitis during childhood. Data on parental occupation and occupational exposures around conception were collected in two phases. In the first phase, a postal questionnaire was sent to all the parents, including questions on parental occupation and potential confounders, such as use of antiepileptic agents, use of oral contraceptives, diabetes mellitus, family history of neural tube defects, smoking, and alcohol use. The second phase comprised occupation-specific personal interviews with a sample of all the parents who had occupations with potential chemical or physical exposure. 
Two methodological studies were performed to give insight into validity aspects of the study. A comparison of occupational exposure data derived from a postal questionnaire, and from occupation-specific personal interviews, showed that a postal questionnaire cannot substitute for a detailed exposure assessment by personal interview, preferably reviewed by experts. Overreporting in the questionnaire was common for some exposure categories, which may particularly influence risk estimates of exposures with a low prevalence.

To compare the use of hospital referents with the use of population referents, recall bias, selection bias, and feasibility aspects were studied. An indication was found for the existence of selection bias with regard to educational level of the parents and paternal occupation: farmers were overrepresented among the hospital referents. As a result, the hospital referents were excluded from the analyses on occupational title. No differences were observed in the reporting of lifestyle factors such as alcohol use and smoking. Obtaining population referents was more feasible than obtaining hospital referents in this study. In addition, the response rate on the questionnaire was higher among population referents than among hospital referents.

The analysis on occupational titles was restricted to 353 cases with spina bifida aperta and 1329 population referents. Maternal occupations around conception that appeared to be associated with spina bifida in offspring after adjustment for confounding factors were cleaners $(O R=1.9,95 \% \mathrm{Cl}: 0.9-3.9)$ and especially agricultural occupations $(\mathrm{OR}=5.6,95 \% \mathrm{Cl}$ : 1.7-17.7). Regarding the fathers, a weak association was observed for transport workers $(\mathrm{OR}=1.4,95 \% \mathrm{Cl}: 0.9-2.1)$ and for welders $(\mathrm{OR}=2.0,95 \% \mathrm{Cl}: 0.6-6.9)$. To look for associations between risk factors and specific subgroups of spina bifida, cases were splitted into dysmorphologically homogeneous groups (high vs low, open vs closed). The analyses included numbers too small to draw firm conclusions, but indications were found for stronger associations between genetic susceptibility factors and some occupations, and high and open spina bifida. Criteria for the classification of subgroups need to be further investigated.

To gather more evidence about a possible relation between spina bifida and agricultural and other occupations, register-based studies were performed in three European countries. In Sweden, 482 cases and 964 referents were derived from the Swedish Registry of Congenital Malformations and the Medical Birth Registry, respectively. Occupational information was obtained from the Medical Birth Registry. A slightly increased OR of 1.8 (95\% Cl: 0.8-4.2) was observed for women in agricultural occupations, which increased to $2.2(95 \% \mathrm{Cl}: 1.3-3.8)$ when women who lived on a farm were also included in the exposed category. In the Spanish study, with 478 cases and 434 healthy referents who were born in the same hospitals as the cases, we also found a moderately increased risk for women working in agriculture 
$(\mathrm{OR}=2.2,95 \% \mathrm{Cl}$ : $0.8-5.9)$. This was not found in an analysis of Hungarian data, which included 1119 cases and 1489 population referents. Subdividing agricultural workers into more homogeneously exposed groups was not possible due to lack of data on agricultural tasks and small numbers. Inconsistently increased risks were also observed for some other occupations in Spain and Hungary.

Associations between spina bifida and maternal and paternal occupational exposure to chemicals or radiation were explored in two separate sub-studies within the Dutch case-referent study. With regard to the mothers, personal interviews at home were performed with 55 case mothers and 66 referent mothers who had occupations with a potential for exposure, using job specific questionnaires including questions on tasks and actvities, frequency of exposure, protective equipment, and use of chemicals or radiation by colleagues. Only a few women appeared to be occupationally exposed to chemical or physical agents. No differences in the occurrence of specific exposures were detected between cases and referents. The job-specific interviews with 122 case fathers and 411 referent fathers were conducted by telephone, again using job and task specific questionnaires. The study yielded suggestive findings of an association between spina bifida and exposure to moderate or high levels of pesticides (OR=1.7, 95\% Cl: $0.7-4.0)$, low levels of welding fumes $(O R=1.6,95 \% \mathrm{Cl}: 1.0-2.6)$, low levels of UV radiation during welding $(O R=2.6$, $95 \% \mathrm{Cl}: 1.2-5.6)$, and stainless steel dust $(\mathrm{OR}=2.0,95 \% \mathrm{Cl}$ : $0.8-5.2)$. No associations were identified for other exposures suspected for an increased risk, such as organic solvents.

The conclusion of this thesis is that a potential aetiologic role for occupational factors in agriculture, and for paternal welding tasks, is suggested. However, it should be noted that these occupational factors can play only a minor role in the causation of spina bifida in The Netherlands, due to the low prevalence of specific occupations and exposures. No arguments are provided to focus primary prevention of spina bifida in general on improvements in the occupational environment. Before recommendations for specific occupational branches can be put forward, more research on specific teratogenic exposures should be conducted. Because indications for increased risks of other reproductive disorders among agricultural workers have also been found, a detailed retrospective cohort study, focussing on specific agricultural exposures and including reproductive experiences such as time to pregnancy, spontaneous abortion, birth defects, birth weight, and functional developmental disorders is recommended. 


\section{SAMENVATTING}

Spina bifida ('open ruggetje') is een aangeboren afwijking die wordt veroorzaakt door een storing in de fusie van de neurale wallen, een proces dat in normale omstandigheden plaatsvindt in de vierde week van de zwangerschap. De prevalentie van de aandoening is gemiddeld ongeveer 7 op de 10.000 levendgeboren kinderen maar vertoont variatie in de tijd. Tussen populaties met verschillende ethnische achtergrond, in verschillende geografische gebieden en populaties met verschillende sociaal-economische status bestaan eveneens verschillen in prevalentie. Deze verschillen worden in verband gebracht met genetische factoren en met voeding en preconceptionele foliumzuursuppletie van de moeder. Ook is de hypothese naar voren gebracht dat beroepsmatige blootstelling van de ouders aan chemische stoffen het risico op nageslacht met spina bifida verhoogt. Dit zou naast voeding een additionele verklaring kunnen vormen voor de prevalentieverschillen tussen hoge en lage sociaal-economische klassen.

In een uitgebreid literatuuroverzicht zijn de mogelijke risicofactoren voor neurale buisdefecten (NBD), waaronder spina bifida, beschreven, waarbij de nadruk is gelegd op factoren die samenhangen met arbeid en milieu. Aangezien publikaties over studies naar de specifieke relatie tussen NBD en het beroep van de ouders zeldzaam waren, zijn ook studies naar aangeboren afwijkingen van het centraal zenuwstelsel in het algemeen in het literatuuronderzoek meegenomen. Voor verscheidene beroepen werden verhoogde risico's gesuggereerd op het krijgen van een kind met een NBD. Associaties tussen beroep van de moeder en NBD zijn beschreven voor industriële beroepen en beroepen in de bouw, gezondheidszorg, in de agrarische sector en voor kapsters. Beroepen bij mannen die in verband gebracht worden met NBD zijn schilders en drukkers, agrarische beroepen en beroepen in de transportsector of de industrie. Opgemerkt dient te worden dat de beroepsgegevens vaak afkomstig zijn van geboorteregisters. Het gebruik van deze informatiebron zou vertekening veroorzaakt kunnen hebben in de resultaten van de onderzoeken. Slechts weinig beroepen werden in meerdere onderzoeken aangewezen als risicofactor.

Een case-referent onderzoek is opgezet om beroepen te identificeren die in verband kunnen worden gebracht met een verhoogd voorkomen van spina bifida. Ook is onderzocht of beroepsmatige blootstelling aan chemische stoffen of straling rond de conceptie het risico op spina bifida kan verhogen. De onderzoekspopulatie bestond uit 533 kinderen met spina bifida die levend geboren zijn tussen 1980 en 1992 en onder behandeling geweest bij afdelingen Kinderneurologie van 9 algemene en academische ziekenhuizen en een revalidatiecentrum in Nederland (cases). Als 
afspiegeling van de beroepsverdeling in de populatie waar de cases uit afkomstig waren is een referentiegroep meegenomen van 2350 kinderen die eveneens tussen 1980 en 1992 geboren zijn, en afkomstig uit dezelfde regio's als de cases. Het grootste gedeelte van de referentiegroep $(N=1894)$ is verkregen door middel van aselecte steekproeven uit gemeentelijke bevolkingsregisters; een klein deel van de referentiegroep ( $N=456$ ) bestond uit kinderen bij wie op jonge leeftijd in een van de participerende ziekenhuizen een trauma capitis of meningitis geconstateerd is.

Gegevens over het beroep dat de ouders uitoefenden rond de conceptie van het kind zijn verzameld in twee fasen. In de eerste fase werd een vragenlijst naar beide ouders gezonden, waarin vragen opgenomen waren over het beroep en over mogelijk verstorende factoren voor de relatie tussen spina bifida en beroep. Hieronder vallen bijvoorbeeld het gebruik van antiepileptica, orale anticonceptiva, vitaminepreparaten, diabetes mellitus, het voorkomen van NBD in de familie, roken en alcoholconsumptie. In de tweede fase zijn persoonlijke interviews afgenomen bij die ouders met een beroep waarin blootstelling aan chemische stoffen of straling mogelijk was. De vragen in de interviews waren specifiek per beroep en hadden betrekking op de taken die de ouders uitoefenden binnen dat beroep en de bijbehorende blootstellingen.

Twee methodologische studies zijn uitgevoerd om inzicht te verkrijgen in een aantal aspecten van de kwaliteit van de onderzoeksopzet. Aangezien van een grote groep mensen zowel gegevens over beroepsexpositie uit de vragenlijst als uit de persoonlijke interviews beschikbaar waren, was het mogelijk deze informatie te vergelijken. Overrapportage bleek vaak voor te komen in de schriftelijke vragenlijst, hetgeen juist bij exposities die niet vaak voorkomen belangrijke vertekening in de resultaten kan veroorzaken.

De bruikbaarheid van een referentiegroep uit het ziekenhuis en uit de algemene bevolking voor onderzoek naar aangeboren afwijkingen werd vergeleken door informatiebias, selectiebias en haalbaarheidsaspecten te bestuderen. Aanwijzingen voor het bestaan van selectiebias werden gevonden in de zin dat de ouders van kinderen afkomstig uit het ziekenhuis iets lager opgeleid waren dan ouders van kinderen uit de algemene bevolking. Ook bleken vaders in agrarische beroepen oververtegenwoordigd bij de ouders uit het ziekenhuis. De referentiegroep uit het ziekenhuis is daarom uitgesloten van de statistische analyses naar de relatie tussen spina bifida en beroep van de ouders. Tussen de twee referentiegroepen werden geen verschillen gevonden in de rapportage van leefstijlfactoren, zoals alcohol en roken, maar wel in de rapportage van beroepsexpositie. Het verkrijgen van een referentiegroep via bevolkingsregisters bleek efficiënter te verlopen dan de selectie van een referentiegroep uit het ziekenhuis. Bovendien was de respons op de schriftelijke vragenlijst hoger in de referentiegroep uit de algemene bevolking dan in 
die uit het ziekenhuis.

Uit het onderzoek naar beroep als risicofactor voor spina bifida bleek dat schoonmaaksters $(\mathrm{OR}=1.9,95 \% \mathrm{Cl}$ : 0.9-3.9) en vooral vrouwen met een agrarisch beroep (OR $=5.6,95 \% \mathrm{Cl}: 1.8-17.8)$ rond de conceptie een verhoogd risico hadden op het krijgen van een kind met spina bifida. Deze resultaten zijn gecorrigeerd voor de effecten van verstorende variabelen. Met betrekking tot het beroep van de vader bleek een licht verhoogd risico op nageslacht met spina bifida voor vaders werkzaam in de transportsector $(\mathrm{OR}=1.4,95 \% \mathrm{Cl}: \mathbf{0 . 9 - 2 . 1}$ ) en een verhoogd risico voor lassers $(\mathrm{OR}=2.0,95 \% \mathrm{Cl}: 0.6-6.9)$. Dit laatste verband is echter gebaseerd op kleine aantallen. Vervolgens is bestudeerd of bepaalde risicofactoren voor spina bifida specifiek geassocieerd zijn met een subgroep van spina bifida, zoals hoge of lage, en open of gesloten spina bifida. Door kleine aantallen konden geen duidelijke conclusies getrokken worden, maar het onderzoeksmateriaal geeft wel aanwijzingen dat associaties tussen spina bifida en het voorkomen van spina bifida in de familie sterker zijn bij de hoge en open vormen van deze aandoening. Duidelijke citeria voor indeling van spina bifida in de diverse subgroepen zijn helaas niet voorhanden.

Naar aanleiding van het verhoogde risico dat gevonden werd voor vrouwen in de agrarische sector, zijn meer gegevens verzameld over deze relatie met behulp van registraties van aangeboren afwijkingen in drie landen in Europa. In een studie in Zweden werden 482 cases met spina bifida en 964 controles met elkaar vergeleken, die respectievelijk afkomstig waren van de registratie voor aangeboren afwijkingen en de medische geboorteregistratie. Vrouwen werkzaam in de agrarische sector hadden een verhoogd risico op het krijgen van een kind met spina bifida $(O R=1.8$, 95\% Cl: 0.8-4.2). Voor alle vrouwen die op een boerderij woonden of agrariër waren, was het relatief risico $2.2(95 \% \mathrm{Cl}$ : 1.3-3.6). In een onderzoek in Spanje werden $\mathbf{4 7 8}$ cases en $\mathbf{4 3 4}$ gezonde controles betrokken die in hetzelfde ziekenhuis geboren waren. In deze studie werd eveneens een verhoogd risico op spina bifida gevonden voor vrouwen met een agrarische beroep (OR $=2.2,95 \% \mathrm{Cl}$ : 0.8-5.9). Deze bevindingen werden niet gerepliceerd in Hongarije, waar analyses uitgevoerd werden met 1119 cases en 1489 kinderen uit de algemene populatie als controlegroep. In Spanje en Hongarije werden ook voor enkele andere beroepsgroepen verhoogde risico's gevonden, maar deze bevindingen waren niet consistent.

In de tweede fase van het onderzoek werden twee afzonderlijke deelstudies opgezet om associaties. tussen beroepsmatige blootstelling van moeder en vader aan chemische stoffen en straling rondom de conceptie en het optreden van spina bifida te onderzoeken. Persoonlijke interviews zijn afgenomen bij 55 moeders van een kind met spina bifida en 66 moeders van kinderen uit de referentiegroep. Er bleken slechts weinig vrouwen gewerkt te hebben met chemische stoffen of straling. Er werd geen relatie waargenomen tussen beroepsmatige blootstelling en het voorkomen van 
spina bifida. Bij 122 vaders van kinderen met spina bifida en 411 vaders van kinderen uit de referentiegroep zijn telefonische interviews afgenomen. Spina bifida bleek gerelateerd te zijn aan matige of hoge blootstelling aan pesticiden $(O R=1.7$, 95\%C: $0.7-4.0)$, lage blootstelling aan lasrook (OR = 1.6, 95\% Cl: 1.0-2.6), UV-straling tijdens lassen (OR=2.6, 95\% $\mathrm{Cl}$ : $1.2-5.6)$, en blootstelling aan roestvrijstaalstof $(\mathrm{OR}=2.0,95 \% \mathrm{Cl}$ : 0.8-5.2). Er werden geen associaties gevonden voor andere verdachte exposities, zoals oplosmiddelen.

De resultaten beschreven in dit proefschrift suggereren dat exposities die samenhangen met agrarische beroepen of met het werken als lasser een mogelijke rol spelen in de etiologie van spina bifida. Door de lage frequentie van voorkomen van deze beroepen en exposities in Nederland is het aandeel van deze factoren in de etiologie van spina bifida echter klein. Het lijkt dan ook niet aan te bevelen primaire preventie van spina bifida te richten op verbetering van de arbeidsomstandigheden in het algemeen. Voordat specieke aanbevelingen voor de betreffende branches gedaan kunnen worden, zou meer onderzoek uitgevoerd moeten worden naar de teratogene werking van specifieke exposities. Aangezien er in de literatuur aanwijzingen bestaan dat agrariërs ook een verhoogd risico op andere stoornissen in de voortplanting hebben, wordt aanbevolen een gedetailleerde historische cohort studie onder agrariërs uit te voeren. In deze studie, die zich vooral dient te richten op specifieke exposities, zouden meerdere zwangerschapsuitkomsten moeten worden bestudeerd, zoals tijd tot zwangerschap, het optreden van spontane abortus, aangeboren afwijkingen, laag geboortegewicht en ontwikkelingsstoornissen. 


\section{DANKWOORD}

Het opzetten en uitvoeren van een epidemiologisch onderzoek en de rapportage ervan in de vorm van een proefschrift is onmogelijk zonder de hulp van velen, die ik hieronder wil bedanken.

Ten eerste Nel Roeleveld, bedankt voor je prettige begeleiding, de inspirerende brainstorm sessies, en de vruchtbare samenwerking. Gerhard Zielhuis, bedankt voor je heldere wetenschappelijke aanpak van problemen en - hoewel ik dat achteraf meer waardeer dan soms tijdens het onderzoek - je functie als stok-achter-de-deur bij tijdsplanningen en deadlines. Professor Gabreëls van het Interdisciplinair Kinderneurologisch Centrum (IKNC) wil ik bedanken voor zijn niet aflatende interesse en betrokkenheid bij een vakgebied dat toch slechts zijdelings de zijne is, en André Verbeek voor zijn frisse kijk op het onderzoek, die voor de inhoudelijke discussies in de laatste fase een toegevoegde waarde had.

Het onderzoek zou zeker veel langer geduurd hebben zonder de studenten Biomedische Gezondheidswetenschappen Marjolijn van der Star, Esther Welp, Marjan Bakker, Rosella Hermens en Rianne Lafeber, die hebben meegedacht over de opzet van deelprojecten en gedeelten van de dataverzameling voor hun rekening hebben genomen. Rosella Hermens wil ik speciaal bedanken voor het feit dat zij mij, na haar stage, in de luxe positie gebracht heeft een jaar lang een gezondheidswetenschapper als 'onderzoeksassistent' te hebben.

Annelies Pellegrino wil ik bedanken voor het invoeren van gegevens en de coördinatie van de interviews, Leo van Rossum voor het invoeren van gegevens, en Miep Opsteeg en Ellen Arends voor het interviewen van de vrouwen.

Reinier Mullaart van het IKNC, Paul Peters van de Universiteit Utrecht en Jenny Copius Peereboom-Stegeman van de afdeling Toxicologie ben ik erkentelijk voor hun inbreng in de begeleidingscommissie in de eerste jaren van het onderzoek. In latere fasen bleken bilaterale besprekingen erg vruchtbaar te zijn.

Veel dank ben ik uiteraard ook verschuldigd aan de ziekenhuizen die participeerden in het onderzoek door hun patiëntenpopulatie voor ons toegankelijk te maken: het Academisch Ziekenhuis Groningen (JH Begeer), het Academisch Ziekenhuis van de Vrije Universiteit Amsterdam (Mw. CA Kurk), het Academisch Ziekenhuis Rotterdam (PC) de Laat), het Academisch Ziekenhuis Nijmegen (RA Mullaart), revalidatiecentrum De Maartenskliniek in Nijmegen (Mw. MJ Poelma), het Elisabeth Ziekenhuis Tilburg (JA Rammeloo), revalidatiecentrum Het Roessingh in Enschede (Mw. M Stroo), het Academisch Medisch Centrum in Amsterdam (Mw. JW Weber), en het Academisch Ziekenhuis Utrecht (Mw. $\mathrm{H}$ van Wieringen). 
Ook wil ik alle ouders bedanken die belangeloos hebben meegewerkt aan het onderzoek door het invullen en opsturen van de vragenlijst of door hun medewerking aan een persoonlijk interview. De gegevens die zij verschaft hebben, waren een eerste vereiste voor het slagen van dit onderzoek.

Furthermore, I owe many thanks to Professor Castilla, who was the head of the International Centre for Birth Defects in Rome at the time. Without his help, no cooperation would have developed with registries of the International Clearinghouse for Birth Defects Monitoring Systems. I enjoyed working with Professor Bengt Källén from the Tornblad Institute in Lund, Sweden, with Eva Bermejo and Professor Martínez-Frías from the Complutense University in Madrid, Spain, and with Csaba Siffel and Professor Czeizel from the National Institute of Hygiene in Budapest, Hungary, who were willing to let me use their datasets and the facilities at their departments.

Ellen Bakker, Judith Abma-Hill en vooral Beth White wil ik bedanken voor het corrigeren van de Engelse teksten, Rian Litjens voor het invoeren van alle tabellen en Hanny Leezer voor de controle op fouten in typewerk en lay-out.

Veel dank gaat uit naar de medewerkers van de Vakgroep Medische Informatiekunde, Epidemiologie en Statistiek. De gezelligheid tijdens en na het werk vormde een belangrijk aandeel in het plezier waarmee ik mijn onderzoek heb uitgevoerd. Van hen wil ik speciaal Wendy Kersemaekers bedanken. Ik vond het een ideale situatie elkaars klankbord te zijn voor plotselinge ideeën of juist steeds terugkerende methodologische hersenbrekers, en i $\mathrm{k}$ ben blij zo ook iets te hebben meegekregen van jouw onderzoek.

Tenslotte familie en vrienden, bedankt voor de interesse, het medeleven en de broodnodige afleiding. En Peter, hoewel het niet altijd even praktisch was, ben ik erg blij dat we tegelijkertijd met ons promotie-onderzoek bezig zijn geweest en dat het werken in avonduren of weekenden daardoor nooit tot problemen heeft geleid. 


\section{CURRICULUM VITAE}

Birgitte Blatter werd geboren op 8 juli 1968 in Eindhoven. In 1986 behaalde zij haar Gymnasium- $\beta$ diploma aan het Lorentz Lyceum te Eindhoven. In datzelfde jaar is zij gestart met de opleiding Biomedische Gezondheidswetenschappen aan de Katholieke Universiteit Nijmegen (KUN). Als afstudeerrichting koos zij voor het vak epidemiologie, met de nadruk op etiologisch onderzoek naar schadelijke effecten van arbeidsomstandigheden. De laatste anderhalf jaar van de studie zijn drie stages uitgevoerd, waarvan een bij de Medische Faculteit van het Muhimbili Medical Centre in Dar es Salaam, Tanzania. Twee stages zijn uitgevoerd bij de afdeling Epidemiologie van de vakgroep Medische Informatiekunde, Epidemiologie en Statistiek (MIES) van de KUN: een onderzoek naar de relatie tussen hersentumoren bij kinderen en het beroep van de ouders (Dr.Ir. $\mathrm{N}$ Roeleveld), en een onderzoek naar menstruatiestoornissen door chemische blootstelling bij kapsters (Prof.Dr.Ir. GA Zielhuis). Na het behalen van het doctoraalexamen in september 1991, is zij op 1 januari 1992 aangesteld als junior epidemiologisch onderzoeker bij de vakgroep MIES van de KUN. Haar functie bestond meerendeels uit het opzetten en uitvoeren van een onderzoek naar de relatie tussen spina bifida en het beroep van de ouders dat zou uitmonden in dit proefschrift, en voor een klein deel uit onderwijstaken ten behoeve van de opleiding Biomedische Gezondheidswetenschappen en de opleiding tot bedrijfsarts. In deze periode zijn eveneens enkele korte werkbezoeken gebracht aan Italië, Zweden, Spanje en Hongarije voor samenwerking met enkele registraties van aangeboren afwijkingen. Op 1 maart 1996 is zij begonnen als arbeidsepidemioloog bij TNO Voeding, Divisie Arbeidstoxicologie en Voeding, Afdeling Consumentenstudies en Epidemiologie, te Zeist. 